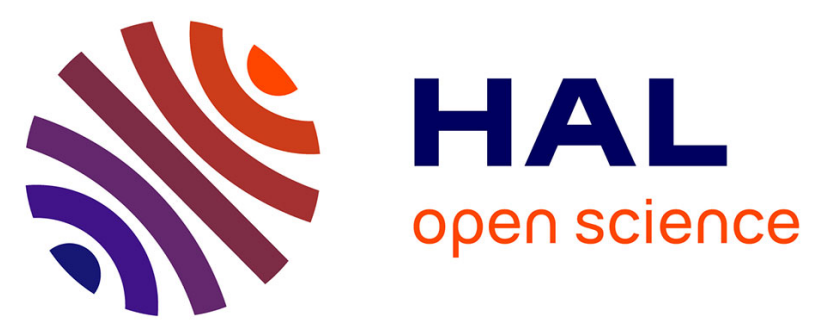

\title{
Few and far apart: integrative taxonomy of Australian species of Gladiobela and Pagodibela (Conoidea: Raphitomidae) reveals patterns of wide distributions and low abundance
}

Anders Hallan, Francesco Criscione, Alexander Fedosov, Nicolas Puillandre

\section{To cite this version:}

Anders Hallan, Francesco Criscione, Alexander Fedosov, Nicolas Puillandre. Few and far apart: integrative taxonomy of Australian species of Gladiobela and Pagodibela (Conoidea: Raphitomidae) reveals patterns of wide distributions and low abundance. Invertebrate Systematics, 2021, 35 (2), pp.181-202. 10.1071/is20017 . hal-03172430

\author{
HAL Id: hal-03172430 \\ https://hal.science/hal-03172430
}

Submitted on 19 Mar 2021

HAL is a multi-disciplinary open access archive for the deposit and dissemination of scientific research documents, whether they are published or not. The documents may come from teaching and research institutions in France or abroad, or from public or private research centers.
L'archive ouverte pluridisciplinaire HAL, est destinée au dépôt et à la diffusion de documents scientifiques de niveau recherche, publiés ou non, émanant des établissements d'enseignement et de recherche français ou étrangers, des laboratoires publics ou privés. 


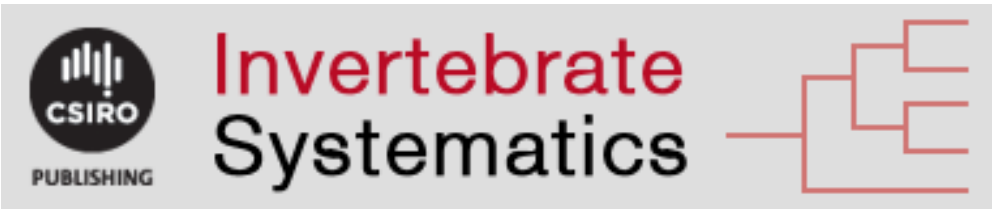

\section{Few and far apart: integrative taxonomy of Australian species of Gladiobela and Pagodibela (Conoidea: Raphitomidae) reveals patterns of wide distributions and low abundance}

\begin{tabular}{|r|l|}
\hline Journal: & Invertebrate Systematics \\
\hline Manuscript ID & IS20017.R2 \\
\hline Manuscript Type: & Research paper \\
\hline Author: & $\mathrm{n} / \mathrm{a}$ \\
\hline Complete List of Authors: & $\begin{array}{l}\text { Hallan, Anders; Australian Museum, Natural Sciences } \\
\text { Criscione, Francesco; Australian Museum, Natural Sciences } \\
\text { Fedosov, Alexander; Russian Academy of Sciences } \\
\text { Puillandre, Nicolas; Museum National d'Histoire Naturelle, Systematique } \\
\text { et Evolution }\end{array}$ \\
\hline Keyword: & $\begin{array}{l}\text { mitochondrial DNA, Australia, Gastropoda, Indo-Pacific, molecular } \\
\text { systematics, south-west Pacific, species delineation }\end{array}$ \\
\hline &
\end{tabular}

\section{SCHOLARONE Manuscripts}



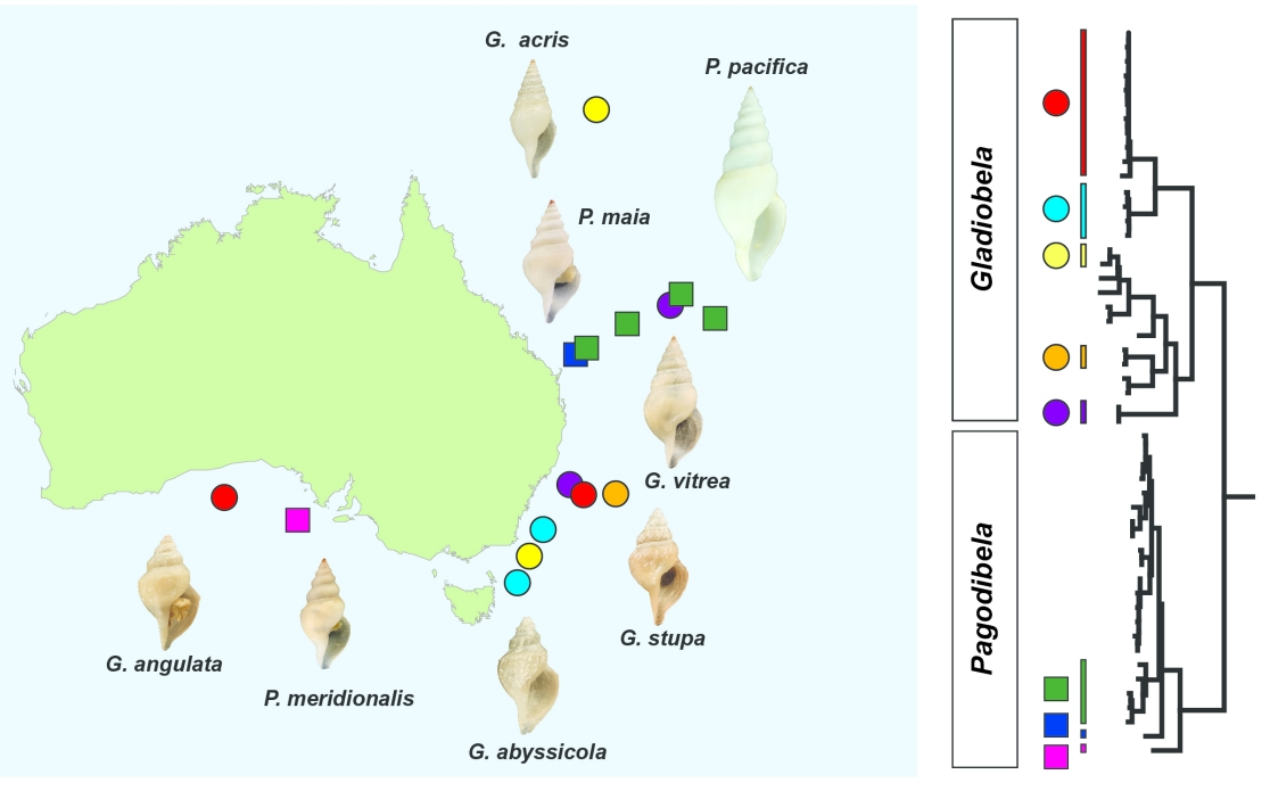

$650 \times 400 \mathrm{~mm}(96 \times 96 \mathrm{DPI})$ 
Short summary

Distribution patterns of deep-sea benthic gastropods remain poorly known, yet such knowledge is crucial to approaching their systematics and understanding their diversity. With a focus on the raphitomid genera Gladiobela and Pagodibela, we combine genetic, shell, anatomy and distribution data to identify seven new species from Australia and beyond, which we here describe. Our findings suggest patterns of extreme rarity in some species, with others exhibiting wide Indo-Pacific distributions. We argue that wide geographic ranges in deep-sea conoidean gastropods may be more common than previously assumed, which has implications for future systematics efforts on this hyper-diverse group. 
1 Few and far apart: integrative taxonomy of Australian species of Gladiobela and Pagodibela

2 (Conoidea: Raphitomidae) reveals patterns of wide distributions and low abundance

3

4 Anders Hallan A, Francesco Criscione ${ }^{A *}$, Alexander Fedosov ${ }^{B}$, Nicolas Puillandre ${ }^{C}$ 5

6

7

8

9 A - Australian Museum, 1 William Street, Sydney NSW 2010, Australia

10 B - A.N. Severtsov Institute of Ecology and Evolution of Russian Academy of Sciences,

11 Leninski Prospect 33, Moscow 119071, Russia

12 C - Institut Systématique Evolution Biodiversité (ISYEB), Muséum National d'Histoire

13 Naturelle, CNRS, Sorbonne Université, EPHE, Université des Antilles. 57 rue Cuvier, CP 26,

1475005 Paris, France

$15 *$ Corresponding author: francesco.criscione@austmus.gov.au

19 Running title: Molecular systematics of Gladiobela and Pagodibela 
Abstract

The deep-sea malacofauna of temperate Australia remains comparatively poorly known. However, a recent influx of DNA-suitable material obtained from a series of deep-sea cruises facilitated integrative taxonomic study on the Conoidea (Caenogastropoda: Neogastropoda). Building on a recent molecular phylogeny of the conoidean family Raphitomidae, this study focussed on the genera Gladiobela and Pagodibela (both Criscione et al., 2020). We subjected a comprehensive mtDNA COI dataset of deep-sea raphitomids to ABGD barcode gap detection, which recognised 14 primary species hypotheses (PSHs), nine of which were converted to secondary species hypotheses (SSHs). Following the additional examination of the shell and hypodermic radula features, as well as consideration of bathymetric and geographic data, seven of these PSHs were recognised as new to science and given full species rank. Subsequently, full systematic descriptions were provided herein. Of these, five were attributed to Gladiobela (three of which are endemic to Australia and with two more widely distributed) and two were placed in Pagodibela (one endemic to southern Australia and one widespread in the Pacific). The rarity of many 'turrids' reported in previous studies was confirmed herein, as particularly indicated by highly disjunct geographic records for two taxa. Additionally, several of the studied taxa exhibited wide Indo-Pacific distributions, suggesting that wide geographic ranges in deep-sea 'turrids' may be more common than previously assumed. Finally, impediments to deep-sea 'turrid' taxonomy in the light of such comparative rarity and unexpectedly wide distributions were discussed. 
Introduction

It is a well-known notion among malacologists that 'turrids' - members of the hyper-diverse superfamily Conoidea (Caenogastropoda: Neogastropoda) not including Conidae and Terebridae and historically treated as Turridae (herein referred to as 'turrids' to clearly distinguish from Turridae sensu stricto) - are a particularly challenging group taxonomically. Hedley (1922: p. 213) stated that the marine gasteropods [sic] embraced in the family Turridae (formerly Pleurotomidae) are considered by those who meddle with them to be more perplexing than any other molluscan family'. The literature provides numerous examples in support of that statement, such as 'turrid pairs', where separate species (not necessarily sister taxa) have virtually indistinguishable teleoconch morphologies but differing protoconchs (Powell 1942) or where even species from different families cannot be readily differentiated based on shell characters (Hallan et al. 2020; Kantor et al. 2018; Sysoev and Kantor 1990). Other impediments to 'turrid' taxonomic study include low abundances in many taxa and relative difficulty in collecting due to their largely subtidal habitats (Bouchet and Waren 1980; Todd and Rawlings 2014). Challenges with 'turrid' taxonomy are further exacerbated in the deep sea, where protoconchs are commonly eroded or missing entirely (Criscione et al. 2020), and sculptural elements of the teleoconch may be significantly worn owing to the dissolution of $\mathrm{CaCO}_{3}$ (Burton 1998). Furthermore, some deep-sea taxa exhibit an overall lack of indicators of terminal shell growth [such as apertural thickening, formation of a varix, or similar (Bouchet and Waren 1980)]. In these cases, inferences about the stage of maturity (and therefore about representative adult size) are difficult, particularly where material is scarce. Paraphrasing the sentiment by Marshall (1983) that material of Triphoridae ought not to be described in the absence of an intact protoconch, Puillandre et al. (2017) emphasised that no new 'turrids' should be described without molecular data, preferably designating a molecular voucher as a type. This is particularly true for deep-sea material, given the issues raised above. When conducting 'turrid' systematics research, notably on deep-sea taxa, there is also the need to consult with taxonomic work on species that may occur far beyond conventionally expected geographic limits of conspecific taxa. A study by Zaharias et al. (2020) demonstrated that several deep-sea species of the genus Cryptogemma Dall, 1918 (Turridae) exhibit notably wide distributions. Corroborated by mitochondrial DNA evidence, one species, C. phymatias (R. B. Watson, 1886) was shown to have a trans-oceanic 
distribution, arguably providing the first molecularly confirmed such case in a benthic gastropod. Such unexpectedly wide geographic ranges may routinely escape the attention of taxonomists, notably where morphologically heterogeneous taxa are concerned; Zaharias et al. (2020) synonymised several species names attributable to Cryptogemma, suggesting that while analyses of molecular data commonly reveal unnamed taxa in the Conoidea (e.g., Fedosov and Puillandre 2012; Puillandre et al. 2010a), taxonomic over-splitting may also occur, arguably in part as a consequence of underestimated distribution ranges. While trans-oceanic ranges, such as that documented for $C$. phymatias, appear to be exceptionally rare based on existing evidence, wide distributions in the deep sea, particularly in the Conoidea, may not be so uncommon. Bouchet and Waren (1980) noted that among their deep-sea study material from the Western and Eastern Atlantic, there was a 34\% species overlap between the two regions, suggesting that a significant portion of deep-sea 'turrids' may have ocean-wide distributions. Furthermore, they predicted that percentage would increase with additional study.

The deep-sea Australian malacofauna has, until recently, remained among the most poorly known in the Indo-Pacific region owing to a lack of study material, particularly that suitable for molecular analysis (Criscione et al. 2020). However, recent deep-sea expeditions in southern and eastern Australia, notably aboard the research vessel Investigator, have delivered a wealth of material from several major groups of the Mollusca (see Maclntosh et al. 2018; O'Hara 2019). The extremely diverse superfamily Conoidea is prevalent in these samples, and now subject to ongoing collaborative study between the Australian Museum, Sydney (AM) and the Muséum National d'Histoire Naturelle, Paris (MNHN) (Criscione et al. 2020; Hallan et al. 2020; Zaharias et al. 2020). The 'turrid' family Raphitomidae is particularly well-represented among this conoidean material (O'Hara 2019). A recent molecular phylogeny by Criscione et al. (2020) revealed a considerable diversity of previously unknown deep-sea raphitomid lineages and included the description of twelve new genera. Building on the classification framework set out by this latter study, two of the genera described therein are further treated here: Gladiobela Criscione et al., 2020 and Pagodibela Criscione et al., 2020. Gladiobela angulata Criscione et al., 2020, type species of its genus, is known from bathyal depths (3350-3807 m) of the Great Australian Bight (henceforth GAB), and from a single locality off the NSW Central Coast ( $2600 \mathrm{~m}$ ). This study describes five additional species of Gladiobela, three of which are possibly endemic to 
109 temperate Australia, and two potentially widespread in the eastern Indo-Pacific, with all 110 members of the genus occurring from bathyal to abyssal depths ( $500-4850 \mathrm{~m}$ ). Pagodibela 111 maia Criscione, 2020, type species of its genus, is known only from a single record from the 112 Coral Sea ( $1000 \mathrm{~m}$ ). Two additional species of Pagodibela, one from the GAB and the other 113 from north Queensland to the Society Islands, are also described herein. Generic diagnoses 114 are provided for both genera, as well as details of the shell and venom apparatus.

115 Furthermore, morphological characters, as well as patterns of bathymetry and biogeography 116 are presented. Finally, impediments to future 'turrid' systematics given their comparative 117 scarcity (in terms of number of individuals) and unusually wide distributions at the species118 level are discussed. 
Materials and methods Taxon sampling

The samples studied herein were selected from among all deep-sea Raphitomidae ethanolpreserved material from the malacological collections of the Australian Museum, Sydney (AMS), the South Australian Museum, Adelaide (SAMA) and the Muséum national d'Histoire naturelle, Paris (MNHN). As a result of ongoing systematic research on the Conoidea at the AMS and MNHN, several hundreds sequences of the mitochondrial gene cytochrome $c$ oxidase subunit 1 (COI) were obtained from a few hundreds largely undescribed representative raphitomid taxa. In order to assist with the selection of the study material, a pilot analysis was performed on a dataset including all raphitomid COI sequences, using the neighbour-joining method (NJ) (Saitou and Nei 1987) implemented in MEGA 7 (Kumar et al. 2016). The dataset encompassed sequences of the type species of many deep-sea raphitomid genera, including the holotypes of G. angulata (MN983180) and P. maia (MN983188). A subset of sequences was generated which included all COI sequences that in the resulting tree (not shown) were more closely related to the sequences of either of the two holotypes than to any type species of any other raphitomid genus in the dataset. The dataset thus obtained (henceforth referred to as 'ingroup') forms the basis for the molecular analysis described below. Additional material relevant to this study, but for which attempts of amplifying COI failed, was selected based on the results of a NJ analysis (see below) of a dataset comprising all $12 \mathrm{~S}$ sequences available for raphitomids. This dataset, albeit much smaller than the COI one (about 200 sequences), included sequences of the holotypes of type species of Gladiobela (MN985672) and Pagodibela (MN985684). A subset of $12 \mathrm{~S}$ sequences was formed with these and other sequences that in the resulting tree (not shown) were more closely related to them than to any type species of any other raphitomid genus in the dataset.

Among the ingroup specimens, morphological examination was only conducted on those collected in Australian waters and some of those collected outside Australia (see Results). Geographic and bathymetric data were available for all ingroup specimens. Geographic distributions were assessed with reference to marine biogeographic realms as delimited in Costello et al. (2017). According to Bouchet et al. (2008), when inferring species distributions from sampling depth intervals, only shallower depth values were considered, as there is no evidence that the species collected occurs beyond that value. 
Molecular methods

Molecular work was performed in laboratories at two different Institutions (AMS and

MNHN). Unless otherwise stated, the same methodology was followed by both laboratories.

DNA extraction was performed on at least one specimen per morphospecies per collecting site. DNA was extracted from small pieces of foot muscle by use of a Bioline Isolate II Genomic DNA extraction kit for animal tissue, following the standard procedure of the manual (AM) or using the Epmotion 5075 robot (Eppendorf), following the recommendations by the manufacturer (MNHN). Fragments of the two mitochondrial genes COI and $12 S$ were amplified using the primer pairs LCO1490/HCO2198 (Folmer et al. 1994) and 12S-I/12S-III for 12S (Simon et al. 1991). PCR reactions were performed in volumes of 25 $\mu \mathrm{l}$, containing $3 \mathrm{ng}$ DNA, 1X Qiagen CoralLoad PCR Buffer, $2.5 \mathrm{mM} \mathrm{MgCl}_{2}, 0.25 \mathrm{mM}$ dNTP, $0.5 \mathrm{mM}$ of each primer, $0.5 \mu \mathrm{g} / \mu \mathrm{l}$ of BSA and $0.2 \mu \mathrm{l}$ of Bioline MyTaq DNA polymerase. Amplification consisted of an initial denaturation step at $94^{\circ} \mathrm{C}$ for $4 \mathrm{~min}$, followed by 37 cycles of denaturation at $94^{\circ} \mathrm{C}$ for $30 \mathrm{~s}$, annealing at $50^{\circ} \mathrm{C}(\mathrm{COI})$ or $57^{\circ} \mathrm{C}(12 \mathrm{~S})$ for $30 \mathrm{~s}$, followed by extension at $72^{\circ} \mathrm{C}$ for $1 \mathrm{~min}$. The final extension was conducted at $72^{\circ} \mathrm{C}$ for 5 $\min$.

PCR products were purified and sequenced by the Macrogen (AMS) and Eurofins (MNHN) sequencing facilities. When necessary, chromatograms were manually corrected for misreads and forward and reverse strands were merged into one sequence file using CodonCode Aligner v. 9.0.1 (CodonCode Corporation, Dedham, MA). COI sequences did not require alignment as these had identical lengths of $658 \mathrm{bp}$ after trimming of the primer sites. Alignments of $12 \mathrm{~S}$ sequences were generated using MUSCLE as implemented in MEGA7 (Kumar et al. 2016). Phylogenetic analyses were conducted on the COI dataset, using Maximum Likelihood (ML) and Bayesian inference (BI) methods. All sequences used deposited in GenBank (Table S1). Sequences of thirteen deep-sea raphitomid genera were added to serve as outgroups (Table S1). Their selection was based on a multi-gene (mitochondrial and nuclear) phylogeny containing many southern and south-eastern Australian Raphitomidae (Criscione et al. 2020). ML was performed using the program MEGA7 with Nearest-Neighbour-Interchange (NNI) as heuristic method and automatic generation of the initial tree. One thousand bootstrap replicates (BS) were performed to assess the topology support. The BI analysis 
was performed in MrBayes 3.2.6 (Ronquist and Huelsenbeck 2003) and included 2 runs of $10^{7}$ generations, with 4 chains each and a sampling frequency of one tree per 1,000 generations. Other parameters were set to default. A consensus tree was then calculated after checking for chain convergence and discarding the first $25 \%$ trees as burn-in. Prior to the model-based ML phylogenetic analyses, $\mathrm{TN} 93+\mathrm{G}+\mathrm{I}$ was identified as best-fit model of nucleotide substitution by means of the Bayesian Information Criterion as implemented in MEGA 7 (Kumar et al. 2016). According to MrBayes manual (p. 94), a priori model testing was not performed, and the $\mathrm{GTR}+\mathrm{G}+\mathrm{I}$ model was applied to the $\mathrm{BI}$ analysis. Nodal support was assessed by values of Bayesian posterior clade probabilities (BPP).

Due to the smaller number of sequences selected to form the $12 \mathrm{~S}$ dataset, a NJ analysis only was deemed sufficient to represent the phylogenetic relationships based on this gene. This analysis was performed in MEGA 7 (Kumar et al. 2016). Uncorrected pairwise genetic distances were calculated using MEGA7 with the option 'pair-wise deletion of gaps'.

\section{Morphological examinations}

All studied samples consisted of soft parts and shells, which had been separated following the methodology (drilling or microwaving) mentioned in Criscione et al. (2020). We studied shell morphology and (when possible) internal anatomy, including radular morphology. Shells were affixed to plasticine and positioned with their vertical axis parallel to the observation plane. Each shell was then photographed from above using a Canon EOS 6D digital SLR camera. Maximum shell length (SL) and width (SW) were measured on digitised images using the calibrated ruler tool in Adobe Photoshop CC v.20.0.6 and measurements rounded to the nearest $0.1 \mathrm{~mm}$. The number of shell whorls was counted under a Leica MZ8 stereomicroscope, according to Bouchet and Kantor (2004). While it was possible to obtain the number of teleoconch whorls $(\mathrm{Wt})$ for all studied specimens, protoconch whorls could only be counted occasionally due to widespread erosion of the apex. In order to capture the shell proportions regardless of their size, the ratios SL/SW, SL/Wt and SW/Wt were generated. Ideally, to prevent the effects of allometry, only shells at terminal growth could be used in the morphometric analysis of this study. However, terminal growth could not be assessed for the samples of this study (see above). As an approximation, shells of a given PSHs were assumed to have reached terminal growth when their Wt were within one unit of 
214 the maximum Wt value observed for that given PSHs. Based on the data obtained, descriptive statistics and plots were produced in SYSTAT v.13.1 (Systat Software, Inc., 2009). Anatomical studies were conducted on animals removed from ethanol and briefly rehydrated in distilled water. Using standard dissection tools, the venom apparatus was excised and the radular sac isolated and placed on a glass slide; during this dissection process, head-foot, mantle, genital and (non-radula) foregut characters were examined where possible. After dissolution in diluted commercial bleach, clusters of hypodermic teeth where rinsed repeatedly in distilled water, then separated into individuals and ligamentconnected pairs/smaller clusters. Subsequently, the glass stub was affixed to a carbon adhesive placed on a $12 \mathrm{~mm}$ diameter aluminium mount. All samples were imaged at Macquarie University, Sydney, using a Phenom XL Scanning Electron Microscope.

Species delimitation

The Automatic Barcode Gap Discovery (ABGD) (Puillandre et al. 2012b) was applied for primary species delimitation to the dataset containing all COI ingroup sequences. The webbased version of ABGD (https://bioinfo.mnhn.fr/abi/public/abgd/abgdweb.html) was used with a $\mathrm{p}$-distance model. The relative gap width $(X)$ was set to 1 and other parameters left to default. Resulting ABGD groups were considered primary species hypotheses, henceforth referred to as PSHs. Following Puillandre et al. (2012c), conversion of PSHs to secondary species hypotheses (SSHs) was conducted through comparative examination of morphological characters as well as through evaluation of geographic and bathymetric data. In particular, for each PSH examined, the co-occurrence of the following conditions was considered evidence supporting such conversion: (i) the PSH is a highly supported clade (BPP $>98 \%$ and $B S>90 \%$ ), (ii) the PSH shows lower values of intra-PSH genetic $p$-distance in $\mathrm{COI}$ when compared with values of inter-PSH distances measured with the most closely related PSH, (iii) all its constituent specimens share at least one distinctive morphological feature deemed not to be polymorphic or ecophenotypic, and without exhibiting intermediate forms. When the above criteria were met, the presence of genetic or morphological divergence and/or bathymetrical partitioning in sympatry was considered additional evidence supporting species delimitation. Clearly, when PSHs are represented by one sequence only, criteria (i) and (ii) cannot be assessed. In those cases, the decision was guided by presence of additional bathymetrical and morphological evidence as well as 
comparisons with intra-generic patterns of genetic distance. When available, species names were assigned to SSHs based on the current taxonomy. New species names were introduced when no names were available, and formal descriptions for these taxa are given in the systematic section below.

Abbreviations

$\mathrm{CMR}=$ Commonwealth Marine Reserve; Ht=holotype; NSW=New South Wales; PNG= Papua New Guinea; Pt=paratype; QLD=Queensland, SA=South Australia, TAS=Tasmania; VIC=Victoria; wet=number of ethanol-preserved (wet) specimens.

Results

Molecular studies

Molecular analyses were based on a total of $75 \mathrm{COI}$ sequences ( 42 newly produced and 33 GenBank-sourced) generated from specimens collected off Australia during the expeditions IN2015_C01, IN2015_C02 (GAB) and IN2017_V03 (Tasman and Coral Seas) and other localities of the tropical and temperate Indian and Pacific Oceans, during a number of voyages that formed part of the Tropical Deep-sea Benthos programme of MNHN (Fig. 1, Table S1). The dataset analysed included 51 ingroup sequences and 24 sequences representing 24 deep-water raphitomid species of 13 different genera that were used as outgroups

Except for extremely low and high prior values, the ABGD analysis of the COI ingroup dataset consistently returned a partition with 14 groups of sequences (PSHs). Among all PSHs (Fig. 2), five (G1, G2, G4, P2 and P3) contain exclusively Australian samples, three (G3, G5 and P1) include samples from Australian seas and beyond, while the remaining six (GAGE and PA) encompass sequences from outside Australian waters. The $\mathrm{BI}$ and $\mathrm{ML}$ analyses generated trees with nearly identical topologies, showing only minor differences in the relative position of individual sequences within some of the PSH clades (Fig. 2). Clades representing PSH-level relationships and above were generally wellsupported, with very few exceptions. In both analyses, two major genus-level clades were retrieved, namely Gladiobela (BPP $=100 \%, \mathrm{BS}=93 \%$ ) and Pagodibela (BPP and $\mathrm{BS}=100 \%$ ). These two clades included ten and four PSHs respectively, all forming well-supported (in 
terms of nodal support: BPP>98\%; BS $>90 \%$ ) and well-differentiated (in terms of branch lengths) PSH clades. Within the two genus-level clades, there was no overlap between intra- and inter-PSH distances. In the Gladiobela clade, the intra-PSH pairwise distances in COI ranged from 0 to $1.1 \%$ (average=0.5 \%) with inter-PSH distances ranging from 4.0 to $11.7 \%$ (average=8.2 \%) (Table 1). The lowest inter-PSH distances were observed between GD and GE and the highest intra-PSH distances were found within G3. In the Pagodibela clade, the intra-PSH pairwise distances were between 1.8 and 1.9\%, whereas inter-PSH distances ranged from 4.4 to $7.1 \%$ (average=5.6\%) (Table 2). The lowest inter-PSH distances were observed between P2 and PA and the highest intra-PSH distances were found within P1. The NJ tree obtained analysing the $12 \mathrm{~S}$ dataset contained four sequences in a cluster, each obtained from samples of four distinct Gladiobela PSHs (G1, G3, G4, G5 - as delimited above). One additional sequence (MT081495), from sample AMS C.571625, was the sister group of this former cluster and exhibited values of $p$-distances (5.1-6.6\%; Table S2) with its members that were within the range of those measured for COI between Gladiobela PSHs. Additionally, its genetic similarity (in terms of $p$-distance values) with G1, G3, G4, G5 was greater than that measured with sequences of samples of Pagodibela or of any other genus in the analysis (data not shown), suggesting its attribution to Gladiobela. Given that $12 \mathrm{~S}$ largely shares patterns of inheritance with $\mathrm{COI}$, this sample was considered an additional Gladiobela PSH (G6) to undergo further testing for conversion to SSH.

Morphological studies

Shell morphology was examined for all sequenced material and internal anatomy, including radular morphology (when possible) for at least two sequenced specimens per PSH. The Gladiobela clade contains three PSHs (G1, G2 and G4) exhibiting a gross shell morphology, whorl profile and sculptural elements that are comparatively similar (Fig. 3A, B, D), whereas the remaining taxa possess heterogeneous shell morphologies, including high-spired and broad fusiform shells with varying sculpture (Fig. 3).

Due to the limited amount of material available (and specifically of shells at a stage equivalent terminal growth), the sample size was too small to permit inclusion of all PSHs in a statistically rigorous morphometric analysis at this time. A scatterplot of SW/Wt and 
(with the latter exhibiting larger values of both length and width) and proportions (with the latter showing a larger SH/SW ratio). The plot shows that G3 has the smallest and most slender shell of all congeners, while G6 has the largest and broadest shell. As protoconchs were largely eroded (an intact protoconch could not be observed for all species), this character will not be given much emphasis herein. However, all larval shells that could be examined were multispiral and exhibited the typical raphitomid diagonally cancellate sculpture (Fig. 5).

All members of Gladiobela shared hypodermic, somewhat tightly rolled teeth with a very long dorsal blade (Fig. 6A), elongate adapical opening and moderately broad to very broad base (Fig. 6). The sister taxa G1, G2 and G3 can be characterised by teeth with extremely long dorsal blades and a very broad, angular base with a crescent-shaped indentation around the perimeter of the lower shaft and an elongate posterior extension (Fig. 7); G4 is a notable outlier with an extremely long tooth compared to its congeners (Fig. 6F), whereas G5 and G6 possess teeth with a narrower, less angular base (Fig. 6B, D). All members exhibit moderate to long, tapering to cylindrical cephalic tentacles with very small eyespots at their lower outer bases.

Pagodibela PSHs vary notably in shell morphology, from strongly pagodiform with prominent sculpture, to subconical and comparatively smooth (Fig. 3G-J). Their radulae consist of hypodermic morphologically uniform teeth: awl-shaped, with a long dorsal barb, an elongate adapical opening and a swollen base with coarse external texture (Fig. 6G-I). All PSHs possess small eyes at the outer lower bases of cylindrical cephalic tentacles.

Geographical and bathymetrical distributions The genus-level clade Gladiobela is recorded from three marine realms (sensu Costello et al. 2017) (Fig. 1A, C) and Pagodibela clade from at least seven marine realms (Fig. 1B, D). Gladiobela exhibits a wide bathymetric range, from 470 to 4750 metres, and Pagodibela from 318 to 1013 metres (Fig. 8). The sister clades G1 and G2, G4 and G6 are known only from off Australia, where they are restricted to bathyal and abyssal depths of the temperate south (Fig. 1A). The three former PSHs are not recorded micro-sympatrically (e.g. in the same trawl haul): G1 exhibits a disjunct distribution with the majority of records in the GAB and a single record in the Hunter CMR (depth range 2474-3389 m); G2 occurs between (off) 
341 G4 is known from a single locality in the Hunter CMR (3980 m). G6, known only from a sole

342 individual, was collected at the same site as G1 in the Hunter CMR. G3 is known from two widely separated localities, both geographically and bathymetrically, namely in the East Gippsland CMR, at 3850 metres and NW Choiseul, Solomon Islands, between 1083 and 1100 metres. G5 is recorded from the Hunter CMR and Canal de l'Havannah, New Caledonia, with depth records occurring between 951 and 1006 metres.

For Pagodibela, P2 and P3 are only known as single specimens from the Coral Sea and GAB respectively, of which the former is known from approximately 1000 metres and the latter approximately 370 metres. Conversely, P1 is widely distributed between (off) North Queensland, via the Coral Sea, New Caledonia and eastward to the Society Islands at a depth range of 450-1013 metres. PA has the most widespread known distribution of all Pagodibela PSHs, occurring in at least four marine realms between the South Pacific and off the east African coast (Fig. 1D).

\section{PSH to SSH conversion}

Comparative examination of the morphological, geographic and bathymetric data available was employed to attempt the conversion of PSHs to SSHs. As generating morphological data for most species with distribution outside Australian waters was beyond the scope of this study, testing of five PSHs (i.e. GA-GE), out of the total of fourteen retrieved by ABGD, was not attempted and these are pending further sampling and taxonomic investigation. As detailed below, all remaining nine PSHs retrieved by ABGD, namely G1-G5, PA and P1-P3 satisfied the three conditions described in the methodological section. G1 and G2 corresponded to highly supported clades (BPP and BS=100\%; Fig. 2) in a sister relationship. Both exhibited low intra-PSH genetic distance (average $0.06 \%$ and $0.05 \%$ respectively; Table 1) and comparatively high reciprocal genetic distance (average 5.4\%; Table 1). Both G1 and G2 could be distinguished from all other PSHs by their distinctly carinated shells (Fig. 3A-B). G1 could be differentiated from G2 by their smaller, broader shells (Fig. 4) with a carina that is comparatively less pronounced. In addition, their bathymetrical range did not overlap (Fig. 8). The genetic, morphological and bathymetrical distinction between $G 1$ and $G 2$ was maintained in spite of their apparent high dispersal potential (as inferred by the multispiral protoconch) and their sympatry in the South Australia realm (Fig. 1A). 
Clade G3 was highly supported (BPP and BS=100\%), exhibiting values of intra-PSH genetic distances (average 1\%; Table 1) well below values of reciprocal between-PSH genetic distance with its most closely related PSHs (4\% with both GE and GD; Table 1). Its shell was the smallest and most elongate of all other PSHs (Fig. 4) and could readily be distinguished by its raised peripheral cord (Fig. 3C).

G4 corresponded to a highly supported clade (BPP and BS=100\%), exhibiting values of intraPSH genetic distances (average $0.5 \%$; Table 1) and comparatively high genetic distance with its most closely related PSH, GA (5.8\%; Table 1). It could be clearly differentiated from all other PSHs by its shell exhibiting a long, clearly demarcated siphonal canal (Fig. 3D) and by its uniquely long hypodermic teeth (Fig. 6F).

Clade G5 was highly supported (BPP and BS=100\%) and included a single haplotype that exhibited a large genetic distance from its most closely related PSH, GC (average 7.9\%; Table 1). All shells of this PSH shared distinctively rounded lower teleoconch whorls (Fig. 3E) that allowed their differentiation from shells of all other PSH in the Gladiobela clade. Along with the aforementioned comparatively high values of inter-PSHs genetic $\mathrm{p}$-distance in $12 \mathrm{~S}$ (Table S2), the shell of G6 could be differentiated from that of all other PSHs by its broad whorls with opisthocline axial ribs, and by its comparatively rounded shoulder (Fig 3F). Such genetic and morphological differentiation was maintained in spite of its sympatry with $\mathrm{G} 1$ at the boundary between the two marine realms encompassing the Australian seas (Fig. 1A).

PA and P1 both corresponded to highly supported clades (BPP $=98 \%$ and $B S=93 \%, B P P$ and $\mathrm{BS}=99 \%$ respectively; Table 2 ) showing comparatively high values of reciprocal genetic differentiation (average 4.7\%; Table 2). These two PSHs exhibited similar shells that could be differentiated from other Pagodibela PSHs by their comparatively thicker and more elongate shells. However, PA and P1 could be differentiated from each other based on shell sculpture - while shells of P1 possess juvenile whorls with weakly opisthocline axial riblets extending across the periphery (although weakening towards suture), in shells of PA the axial elements were significantly weaker, and there was a prominent, slightly gemmate subsutural cord in the early- to median teleoconch whorls (Fig. $3 \mathrm{H}$ and $3 \mathrm{G}$ respectively). In both PA and P1, the overall shell shape was rather conserved across its constituent samples. The minor differences observed among PA shells in their peripheral sculpture (smooth, 
403

404

405

406

407

408

409

410

411

412

413

414

415

416

417

418

419

420

421

422

423

424

425

426

427

428

429

carinate or tuberculate), were consistent with distributional patterns and thus interpreted as intraspecific geographical variation.

The only sample included in P2 was separated from the sister pair PA and P1 by high values of genetic distance ( 4.4 and $4.8 \%$ respectively; Table 1 ). The pagodiform shell of $P 2$ exhibited a gemmate carina that was unique among PSHs of Pagodibela. This distinctiveness was maintained in spite of geographic and bathymetric overlap with P1 in the Coral Sea. Clade P3 was the sister group of all other Pagodibela PSHs, revealing comparatively high values of reciprocal genetic distance with all congeneric PSHs (>6.3\%; Table 2). It included only one sample with a uniquely thin, fragile shell with comparatively rounded whorls (Fig. 3J), which differentiated it from any other PSH within the Pagodibela clade.

\section{Assigning names to $\mathrm{SSHs}$}

A search was conducted for all names available and potentially applicable to the nine SSHs resulting from the conversion process described above. By consulting the relevant literature on Raphitomidae (e.g. Bouchet and Sysoev 2001; Bouchet and Waren 1980; Sysoev and Bouchet 2001) and by comparison of molecular and morphological data available on type specimens with the data generated on sequenced specimens, we found three names applicable to three SSHs. Two SSHs, G1 and P2, included the type material of two species, $G$. angulata and $P$. maia respectively, and could therefore be readily respectively associated with these species. As its constituent specimens shared shells that closely resembled the holotype of Gymnobela baruna Sysoev, 1997 (Fig. 3G), clade PA was attributed to this taxon, thus requiring a formal transfer of this species to Pagodibela as hereby proposed (Pagodibela baruna n. comb.). As no available names could be found for the remaining six SSHs, new taxon names were assigned, namely G. abyssicola n. sp. (G2), G. acris n. sp. (G3), G. stupa n. sp. (G4), G. vitrea n. sp. (G5), G. sinuosa n. sp. (G6), P. pacifica n. sp. (P1) and P. meridionalis n. sp. (P3). Formal taxonomic descriptions of these newly recognised species are provided below. 
Discussion

Phylogenetic relationships and generic taxonomy

Building on the five-gene phylogeny of Criscione et al. (2020), that established the phylogenetic framework upon which Gladiobela and Pagodibela were recognised and described, it is shown herein that there is strong support in both $\mathrm{BI}$ and $\mathrm{ML}$ analyses for their monophyly (Fig. 2).

The integrity of these genera is corroborated by radular features diagnostic for each genus. The radula of Gladiobela is characterised by hypodermic awl-shaped teeth with an elongate adapical opening, a very long dorsal blade about half the length of the shaft, a (mostly) broad, angular base and a broad, medium long ligament (Fig. 6A-F). Members of Pagodibela exhibit evenly tapering awl-shaped hypodermic teeth with a comparatively narrow, sloping base with coarse external texture, and a comparatively small, short ligament (Fig. 6G-I). The wide, strongly perpendicular base and the long posterior extension, particularly noticeable in G. angulata, G. abyssicola and, G. acris (Fig. 6A, C, E; Fig. 7) are particularly prominent features, notably the crescent-shaped indentation around the base of the shaft (Fig. 7A). While nothing is known of any potential corresponding features in the proboscis interior of these taxa, such as the presence and nature of an epithelial pad seen in several 'turrid' lineages (Kantor and Taylor 2002; Medinskaya 1999), the following speculations can nevertheless be made: the long posterior extension (Fig. 7A) facilitates physical contact with the internal proboscis (thus the area which can be attached), while the crescentic indentation possibly facilitates the proboscis sphincter in holding the tooth securely. A firm, secure grip can hypothetically perform a number of functions, such as aiding in speed and precision during attacks and in securing tooth recovery after- or between attacks (thus assisting in both performing successive stabs and conserving teeth).

While the general configuration of the radula of $G$. stupa conforms with that of its congeners, this species is a notable outlier, due to its very long hypodermic tooth (Fig. 6F). Bouchet and Waren (1980; p. 5) stated that 'it must be remembered that the radula is an organ for capture of food'; the fact that G. stupa possesses extremely long teeth compared to its congeners (Fig. 6F) does suggest that the radular morphology of the group may not purely be ascribed to phylogenetic signal, but that feeding mechanism exerts some selective pressure on their morphology. A similar anomalous enlargement of the radula while retaining the overall tooth configuration (i.e., size and configuration of barbs, length of 
462

463

464

465

466

467

468

469

470

471

472

473

474

475

476

477

478

479

480

481

482

483

484

485

486

487

adapical opening, base morphology, etc.) of its congeners is also seen in a hitherto unnamed species of Austrobela Criscione, Hallan, Fedosov \& Puillandre 2020 (unpublished data). The morphology of the radula reflects feeding mechanism to a larger extent than the phylogenetic signal in cone snails (Olivera et al. 2015; Puillandre et al. 2014). However, dietary habits are not sufficiently known for the Raphitomidae and little inference can be made with regards to the respective influences by phylogenetic signal and feeding in shaping their radular morphology. The radulae of Pagodibela species examined here are highly similar (Fig. 6G-J), and therefore present a solid diagnostic generic-level character. In both genera, shells are heterogeneous, but in gross morphology the overall pagodiform shell of Pagodibela is a recognisable character in its composite taxa (Fig. 3G-J). While some species are similar in shell morphology (notably G. angulata and G. abyssicola), Gladiobela cannot readily be circumscribed based on its shell at the genus-level (Fig. 3A-F).

At the species-level, genetic distinctiveness as shown by ABGD and sequence divergence (Tables 1, 2), demonstrable differences in shell morphology and dimensions (Figs 3, 4) and to a lesser extent radular morphology (particularly for Pagodibela, see Fig. 6G-J), translate into robust hypotheses for all the new species described herein.

The genetic distinctiveness reported at the intra- and interspecific levels for the two genera (Tables 1, 2) is comparable, but overall lower than those reported for the raphitomid genera Kermia W. R. B. Oliver, 1915 and Pseudodaphnella Boettger, 1895 (Fedosov and Puillandre 2012), and significantly lower than those reported for Hemilienardia Boettger, 1895 (Fedosov et al. 2017). This could be explained by differences in population effective size, with mutations being fixed more rapidly in smaller populations due to genetic drift.

Biogeographical and bathymetrical patterns

Most species of Gladiobela named herein occur within an area corresponding approximately to the South Australia marine realm of Costello et al. (2017). Unsurprisingly, the records are concentrated in the areas of sampling: a relatively restricted portion of the GAB and on a section of the temperate E Australian coast between NE Tasmania and the Hunter CMR (Fig. $1 A)$. As neighbouring regions with comparable environmental conditions remain virtually unexplored, it is plausible that disjunct distributions, like that observed for G. angulata (Fig. $1 \mathrm{~A})$, are the result of sampling bias, rather than a reflection of any underlying biological process. In G. angulata, the mean genetic p-distance between the Hunter CMR COI 
haplotype and the GAB haplotypes is low $(0.4 \%)$, when compared with the range of $p$ distances calculated within the GAB sequences $(0.2-2.0 \%)$, indicating very recent or ongoing gene flow between the two areas. It remains unclear whether genetic connectivity in $G$. angulata is realised through a stepping-stone process, involving additional geographically intervening populations, or through long range dispersal of the planktotrophic larva (or both).

In a scenario of a continuous distribution of $G$. angulata, there would be potential range overlap with its sister taxon, G. abyssicola, off the southeast Australian coast. However, the two taxa are not recorded in micro-sympatry. Additionally, there is no recorded overlap in their bathymetric ranges, with an approximately 650-metre gap between their lower and upper bathymetric extremes (Fig. 8), despite some sampling coverage within this gap at corresponding areas. It is conceivable that the two taxa have partitioned into separate bathymetric niches, although the present knowledge of their ecological requirements is insufficient to explain the mechanism involved. Separate bathymetric distributions of sister species have been previously reported for at least three conoidean genera, namely Bathytoma Harris \& Burrows, 1891, Lophiotoma T. L. Casey, 1904 and Cryptogemma Dall, 1918 (Turridae) (Puillandre et al. 2017; Puillandre et al. 2010b; Zaharias et al. 2020) and presented as examples of speciation where bathymetric niche partitioning is the driver of genetic isolation in absence of topographic barriers.

The two records of $G$. acris are separated by an entire marine realm (Fig. $1 A, C)$ in which there are no records despite moderately comprehensive sampling in recent times and in the relevant depth range (O'Hara 2019), and within which other congeners (Fig. 1A) as well as several other raphitomids have been recorded (Criscione et al. 2020). Similarly, G. vitrea is recorded from widely separated localities (Hunter CMR and New Caledonia), although both in the same marine realm (Fig. $1 \mathrm{~A}$ ) and both within a relatively narrow depth range when compared to G. acris (Fig. 8). Assuming that all species of Gladiobela have similar dispersal capabilities, it is plausible that the difference in intraspecific p-distance between G. acris (average 1.1\%; Table 1) and G. vitrea (one haplotype only) is the result of their difference in geographical and bathymetrical distribution.

The comparatively wide geographic distributions of P. pacifica, P. baruna, G. acris and G. vitrea are not entirely unexpected given the mounting evidence of wide distributions in deep-sea 'turrids' (Bouchet and Waren 1980; Zaharias et al. 2020; Criscione et al., subm.). 
526 Our results suggest that Gladiobela may comprise species that are comparatively common

527 (e.g., G. angulata/G. abyssicola) and some of which may be either rare in terms of their 528 abundance or exhibit fragmented distributions (or both).

529 The bathymetric range of G. acris (about 2770 m) (Fig. 8) possibly constitutes the widest 530 ever reported for a conoidean species. While similarly wide depth ranges have been 531 documented for a number of deep-sea 'turrids' [including some raphitomids (Bouchet and Waren 1980)], the wide range of the trans-oceanic turrid C. phymatias (about $2000 \mathrm{~m}$ ) is so far the only one reported with support from genetic evidence (Zaharias et al. 2020). Due to the scarcity of material for most other species studied here, little inference can be made with regards to their bathymetric zonation.

Challenges to deep-sea 'turrid' taxonomy

While extremely diverse, most 'turrids' are commonly found in low to very low abundance, frequently even as single individuals (Bouchet et al. 2009; Todd and Rawlings 2014). The findings of this study largely conform to that observation, with P. maia, P. meridionalis and G. sinuosa known from only single specimens and G. acris n. sp. and G. vitrea n. sp. known from two individuals each. Such scarcity of material makes meaningful comparison between taxa with regards to a range of characters difficult. Limited inference can be made about relative size and maturity, as the lack of terminal shell growth makes it is difficult to ascertain if a specimen has attained maturity, particularly in the absence of comparative material. While the number of teleoconch whorls may be an indicator of maturity, Bouchet and Waren (1980) suggested that this may not be a reliable character for some taxa, as terminal shell growth has been observed in taxa with very few teleoconch whorls. While the challenge of assessing maturity persists also where sample populations are larger, a growth series can at least provide some insights into any developmental changes that may occur with increasing size. Studies on the genus Cryptogemma of the Turridae sensu stricto (Kantor and Sysoev 1991; Zaharias et al. 2020), suggest that the characteristic apertural notch and a large penial appendage in Cryptogemma praesignis (Smith, 1895) are both features attained in maturity and which are absent in immature individuals. Criscione et al.

555 (2020) reported developmental changes in the eye morphology of Nodothauma magnifica

556 Criscione, Hallan, Fedosov \& Puillandre, 2020, in which juvenile and young adults may possess large eyes which with maturity become obscured by epidermis. With species known 
only from single or very few specimens, such characters may be readily missed. So, what should then be considered an appropriate threshold in terms of available material for describing a new deep-sea 'turrid'? The absolute minimum ought to be a molecular voucher linked to a type (Puillandre et al. 2017) and providing details of radular- and other non-shell characters where available. Satisfying these criteria, meaningful species descriptions can be conducted even where limited material is known. Any effort towards inventorying the diversity of 'turrids' is vital to the understanding of their evolution and to the characterization of turritoxins (e.g. Gonzales and Saloma 2014; Lopez-Vera et al. 2004; Puillandre et al. 2012a), far lesser known than the pharmacologically relevant conotoxins (Conidae; e.g. Prashanth et al. 2014) and teretoxins (Terebridae; e.g. Gorson et al. 2015). A molecular type voucher also allows for a cumulative taxonomic process, where any future conspecific material suitable for DNA analysis can then be readily identified, and systematic descriptions revised accordingly where new anatomical and/or morphological data are obtained. However, where scarce material (even single individuals) cannot be analysed molecularly, particularly where only the shell is available for study, new species descriptions of deep-sea 'turrids' are virtually meaningless; in fact, such descriptions may complicate integrative taxonomic efforts on this group by the proliferation of taxon names that can never reliably serve as references to any future anatomical and molecular study. With tendencies in several taxa toward shell plasticity, geographically and bathymetrically widespread distributions, and low abundance (Bouchet et al. 2009; Bouchet and Waren 1980; Criscione et al. 2020; Kantor et al. 2008; Zaharias et al. 2020), taxonomic endeavours on 'turrids' pose logistical as well as theoretical challenges best met by integrative, and preferably collaborative efforts to enable optimal sharing of data, material, and expertise. The numerous synonyms in Cryptogemma (Zaharias et al. 2020) are a salient recent example of how integrative taxonomy is critical to constraining and understanding morphological heterogeneity and elucidating biogeographical patterns at the species level. Todd and Rawlings (2014) give examples of how taxonomic efforts on Polystira (Turridae) have resulted in greatly underestimated distribution ranges due to a lack of examination of museum holdings, and where taxonomic decisions have been made with 'relatively few comparisons with other taxa' (p. 470). The results herein further illustrate the need for the integrative approach, associated with a high sampling effort, without which inadequate or 
589 redundant taxonomic decisions can too readily be made due to lacking consultation with the 590 broader taxonomic, biogeographical and molecular contexts. 
Systematics

General remarks

If not stated otherwise, holotypes are dissected ethanol-preserved specimens and all systematic descriptions are based on the holotype. Shell whorls counts (approximated to one decimal unit) are reported with reference to intact whorls only. When applicable, the expression 'at least' is used in combination with the whorl count to indicate potential additional missing whorls that could not be counted. Shell and head-foot colouration reported in the descriptions are based on observations performed prior to fixation, and thus may not be fully reflected in the illustrations provided (Figs 3,5 ).

Measurements of radular features, mainly the length of the adapical opening and the dorsal blade, are given as ratios of the length of the shaft. The 'shaft' is here defined as the entire length of the tooth minus the base, where there is a notable swelling and angulation that clearly differentiates it from the comparatively thin-walled hypodermic, rolled structure. This is done to ensure consistency with the terminology used in Criscione et al. (2020).

\section{Superfamily Conoidea Fleming, 1822}

Family Raphitomidae Bellardi, 1875

Genus Gladiobela Criscione, Hallan, Puillandre and Fedosov, 2020

Diagnosis

Shell ( $\mathrm{SH}=13.5-27.3, \mathrm{SW}=7.5-14.0$ ) fusiform-biconical, broadly- to elongate- biconical, thinwalled, semi-translucent to opaque. Protoconch multispiral, orange, cyrthoconoid, with up to four whorls with diagonally cancellate sculpture. Teleoconch of four to eight whitish, cream to orange whorls, suture impressed. Whorl profile medium- to very broad, with wide, rather lightly concave to straight subsutural ramp, indistinctly to clearly demarcated from whorl periphery; distinctly angulated shoulder sometimes bearing clearly defined carina situated at mid-height to abapical third. Lower portion of whorl sub-cylindrical or slightly narrowed toward suture. Teleoconch sculpture of spirals only (striae) or spiral cords and axial riblets/ribs. Subsutural ramp sculpture of axial growth lines to slightly raised riblets, spirals absent to very faint. Last adult whorl evenly convex or with slight concavity below carina, evenly convex below carina (in latter) or below subsutural ramp, clearly demarcated from rather straight, subcylindrical to tapering siphonal canal. Aperture elongate, about $40 \%$ to half total shell length; outer lip thin, unsculptured. Inner lip whitish, gently recurved, with 
or without spiral cords extending onto columella. No distinct callus. Anal sinus wide to very wide, (moderately) deep, u-shaped.

Animal uniform whitish to cream. Cephalic tentacles short to rather long. Eyes very small.

Radula of straight to slightly curved, medium to very long hypodermic teeth (150-460 $\mu \mathrm{m}$ in length); no ventral barb; dorsal blade extremely long, from about $1 / 3$ to half of length of shaft; adapical opening very elongate to subtriangular, rather narrow, ranging from about $1 / 10$ to $1 / 3$ of length of shaft. Base broad to very broad, with or without distinctly indented 'shelf' perpendicular to shaft; large dorsal wall extending posteriorly, with numerous internal pits or folds; exterior of base with fine texture; basal opening large, subcircular. Ligament broad.

Remarks

Gladiobela can be differentiated from other raphitomid genera by the following combined characters: a (generally) broadly to elongate fusiform shell with a large aperture extending about half of total shell length; a weakly to distinctly carinate shoulder (notably in juvenile teleoconch whorls); rather dense, evenly set spiral cords throughout periphery of teleoconch whorls (include base of last adult whorl); straight to slightly curved hypodermic teeth with a very long dorsal blade, elongate adapical opening, a (generally) very broad, distinctly angular base and a broad, medium long ligament. In terms of shell morphology, Gladiobela bears some superficial resemblance to a number of other Australian deep-sea raphitomid genera including Biconitoma, Aplotoma, Pueridaphne and Fusobela (all Criscione et al., 2020), all of which exhibit comparatively broadly fusiform shells where the length of the aperture is approximately half of total shell length. However, Biconitoma and Aplotoma differ from Gladiobela in their opaque, chalky shells, which also exhibit prominent spiral cords. Pueridaphne is characterised by a finely cancellate sculpture and a deep, wide anal sinus (Criscione et al. 2020), whereas Fusobela bears distinctly rounded whorls with a very weakly defined subsutural ramp. Additionally, these genera differ from Gladiobela with respect to a number of anatomical characters (see Criscione et al. 2020) The ranges for this genus are here expanded from those provided in Criscione et al. (2020), with a reported bathymetric range of $470-4750$ metres (Fig. 8) and occurring in the GAB, Tasman Sea, Coral Sea, New Caledonia and the Solomon Islands (Fig. 1A, C). 
Material examined

Holotype: Australia, NSW, off Bermagui, (-36.351, 150.914), IN2017_V03_043, 4750-4763 m, (AMS C.571656). COI: MT081415.

661

Paratype material: As for holotype, 1 wet (AMS C.571717), 1 wet (AMS C.519389), Australia, Bass Strait, (-39.552, 149.553), IN2017_V03_030, 4133-4197 m, 1 wet (AMS C.519329).

Etymology

In reference to its presence in the abyssal zone, derived from 'abyssus' (Latin=abyss) and colus (New Latin=inhabitant). Adjective of feminine gender.

Distribution

Known from abyssal waters off the southern coast of NSW and Bass Strait, Australia.

Shell ( $\mathrm{SH}=25.6 \mathrm{~mm}, \mathrm{SW}=12.8 \mathrm{~mm}$ ) broadly fusiform-biconical, rather thin-walled, semitranslucent. Protoconch eroded. Teleoconch of at least 5.2 rather uniformly cream whorls, suture impressed. Whorls broad, with very wide, lightly concave to straight subsutural ramp; well-defined carina situated at approximately mid-height of whorl, periphery subcylindrical. Axial sculpture of growth lines only, on early whorls forming slightly raised, densely set riblets. Spiral sculpture of evenly paced, densely set subperipheral cords (about 6 on median whorl, 8 on penultimate whorl, $40+$ on last whorl), few weaker supra-peripheral cords present immediately above carina. Last adult whorl with slight concavity immediately below carina, later - evenly convex, rather clearly demarcated from slightly tapering, moderately long siphonal canal. Aperture elongate, approximately equal to spire length; outer lip thin, unsculptured. Inner lip whitish, gently recurved, spiral cords extending uninterrupted onto columella. No distinct callus. Anatomy (based on AMS C.571656 [female] and AMS C.519329 [male]). Animal uniform whitish. Cephalic tentacles broad, muscular, short to medium length, somewhat tapering toward blunt tip; miniscule eyespots situated at their outer lower bases. Short, muscular 
687

688

689

690

691

692

693

694

695

696

697

698

699

700

701

702

703

704

705

706

707

708

709

710

711

712

713

714

715

716

717

718

introvert. Proboscis long; venom gland very long, white, convoluted; muscle bulb large, elongate, lustrous; large radular sac. Oviduct large. Penis narrow, simple, no obvious glands or swellings.

Radula (based on AMS C.519389 and AMS C.571717) of straight to slightly curved hypodermic teeth attaining $215 \mu \mathrm{m}$ in length; no ventral barb; dorsal blade sharp, extremely long, approximately half of length of shaft; adapical opening very elongate, rather narrow, about 1/3-1/4 of length of shaft. Base broad, with distinct crescentic, slightly excavated shelf more or less perpendicular to orientation of tooth; large dorsal platform extending posteriorly, with numerous, densely arranged folds on inner surface; exterior of base with comparatively fine texture; basal opening large, subcircular. Ligament broad.

\section{Remarks}

G. abyssicola n. sp. is the sister taxon to G. angulata, with which it shares notable similarities in shell- and radular morphology. In terms of shell morphology, G. abyssicola possesses a more acute carina, which forms an elevated spiral cord at the whorl periphery and a slightly shorter, less attenuated siphonal canal (Fig. 3B). Compared to its sister taxon, G. abyssicola has larger and more slender shells (Fig. 4). It can readily be differentiated from the remaining Gladiobela spp. by its distinctly carinate shell. Of all Gladiobela and Pagodibela species, G. abyssicola n. sp. and G. angulata are the only to appear in comparative abundance. The two latter species occupy different bathymetric ranges, in which G. abyssicola is recorded only from abyssal depths ( $\sim 100-4800 \mathrm{~m}$ ) (Fig. 8). Gladiobela abyssicola constitutes the deepest-living conoidean gastropod to be described from Australian waters.

Gladiobela acris n. sp.

(Figs 3C, 5A, 6C)

Material examined:

Holotype: Australia, VIC, East Gippsland CMR, (-38.479, 150.185), IN2017_V03_032, 38503853 m, 1 wet (AMS C.571697). COI: MN983181.

Paratype: Solomon Islands, (-6.417, 156.35), SOLOMON_2, CP2231, 1083-1100 m, 1 wet

(MNHN-IM-2009-19029). 
Etymology

721 In reference to the pointed shape of its shell, derived from 'acer' (Latin=pointed). Adjective of feminine gender.

Distribution

Distribution: Known only from the Hunter Commonwealth Reserve, NSW, Australia and NW Choiseul, Solomon Islands. Potentially widespread.

Shell ( $\mathrm{SH}=19.0 \mathrm{~mm}, \mathrm{SW}=7.5 \mathrm{~mm}$ ) fusiform-biconical, thin, semi-translucent, with tall, orthoconoid spire. Protoconch multispiral, orange, with at least four whorls. PI largely eroded; PII with indistinctly shouldered median whorl, sculpture of axial riblets on shoulder slope changing to diagonally cancellate on whorl periphery. Protoconch-teleoconch transition well-defined, broadly sinuate. Teleoconch of eight uniformly white whorls, suture deeply impressed. Whorls medium-broad, with wide, steep, flat subsutural ramp followed by cylindrical low periphery limited to abapical third in early whorls and subsequently occupying about half of whorl height. Periphery notably raised on early whorls, having appearance of strongly widened cord, in later whorls transition from subsutural ramp to whorl periphery with clear angulation forming distinct shoulder at abapical third of whorl. Axial sculpture of regularly arranged, rounded opisthocline ribs on whorl periphery $(20+$ on penultimate and last whorls), rapidly weakening and becoming obsolete toward base of last whorl. Spiral sculpture of evenly spaced, gently undulating spiral cords, also confined to whorl periphery (3-4 on mature whorls, 15+ on last whorl). Microsculpture of growth lines, forming arcuate riblets on subsutural ramp, reflecting outline of anal sinus. Last adult whorl evenly convex below subsutural ramp, clearly demarcated from long, tapering siphonal canal. Aperture very elongate, narrow, approximately half of shell length; outer lip thin, unsculptured. Inner lip whitish, distinctly recurved, no distinct callus. Anal sinus wide, moderately deep, u-shaped.

747 Cephalic tentacles long, cylindrical; eyes very small. Muscular bulb elongate. Radula (Fig. 6C) of straight to slightly curved hypodermic teeth attaining $175 \mu \mathrm{m}$ in length; no ventral barb; dorsal blade sharp, extremely long, approximately half of length of shaft; adapical opening very elongate, rather narrow, about $1 / 3$ of length of shaft. Base broad, 
751

752

753

754

755

756

757

758

759

760

761

762

763

764

765

766

767

768

769

770

771

772

773

774

775

776

777

778

779

780

781

782

with distinct crescentic, slightly excavated shelf more or less perpendicular to orientation of tooth; large dorsal platform extending posteriorly, with numerous, densely arranged folds on inner surface; exterior of base with comparatively fine texture; basal opening large. Ligament broad.

Remarks

This species exhibits the smallest and most slender shell of all congeners (Fig. 4) and it is characterised by its distinctly raised whorl periphery. While differing significantly from the sister taxa G. angulata/abyssicola in its shell morphology, it possesses a similar radula with a broad, angular base with a crescentic indentation around the lower shaft (Fig. 6C). Its only two records (Fig. 1A) suggest a wide bathymetric range of at least 2760 metres (Fig. 8).

Gladiobela sinuosa n. sp.

(Figs 3F, 6D)

Material examined:

Holotype: Australia, NSW, Hunter CMR, (-32.575, 153.162), IN2017_V03_070, 2474-2595 m, (AMS C.571625).

In reference to the undulating pattern of its shells axial sculpture, derived from 'sinuosus' (Latin=sinuous, flexuous). Adjective of feminine gender.

Distribution

Known from a single locality in the Hunter CMR, NSW.

Shell (SL=25.6 mm, SW=14.1 mm) broadly fusiform, rather thin, opaque. Protoconch at least two heavily eroded, orange whorls with diagonally cancellate sculpture. Teleoconch of at least five uniformly whitish whorls, suture deeply impressed. Whorls very broad, tumid, with very wide subsutural ramp, straight in early whorls then weakly concave in later whorls; distinctly angulated shoulder at mid-height of whorl, relatively consistent throughout. Axial 
sculpture of raised, sharp, evenly interspaced opisthocline ribs below subsutural ramp (25+ on penultimate whorl, $30+$ on last whorl), becoming subobsolete toward base of last whorl. Spiral sculpture of densely set, evenly spaced, straight to somewhat undulating cords below subsutural ramp (12+ on penultimate whorl, $50+$ on last whorl), weakening towards base of last whorl. Microsculpture of growth lines only, forming semi-regularly spaced arcuate riblets on subsutural ramp. Anal sinus broad, moderately deep, u-shaped. Aperture elongate-pyriform.

Cephalic tentacles muscular, long, cylindrical. Extremely reduced eye spots on outer lower base of tentacles. Mantle roof with large oviduct; ctenidium large, covering much of length of mantle roof; osphradium large. Proboscis long, conical; radular sac of medium size; venom gland long; muscular bulb large.

Radula of straight to slightly curved hypodermic teeth attaining $180 \mu \mathrm{m}$ in length; no ventral barb; dorsal blade sharp, very long, ranging between $1 / 3$ and half of length of shaft; adapical opening elongate-triangular, about $1 / 4$ of length of shaft. Base rather broad, with distinct crescentic, steep shelf more or less perpendicular to orientation of tooth; large dorsal platform, extending posteriorly, with numerous, densely arranged folds and pits on inner surface; exterior of base with comparatively fine texture; basal opening large, subcircular. Ligament broad.

\section{Remarks:}

This new taxon exhibits the largest and least slender shell of all congeners (Fig. 4), which can readily be differentiated by its broad whorls with opisthocline axial ribs and comparatively rounded shoulder, the latter usually more prominent in most other taxa (see below for comparison with $G$. vitrea). The siphonal canal is broken in the only specimen available, thus the length of both the aperture and the siphonal canal could not be ascertained. The intestine contained ample polychaete fragments.

(1)

Gladiobela stupa n. sp.

(Figs 3D, 5F, 6F)

\section{Material examined:}


Holotype: Australia, NSW, Hunter CMR, (-32.138, 153.527), IN2017_V03_078, 3980-4029 m, 1 wet (AMS C.571683). COI: MN983183.

Paratype: As for holotype (AMS C.519345).

818

Etymology

In reference to the shape of its shell, somewhat recalling some sacred Buddhist buildings, derived from the Latinised term 'stupa'. Noun of feminine gender in apposition.

Shell (SH=20.9 mm, SW=10.6 mm) broadly fusiform, rather thin, semi-translucent.

Protoconch eroded. Teleoconch of at least 5 uniformly orange whorls, suture impressed. Whorls broad, with wide, straight, poorly defined subsutural ramp. Lower portion of whorl convex, with shell periphery situated at lower third of whorl, producing slightly pagodiform spire outline. Axial sculpture of growth lines only, most noticeable as slightly raised, rather evenly spaced arcuate riblets on subsutural ramp. Spiral sculpture of densely set, low, spiral cords (8+ on penultimate whorl, $30+$ on last whorl), somewhat undulating, at irregular intervals distorted by growth lines. Last adult whorl evenly convex below subsutural ramp, very clearly demarcated from straight, long siphonal canal. Aperture elongate, approximately equal to spire length; outer lip thin, unsculptured, convex at its mid-height, its anterior part extended towards end of siphonal canal. Inner lip orange, rather straight, no distinct callus. Anal sinus wide, deep, u-shaped. Penis large, thick, muscular, club-shaped, with near-distal swelling and distal seminal papilla; dense latitudinal folds. Cephalic tentacles long, muscular, cylindrical, with distinct longitudinal groove. Minuscule eyespots on outer lower base of tentacles. Radula (based on AMS C.571683 and AMS C.519345) of very long, narrow, straight hypodermic teeth attaining $460 \mu \mathrm{m}$ in length; no ventral barb; dorsal blade sharp, extremely long, approximately $40 \%$ of shaft length; adapical opening elongate, rather narrow, about $1 / 10$ of length of shaft. Base rather broad, with large dorsal platform extending posteriorly, with numerous, densely arranged pits on inner surface; exterior of base with comparatively fine texture; basal opening rather large. Ligament broad. 
In terms of shell morphology, G. stupa is most similar to G. angulata and G. abyssicola, from which it can readily be differentiated by its distinctly less shouldered whorl profile (Fig. 3D), and the comparatively sharper concavity, where the outer lip meets the siphonal canal, the latter of which is also markedly longer in the observed material. Its radula is considerably longer than that of any of its congeners (Fig. 6F).

A longitudinal groove in the cephalic tentacles is also observed for Pueridaphne cirrisulcata Criscione, Hallan, Fedosov \& Puillandre, 2020 (Criscione et al. 2020; Fig. S4). Gladiobela stupa n. sp. is differentiated from the former in its orange shell with a rather long, clearly delineated siphonal canal, its very long radular teeth, and in the former having a reddishbrown animal and cancellate sculpture of the teleoconch.

\section{Gladiobela vitrea n. sp.}

(Figs 3E, 5C, 6B)

Material examined:

Holotype: Australia, NSW, Hunter CMR, (-32.479, 152.994), IN2017_V03_069, 1006-1036 m, (AMS C.482311). COI: MN983184.

Paratype: New Caledonia, Canal de I'Havannah, (-22.267, 167.383), EXBODI, CP3793, 9511180 m, 1 wet (MNHN-IM-2013-52094).

\section{Etymology}

In reference to its transparent, somewhat glass-like shell, derived from 'vitreus' (Latin=made of glass). Adjective of feminine gender.

Distribution: Known only from the Hunter CMR, NSW, Australia and Canal de I'Havannah, New Caledonia. Potentially widespread.

Shell (SH=21.4, SW=9.5) elongate-fusiform, rather thin-walled, semi-translucent. Protoconch orange, cyrtoconoid, multispiral, of at least 4 evenly convex whorls. Sculpture diagonally cancellate. Protoconch teleoconch transition, wide, narrowly sinuated. Teleoconch of 6.5 uniformly whitish whorls, suture impressed. Whorls medium broad, with wide subsutural ramp, moderately straight, rather poorly demarcated; early to median whorls with distinct 
carina at lower third mark, with rounded shoulder on median whorl, penultimate and last whorl rather evenly convex. Axial sculpture of growth lines only, on early whorls forming slightly raised, semi-regular riblets. Spiral sculpture of regularly set, distinct, straight to somewhat undulating spiral cords (about 13 on penultimate whorl, 40+ on last whorl), commencing below subsutural ramp, evenly pronounced except for last whorl where they weaken towards base. Last adult whorl evenly convex below subsutural ramp, clearly demarcated from medium long, subcylindrical siphonal canal. Aperture elongate, about $40 \%$ of total shell length; outer lip thin, unsculptured. Inner lip whitish, very gently curved. No distinct callus. Anal sinus wide, moderately deep, u-shaped.

Eyes very small. Anal gland rather long. Radular sac small, bearing few teeth; muscular bulb large.

Radula of straight to gently curved, tapering hypodermic teeth attaining $140 \mu \mathrm{m}$ in length; no ventral barb; dorsal blade long, approximately $1 / 3$ of length of shaft; adapical opening elongate, rather narrow, about 1/4 of length of shaft. Base rather broad; large dorsal platform, extending posteriorly, bearing numerous internal pits; exterior of base with comparatively fine texture; basal opening large. Ligament broad.

\section{Remarks}

This new species is readily differentiated from its congeners in its comparatively elongate shell with a comparatively taller spire (with the height of the aperture is about $40 \%$ of total shell length) and its relatively short siphonal canal. With the exception of $G$. sinuosa, all other Gladiobela species treated herein (G. angulata, G. abyssicola, G. acris and G. stupa) possess an angulate whorl profile, which is more or less evenly convex in G. vitrea. It can be differentiated from $G$. sinuosa by its far narrower shell and its absence of axial ribs.

Type species Pagodibela maia Criscione, 2020 by monotypy and original designation.

Pagodibela Criscione, Hallan, Puillandre and Fedosov, 2020

Diagnosis 
Shell (SL=16-36 mm, SW=6-12 mm), fusiform-biconical, thin-walled, semi-translucent. Protoconch multispiral (2.5-3.5 whorls), orange, broadly conical, cyrtoconoid, sculpture diagonally cancellate. Teleoconch of 5.7-8.5 whorls, whitish to pale cream, suture impressed, whorl profile indistinctly angulated to pagodiform. Subsutural ramp wide, straight, indistinctly to clearly demarcated from whorl periphery. Lower portion of whorl sub-cylindrical or narrowing toward suture. Teleoconch sculpture of spirals only (striae) or spiral cords and axial riblets. Subsutural ramp sculpture of axials only (growth lines or riblets) or of spiral cords and axial riblets. Last adult whorl evenly convex below subsutural ramp, clearly demarcated from stout, tapering siphonal canal. Aperture elongate, approximately $40 \%$ to half of shell length; outer lip thin; inner lip whitish, with thin callus, straight. Anal sinus narrow to broad, shallow to moderately deep, u-shaped.

Head wide, cephalic tentacles of median size, cylindrical; small black eyes situated at their bases. Penis small, simple. Proboscis elongate, conical; venom gland short with large muscular bulb. Osphradium large, approximately $2 / 3$ of ctenidium length, and of equal width. Rhyncocoel not capacious; proboscis small, shifted leftward; venom gland long, on right; muscular bulb very large.

Radular teeth of hypodermic type, slender, straight to slightly curved, $\sim 140-200 \mu \mathrm{m}$ in length; barbs absent; dorsal blade nearly half of length of shaft; adapical opening very narrow to narrow and elongate, 1/4 to $1 / 3$ of length of shaft; base comparatively narrow, steep, with coarse external texture; lateral process very weak; basal opening subcircular; ligament small, short.

\section{Remarks}

Pagodibela can be differentiated from other raphitomid genera by the following combined characters: a (generally) distinctly pagodiform shell (notably in juvenile and subadult juvenile whorls), a medium- to tall spire, and awl-shaped, evenly tapering hypodermic teeth with a comparatively narrow, steep base with coarse external texture. It can be differentiated from the similarly named raphitomid genus Pagodidaphne Shuto, 1983 (comparison made with type species $P$. colmani Shuto, 1983) by the very prominent spiral sculpture, tall cylindrical periphery and tall aperture of the latter. Pagodibela, particularly 
941

942

943

944

945

946

947

948

949

950

951

952

953

954

955

956

957

958

959

960

961

962

963

964

965

966

967

968

969

970

971

972

the tall-spired $P$. baruna and $P$. pacifica, bears superficial resemblance to tall-spired members of Typhlosyrinx Thiele, 1925 and Leiosyrinx Bouchet \& Sysoev, 2001, but can be differentiated from both of the latter in the (generally) distinctly pagodiform early teleoconch whorls in Pagodibela, and also in details of the radula, with the type species $T$. vepallida (Martens, 1902) and T. supracostata (Schepman, 1913) shown to have two distinct barbs, and the L. immedicata Bouchet \& Sysoev, 2001 (genus type species) and L. matsukumai Bouchet \& Sysoev, 2001 both exhibiting comparatively short (both $<100 \mu \mathrm{m}$ ) teeth with short blades and very large, broad bases (Bouchet and Sysoev 2001). Furthermore, the molecular phylogeny by Criscione et al. (2020) recovered Typhlosyrinx and Pagodibela in separate, non-sister clades.

The ranges for this genus are here expanded from those provided in Criscione et al. (2020), with a bathymetric range of 318-1013 metres (Fig. 8) and occurring in the GAB, temperate to tropical eastern Australia, and large swathe of the Indo-Pacific, from the central South Pacific, PNG, Indonesia and north toward Taiwan, and to the far western Indian Ocean off the East African coast (Fig. 1B, D).

\section{Pagodibela baruna (Sysoev, 1997)}

(Fig. 3G)

Gymnobela baruna Sysoev, 1997: 339, figs 6, 49-50.

Material examined

Holotype: Indonesia, Kai Islands, N of channel between small and Big Kai Island (-5.230, 133.000), KARUBAR, CC21, 688-694 m.

Paratype: As for holotype.

Other material: Glorioso Islands, $(-12.5,44.933)$, BIOMAGLO, DW4863, 606-610 m, 1 wet (MNHN-IM-2013-62987); New Caledonia, Chesterfield Islands, (-21.483, 162.600), EBISCO, CP2651, 883-957 m, 1 wet (MNHN-IM-2007-42312); (-21.683, 166.617), EXBODI, CP3809, 685-880 m, 1 wet (MNHN-IM-2009-29111); PNG, (-4.967, 145.833), BIOPAPUA, CP3708, 502-529 m, 1 wet (MNHN-IM-2009-17156), 1 wet (MNHN-IM-2009-17197); (-9.150, 152.250), BIOPAPUA, CP3739, 503-546 m, 1 wet (MNHN-IM-2009-17116); (-4.733, 146.183), PAPUA_NIUGINI, CP3979, 540-580 m, 1 wet (MNHN-IM-2013-19691); (-5.183, 147.050), PAPUA_NIUGINI, CP3981, 688 m, 1 wet (MNHN-IM-2013-19729); (-5.367, 145.85), 
PAPUA_NIUGINI, CP4026, 620-677 m, 1 wet (MNHN-IM-2013-9836). Solomon Islands, (7.717, 156.417), SALOMON_2, CP2246, 664-682 m, 1 wet (MNHN-IM-2007-42518); (-7.750, 156.933), SALOMON_2, CP2269, 768-890 m, 1 wet (MNHN-IM-2007-42519); (-9.150, 158.983), SALOMON_2, CP2176, 600-875 m, 1 wet (MNHN-IM-2007-42528). South Madagascar, (-25.617, 46.367), ATIMO_VATAE, CP3566/DW3565, 618-624 m, 1 wet (MNHNIM-2009-14887); Taiwan, (16.233, 114.500), ZhongSha_2015, CP4153, 318 m, 1 wet (MNHNIM-2013-59316); (16.250, 114.567), ZhongSha_2015, CP4154, 321-326 m, 1 wet (MNHN-IM2013-59352). Vanuatu, (-16.717, 167.983), BOA1, CP2465, 770-799 m, 1 wet (MNHN-IM2007-17695).

Distribution: W Pacific: Indonesia, PNG, New Caledonia and Vanuatu in the south; Taiwan in the north. SW Indian Ocean: Madagascar and Glorioso Islands.

\section{Remarks}

G. baruna was previously known exclusively for its live-collected holotype (Fig. 3D) and the shell of its paratype (Sysoev 1997, fig. 50), both collected off the Kai Islands (Indonesia). As already noted by Sysoev (1997, p. 339), the two specimens differ mainly in the prominence of their shell sculpture, specifically with the paratype exhibiting a distinctively more pronounced shoulder. The examination of shells of $P$. baruna conducted in this study, reveals that, while the first 4-5 teleoconch whorls are distinctively more shouldered in all studied shells, only some specimens have shells exhibiting this feature on subsequent $(5+)$ whorls.

The degree of prominence of the whorl angulation, as well as of other sculptural elements, varies across the sample along a morphological continuum, suggesting that such differences are likely to be the expression of intraspecific variability.

In our molecular analysis (Fig. 2), sequences of this species form a strongly supported clade, exhibiting significant genetic structure, which is largely consistent with geographical patterns. The comparatively low average intraspecific pairwise distance in COI (less than $2 \%)$, along with the relative homogeneity in shell morphology, suggest that no further taxonomic splitting is required. 
1003

1004

1005

1006

1007

1008

1009

1010

1011

1012

1013

1014

1015

1016

1017

1018

1019

1020

1021

1022

1023

1024

1025

1026

1027

1028

1029

1030

1031

1032

1033

1034

The inclusion of additional material into P. baruna, results in an expansion of the geographical and bathymetrical ranges of this taxon, now spanning over 13,000 kilometres, from the SW to the NW Pacific, to the W Indian Ocean, at depths between 318 and $883 \mathrm{~m}$. Given the widespread occurrence of shell character homoplasy in the Conoidea (Bouchet et al. 2011; Hallan et al. 2020; Kantor et al. 2018), the shell-based attribution of the material studied herein to this taxon is considered tentative. Further investigation, based on sequence data of freshly collected topotypical material of $G$. baruna, supplemented by anatomical data, will elucidate whether the taxon studied herein is indeed G. baruna or an additional, yet unnamed and conchologically similar species.

\section{Pagodibela meridionalis n. sp.}

(Figs 3J, 5E, 6H)

Material examined

Holotype: Australia, SA, GAB, (-35.043, 134.079), IN2015_C02_126, 367-409 m, (SAMA D44173). COI: MN983189.

\section{Etymology}

For its presence in the southernmost part of the genus range, derived from 'meridionalis' (Latin=from the south). Adjective of feminine gender.

\section{Shell}

Shell ( $\mathrm{SL}=19 \mathrm{~mm}, \mathrm{SW}=8 \mathrm{~mm}$ ), fusiform-biconical, thin-walled, semi-translucent. Protoconch orange, broadly conical, of at least three gently convex, diagonally cancellate whorls.

Teleoconch of 6.5 pale cream whorls, suture impressed, whorl profile convex, with moderate, non-carinate angulation at periphery. Subsutural ramp wide, straight, indistinctly demarcated from rounded whorl periphery located at whorl mid-height. Lower portion of whorl sub-cylindrical, narrowing towards lower suture. Subsutural ramp sculpture of dense arcuate growth lines, reflecting shape of anal sinus. Sculpture of regularly spaced, fine, shallow striae, uniformly pronounced over entire shell surface, and dense collabral growth lines. Last adult whorl evenly convex below subsutural ramp, clearly demarcated from stout, tapering whitish siphonal canal with wide opening. Aperture elongate, approximately half of 
shell length; outer lip thin; inner lip whitish, with thin callus, straight. Anal sinus moderately deep, u-shaped.

Head wide, cephalic tentacles of median size, cylindrical; small black eyes situated at their bases. Osphradium large, approximately $2 / 3$ of ctenidium length, and of equal width. Rhyncocoel not capacious; proboscis small, shifted leftward; venom gland long, on right; muscular bulb very large.

Radular teeth of hypodermic type, attaining about $200 \mu \mathrm{m}$ in length, straight to slightly curved, somewhat loosely rolled; barbs absent; dorsal blade nearly half of length of shaft; adapical opening wide and elongate, approximately $1 / 4$ of length of shaft; base comparatively narrow, steep with coarse external texture; lateral process very weak; basal opening large, subcircular. Ligament short, small.

\section{Remarks}

This new taxon can be differentiated from the Pagodibela spp. studied herein based on its thin, semi-translucent, smooth shell with no distinct carina. Pagodibela baruna (Sysoev, 1997 ) is superficially similar in also having a comparatively smooth (in adults), tall-spired shell, but the latter is opaque and chalky in texture, possesses a significantly taller spire, and more marked angulations at the shoulder in early teleoconch whorls and a comparatively prominent, gemmate supra-sutural cord in early teleoconch whorls (Fig. 3G). None of the Pagodibela spp. can readily be differentiated on the basis of radular morphology only (Fig. 6G-I).

This is the only Pagodibela taxon from temperate Australia, where it is known only from upper bathyal depths in the GAB.

Pagodibela pacifica n. sp.

(Figs $3 \mathrm{H}, 6 \mathrm{~J}$ )

\section{Material examined}

Holotype: New Caledonia, Chesterfield Islands, (-20.967, 160.967), EBISCO, CP2645, 641-652 m, (MNHN-IM-2007-17844). COI: EU015652. 
1066

1067

1068

1069

1070

1071

1072

1073

1074

1075

1076

1077

1078

1079

1080

1081

1082

1083

1084

1085

1086

1087

1088

1089

1090

1091

1092

1093

1094

1095

1096

Paratypes: Tuamotu Archipelago, (-17.783, -149.383), TARASOC, DW3489, 450-720 m, 1 wet

(MNHN-IM-2007-38860); New Caledonia, (-22.283, 171.3), EXBODI, DW3876, 518-833 m, (MNHN-IM-2009-29189); New Caledonia, (-23.283, 167.933), KANACONO, CP4750, 750-850

m, 1 wet (MNHN-IM-2013-69658); Australia, QLD, Coral Sea CMR, (-23.587, 154.194),

IN2017_V03_121, 1013-1093 m, 1 wet (AMS C.519402).

\section{Etymology}

For its wide distribution across the Pacific Ocean, derived from 'pacificus' (New Latin=from the Pacific Ocean). Adjective of feminine gender.

\section{Distribution}

Widespread; recorded from off north Queensland, Coral Sea, New Caledonia and to the Society Islands.

Shell ( $\mathrm{SL}=30 \mathrm{~mm}, \mathrm{SW}=11 \mathrm{~mm}$ ) elongate, fusiform-biconical, moderately thin-walled, rather opaque. Protoconch of 3.5 whorls, broadly cyrthoconoid, light orange. Protoconch 2 with distinct diagonally cancellate sculpture throughout whorl height. Protoconch-teleoconch transition somewhat weakly defined, only detectable by change in sculpture pattern. Teleoconch of 8.5 whorls, pale cream; suture deeply impressed. Whorl profile distinctly angulated, with peripheral carina in early to median teleoconch whorls and rounded angulation in mature whorls. Subsutural ramp wide, straight, concluded by peripheral carina at about mid-height of whorl in early to median teleoconch whorls. Lower portion of whorl subcylindrical or slightly narrowed towards lower suture. Subsutural ramp sculpture of arcuate riblets, reflecting shape of anal sinus, intersected by narrow raised spiral cords, forming somewhat reticulate pattern in juvenile whorls; arcuate riblets continuous across periphery of early to median teleoconch whorls, strongly opisthocline, sub-obsolete to absent in subsequent whorls. Spiral sculpture of supra-peripheral cords in early to median teleoconch whorls, forming weak nodules at intersections with arcuate riblets, with cords less prominent and more densely set in subsequent whorls. Last adult whorl evenly convex below subsutural ramp, clearly demarcated from broad, stout siphonal canal with distinct concavity on left side (when seen in apertural view, Fig. 3H). Aperture elongate, 
1097

1098

1099

1100

1101

1102

1103

1104

1105

1106

1107

1108

1109

1110

1111

1112

1113

1114

1115

approximately $40 \%$ of total shell length; outer lip thin, unsculptured; inner lip whitish, with thin callus, slightly recurved. Anal sinus moderately wide and deep, u-shaped.

Radula (based on paratype AMS C.519402) of hypodermic type, approximately $140 \mu \mathrm{m}$ long, straight to slightly curved; barbs absent; dorsal blade sharp, nearly half of length of shaft; adapical opening narrow and elongate, $1 / 3$ of length of shaft; base comparatively narrow, steep, with coarse external texture; lateral process very weak; basal opening large, subcircular. Ligament short, small.

\section{Remarks}

This species can be recognised by its elongate, slender shell with strongly carinated early teleoconch whorls. It is rather similar to the sister taxon P. baruna in its shell morphology, with both species exhibiting comparatively large, elongate shells with distinctly pagodiform early to median teleoconch whorls (Fig. 3G, H). However, when compared to the holotype of the latter (Fig. 3G), P. pacifica is comparatively smaller, less opaque, and possessing more prominent axial ribs and carina on early teleoconch whorls, and does not possess a distinct, gemmate supra-sutural cord in early teleoconch whorls (Fig. 3G, H).

This new species, along with the sister species G. baruna, appear to be the most geographically and bathymetrically widespread members of the genus. However, unlike the sister species G. angulata/abyssicola (Fig. 3A, B) they are not allopatric, with largely overlapping bathymetric ranges and with both taxa occurring in the New Caledonian region (Figs 1, 8). 
Conflict of interest

1119

The authors declare no conflicts of interest.

Acknowledgments

This work has been made possible through financial support from the Australian Government (ABRS grant RF217-57, principal investigator FC). The participation of AF was also supported by the Russian Science Foundation (grant 16-14-10118 to Yuri Kantor). Voyages in the GAB were part of: (a) the GAB Research Program [GABRP - a collaboration between BP, CSIRO, the South Australian Research and Development Institute (SARDI), the University of Adelaide, and Flinders University] and (b) the GAB Deepwater Marine Program (GABDMP - a CSIRO led research program sponsored by Chevron Australia]. Funding for the 'Eastern Abyss' voyage (IN2017_V03) was provided by the Marine Biodiversity Hub (MBH), supported through the Australian Government's National Environmental Science Program (NESP). The authors wish to thank the CSIRO MNF for its support in the form of sea time aboard, support personnel, scientific equipment and data management. We also thank all the scientific staff and crew who participated in all voyages generating the samples studied herein. The MNHN samples used in this study originates from shore-based expeditions (ATIMO VATAE, PAPUA NIUGINI; PI Philippe Bouchet) and deep-sea cruises (BIOMAGLO, BIOPAPUA, BOA1, EBISCO, EXBODI, KANACONO, TARASOC, SALOMON 2, ZHONGSHA 2015; PIs Philippe Bouchet, Tin-Yam Chan, Laure Corbari, Nicolas Puillandre, Sarah Samadi, Wei-Jen Chen) conducted by MNHN, Pro-Natura International (PNI) and Institut de Recherche pour le Développement as part of the Our Planet Reviewed and the Tropical Deep-Sea Benthos programs. Funders and sponsors included the CONOTAX project funded by the French National Research Agency [grant number ANR-13-JSV7-0013-01], a bilateral cooperation research funding from the Taiwan Ministry of Science and Technology (MOST 102-2923-B002-001-MY3, PI Wei-Jen Chen) and the French National Research Agency (ANR 12-ISV70005-01, PI Sarah Samadi), the Total Foundation, Prince Albert II of Monaco Foundation, Stavros Niarchos Foundation, and Richard Lounsbery Foundation. All expeditions operated under the regulations then in force in the countries in question and satisfy the conditions set by the Nagoya Protocol for access to genetic resources (expeditions.mnhn.fr). We would like to express our gratitude to Mandy Reid, Alison Miller and Jennifer Caiza (AM) for 
1150 assistance with registration and databasing of material, to Barbara Buge and Virginie Héros

1151 (MNHN) for the sample preparation, and to Andrea Crowther (SAMA, Adelaide) for

1152 smoothly and promptly handling our loan requests. Special thanks are due to Sue Lindsay

1153 and Chao Shen (Macquarie University, Sydney) for assisting with SEM work. The holotype of

1154 Gymnobela baruna was taken by Manuel Caballer (MNHN) (project E-RECOLNAT: ANR-11-

1155 INBS-0004). Finally, the reviewers are thanked for their helpful suggestions which served to improve the manuscript. 
1157

References

Bouchet, P., Heros, V., Lozouet, P., and Maestrati, P. (2008) 'A quarter - century of deep-sea malacological exploration in the South and West Pacific: where do we stand? How far to go?' $9-40$

Bouchet, P., Kantor, Y.I., Sysoev, A., and Puillandre, N. (2011) A new operational classification of the Conoidea (Gastropoda). Journal of Molluscan Studies 77(3), 273308.

Bouchet, P., Lozouet, P., and Sysoev, A. (2009) An inordinate fondness for turrids. Deep-Sea Research Part II Topical Studies in Oceanography 56(19-20), 1724-1731.

Bouchet, P., and Sysoev, A. (2001) Typhlosyrinx-like tropical deep-water turriform gastropods (Mollusca, Gastropoda, Conoidea). Journal of Natural History 35(11), 1693-1715. [In English]

Bouchet, P., and Waren, A. (1980) Revision of the north east Atlantic bathyal and abyssal Turridae (Mollusca, Gastropoda). Journal of Molluscan Studies Supplement 8, 1-119.

Burton, E.A. (1998) Carbonate compensation depth. In 'Geochemistry.' pp. 73-73. (Springer Netherlands: Dordrecht)

Costello, M.J., Tsai, P., Wong, P.S., Cheung, A.K.L., Basher, Z., and Chaudhary, C. (2017) Marine biogeographic realms and species endemicity. Nature Communications 8(1), 1057.

Criscione, F., Hallan, A., Puillandre, N., and Fedosov, A.E. (2020) Where the snails have no name: A molecular phylogeny of Raphitomidae (Neogastropoda: Conoidea) uncovers vast unexplored diversity in the deep seas of temperate southern and eastern Australia. Zoological Journal of the Linnean Society, In press.

Fedosov, A.E., and Puillandre, N. (2012) Phylogeny and taxonomy of the KermiaPseudodaphnella (Mollusca: Gastropoda: Raphitomidae) genus complex: a remarkable radiation via diversification of larval development. Systematics and Biodiversity 10(4), 447-477. [In English]

Fedosov, A.E., Stahlschmidt, P., Puillandre, N., Aznar-Cormano, L., and Bouchet, P. (2017) Not all spotted cats are leopards: evidence for a Hemilienardia ocellata species complex (Gastropoda: Conoidea: Raphitomidae). European Journal of Taxonomy 268, 1-20. [In English] 
Folmer, O., Black, M., Hoeh, W., Lutz, R., and Vrijenhoek, R. (1994) DNA primers for amplification of mitochondrial cytochrome c oxidase subunit I from diverse metazoan invertebrates. Molecular Marine Biology and Biotechnology 3(5), 294-299.

Gonzales, D.T.T., and Saloma, C.P. (2014) A bioinformatics survey for conotoxin-like sequences in three turrid snail venom duct transcriptomes. Toxicon 92, 66-74. [In English]

Gorson, J., Ramrattan, G., Verdes, A., Wright, M.E., Kantor, Y., Rajaram Srinivasan, R., Musunuri, R., Packer, D., Albano, G., Qiu, W.G., and Holford, M. (2015) Molecular Diversity and Gene Evolution of the Venom Arsenal of Terebridae Predatory Marine Snails. Genome biology and evolution 7.

Hallan, A., Criscione, F., Fedosov, A.E., and Puillandre, N. (2020) Bouchetispira ponderi n. sp. (Conoidea: Bouchetispiridae), a new deep-sea gastropod from temperate Australia. Molluscan Research 40(1), 86-92.

Hedley, C. (1922) A revision of the Australian Turridae. Records of the Australian Museum 13, pp. 213-359. [In English]

Kantor, Y.I., Fedosov, A.E., and Puillandre, N. (2018) New and unusual deep-water Conoidea revised with shell, radula and DNA characters. Ruthenica $\mathbf{2 8}$, 47-82.

Kantor, Y.I., Puillandre, N., Olivera, B.M., and Bouchet, P. (2008) Morphological proxies for taxonomic decision in turrids (Mollusca, Neogastropoda): a test of the value of shell and radula characters using molecular data. Zoological Science (Tokyo) 25(11), 11561170.

Kantor, Y.I., and Sysoev, A.V. (1991) Sexual dimorphism in the apertural notch of a new species of Gemmula (Gastropoda: Turridae). Journal of Molluscan Studies 57, 205209. [In English]

Kantor, Y.I., and Taylor, J.D. (2002) Foregut anatomy and relationships of raphitomine gastropods (Gastropoda: Conoidea: Raphitominae). Bollettino Malacologico 38, 83110. [In English]

Kumar, S., Stecher, G., and Tamura, K. (2016) MEGA7: Molecular Evolutionary Genetics Analysis version 7.0 for bigger datasets. Molecular Biology and Evolution 33, 1870 1874.

Lopez-Vera, E., de la Cortera, E.P.H., Maillo, M., Riesgo-Escovar, J.R., Olivera, B.M., and Aguilar, M.B. (2004) A novel structural class of toxins: the methionine-rich peptides 
from the venoms of turrid marine snails (Mollusca, Conoidea). Toxicon 43(4), 365374. [In English]

Maclntosh, H., Althaus, F., Williams, A., Tanner, J.E., Alderslade, P., Ahyong, S.T., Bax, N., Criscione, F., Crowther, A.L., Farrelly, C.A., Finn, J.K., Goudie, L., Gowlett-Holmes, K., Hosie, A.M., Kupriyanova, E., Mah, C., McCallum, A.W., Merrin, K.L., Miskelly, A., Mitchell, M.L., Molodtsova, T., Murray, A., O’Hara, T.D., O’Loughlin, P.M., Paxton, H., Reid, A.L., Sorokin, S.J., Staples, D., Walker-Smith, G., Whitfield, E., and Wilson, R.S. (2018) Invertebrate diversity in the deep Great Australian Bight (200-5000 m). Marine Biodiversity Records 11(1), 23.

Marshall, B.A. (1983) A revision of the Recent Triphoridae of southern Australia (Mollusca: Gastropoda). Records of the Australian Museum 35, 1-119. [In English]

Medinskaya, A. (1999) Foregut anatomy of Cochlespirinae (Gastropoda, Conoidea, Turridae). Zoosystema 21(2), 171-198.

O'Hara, T.D. (2019) The eastern Australian Marine Parks: biodiversity, assemblage structure, diversity and origin.

Olivera, B.M., Seger, J., Horvath, M.P., and Fedosov, A.E. (2015) Prey-Capture Strategies of Fish-Hunting Cone Snails: Behavior, Neurobiology and Evolution. Brain Behav Evol 86(1), 58-74. [In eng]

Powell, A.W.B. (1942) The New Zealand recent and fossil Mollusca of the Family Turridae with general notes on turrid nomenelature and systematics. Bulletin Auckland Institute and Museum 2, pp. 1-188. [In English]

Prashanth, J.R., Brust, A., Jin, A.-H., Alewood, P., Dutertre, S., and Lewis, R. (2014) Cone snail venomics: From novel biology to novel therapeutics. Future medicinal chemistry 6, 1659-75

Puillandre, N., Bouchet, P., Duda, T.F., Kauferstein, S., Kohn, M., Olivera, B., Watkins, M., and Meyer, C. (2014) Molecular phylogeny and evolution of the cone snails (Gastropoda, Conoidea). Molecular Phylogenetics and Evolution 78.

Puillandre, N., Cruaud, C., and Kantor, Y.I. (2010a) Cryptic species in Gemmuloborsonia (Gastropoda: Conoidea). Journal of Molluscan Studies 76, 11-23.

Puillandre, N., Fedosov, A.E., Zaharias, P., Aznar-Cormano, L., and Kantor, Y.I. (2017) A quest for the lost types of Lophiotoma (Gastropoda: Conoidea: Turridae): integrative 
taxonomy in a nomenclatural mess. Zoological Journal of the Linnean Society 181(2), 243-271.

Puillandre, N., Koua, D., Favreau, P., Olivera, B.M., and Stoecklin, R. (2012a) Molecular Phylogeny, Classification and Evolution of Conopeptides. Journal of Molecular Evolution 74, 297-309.

Puillandre, N., Lambert, A., Brouillet, S., and Achaz, G. (2012b) ABGD, Automatic Barcode Gap Discovery for primary species delimitation. Molecular Ecology 21, 1864-1877.

Puillandre, N., Modica, M.V., Zhang, Y., Sirovich, L., Boisselier, M.C., Cruaud, C., Holford, M., and Samadi, S. (2012c) Large-scale species delimitation method for hyperdiverse groups. Molecular Ecology 21(11), 2671-2691.

Puillandre, N., Sysoev, A.V., Olivera, B.M., Couloux, A., and Bouchet, P. (2010b) Loss of planktotrophy and speciation: geographical fragmentation in the deep-water gastropod genus Bathytoma (Gastropoda, Conoidea) in the western Pacific. Systematics and Biodiversity 8(3), 371-394. [In English]

Ronquist, F., and Huelsenbeck, J.P. (2003) MrBayes 3: Bayesian phylogenetic inference under mixed models. Bioinformatics 19(12), 1572-1574.

Saitou, N., and Nei, M. (1987) The neighbor-joining method: a new method for reconstructing phylogenetic trees. Molecular Biology and Evolution 4(4), 406-425. [In English]

Simon, C., Franke, A., and Martin, A. (1991) The polymerase chain reaction: DNA extraction and amplification. NATO ASI Series Series H Cell Biology 57, 329-355.

Sysoev, A. (1997) Mollusca Gastropoda: new deep-water turrid gastropods (Conoidea) from eastern Indonesia. Memoires du Museum National d'Histoire Naturelle 172, 325-355. [In English]

Sysoev, A., and Bouchet, P. (2001) New and uncommon turriform gastropods (Gastropoda: Conoidea) from the South-West Pacific. Memoires du Museum National d'Histoire Naturelle 185, 271-320. [In English]

Sysoev, A.V., and Kantor, Y.I. (1990) A new genus and species of 'Cochlespira-like' turrids (Gastropoda, Toxoglossa, Turridae). Apex (Brussels) 5, 1-6.

Todd, J.A., and Rawlings, T.A. (2014) A review of the Polystira clade-the Neotropic's largest marine gastropod radiation (Neogastropoda: Conoidea: Turridae sensu stricto). Zootaxa 3884(5), 445-491. [In English] 
1283 Zaharias, P., Kantor, Y.I., Fedosov, A.E., Criscione, F., Hallan, A., Kano, Y., Bardin, J., and 1284 Puillandre, N. (2020) Just the once will not hurt: DNA suggests species lumping over two oceans in deep-sea snails (Cryptogemma). Zoological Journal of the Linnean 1286 Society. 

Thochodaphne cuprosa Ht AMS C.571611

95e 49 of 111 Taranis sp. MNHN IM-2007-42296 $7869-$ Pueridaphne cirrisulcata Ht AMS C.572165 - Typhlosyrinx sp. AMS C. 519335

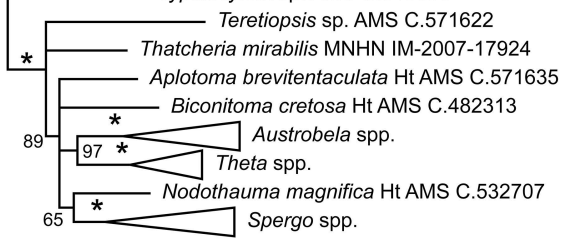

Trochodaphne cuprosa Ht AMS C.571611
Mioawateria sp. AMS C.482239

Invertebrate Systematic\$

Pueridaphne cirrisulcata Ht AMS C.572165

Typhlosyrinx sp. AMS C.519335

Aplotoma brevitentaculata Ht AMS C. 571635 Nodothauma magnifica Ht AMS C.532707 Thatcheria mirabilis MNHN IM-2007-17924 Austrobela spp. Teretiopsis sp. AMS C.571622

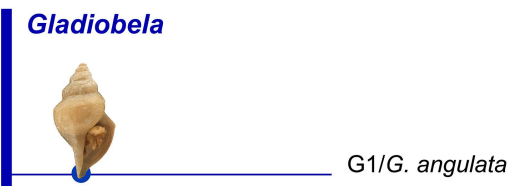

Pt AMS C.572166 Pt AMS C.572167

* Pt AMS C. 572168 Pt SAMA D49341 Pt AMS C.571737 Ht AMS C.571656 * Pt AMS C.519329

Pt AMS C.571717

Pt AMS C. 519389

* Ht AMS C. 571697

L MNHN IM-2009-19029

97 - MNHN IM-2013-39524

* L MNHN IM-2007-61660

* MNHN IM-2013-61802 MNHN IM-2013-52059

87 MNHN IM-2007-39375

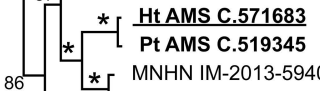

MNHN IM-2013-52055

Ht AMS C.482311

MNHN IM-2013-52094

MNHN IM-2007-42312

MNHN IM-2009-17116

MNHN IM-2009-29111

MNHN IM-2013-19691

MNHN IM-2007-17695

4 MNHN IM-2009-14887

98 MNHN IM-2013-62987 MNHN IM-2007-42528

MNHN IM-2013-59316

MNHN IM-2013-59352

62 [ $\begin{aligned} & \text { MNHN IM-2007-42518 } \\ & \text { MNHN IM-2009-17197 }\end{aligned}$ MNHN IM-2007-42519

MNHN IM-2009-17156 MNHN IM-2013-19729

MNHN IM-2013-9836

69 _ MNHN IM-2013-69658
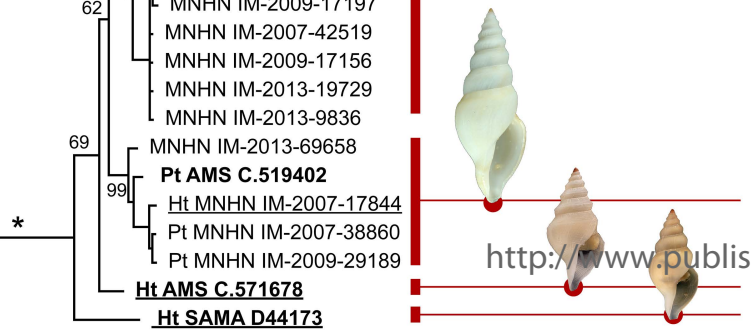

P1/P. pacifica n. sp.

1

Ht AMS C. 571678

Ht SAMA D44173

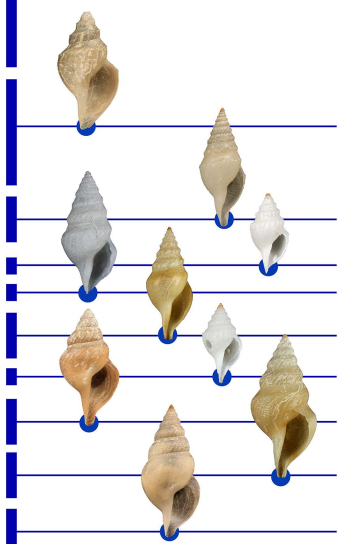

Pagodibela

$\mathrm{PA} / P$. baruna

(3)

G3/G. acris n. sp.

GE

GD

GD

$\mathrm{GC}$

G4/G. stupa n. sp.

G5/G. vitrea n. sp.

(1)

(B)

(4)

(A)

(5) P2/P maia
(2)

T4 74

(E) MNHN IM-2007-39254 -84

(D) MNHN IM-2013-61660 $\longrightarrow 93$

(C)

MNHN IM-2013-61802

MNHN IM-2013-52059

MNHN IM-2007-39375

Ht AMS C. 571683 , *

Pt AMS C.519345

MNHN IM-2013-59402

MNHN IM-2013-52055

Ht AMS C.482311

MNHN IM-2013-52094

MNHN IM-2007-42312

MNHN IM-2013-19691

MNHN IM-2009-17116

MNHN IM-2009-29111

MNHN IM-2007-42528

MNHN IM-2007-17695

MNHN IM-2009-14887

MNHN IM-2013-62987

MNHN IM-2013-59316

MNHN IM-2013-59352

MNHN IM-2007-42519

MNHN IM-2009-17156

MNHN IM-2013-9836

MNHN IM-2007-42518

MNHN IM-2009-17197

MNHN IM-2013-19729

MNHN IM-2013-69658

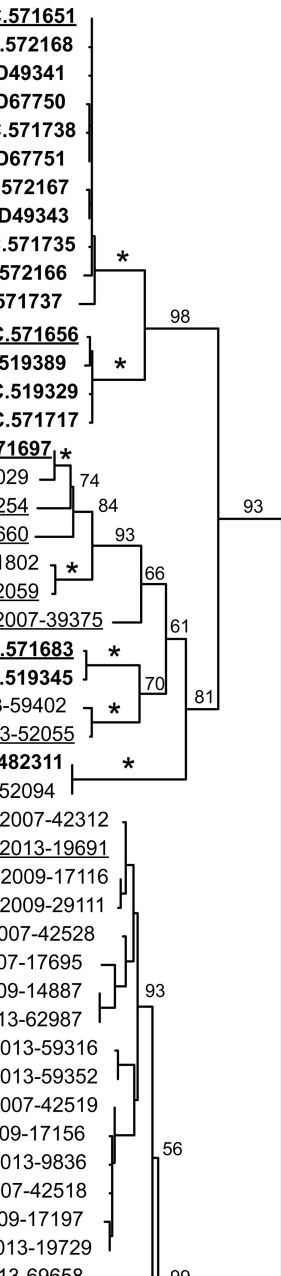

98

S C. 51940

Pt MNHN IM-2007-38860 Pt MNHN IM-2009-29189

Ht MNHN IM-2007-17844 $\mathrm{P} 3 / \boldsymbol{P}$. meridionalis n .sp. 3
Ht AMS C.571678 Ht SAMA D44173 

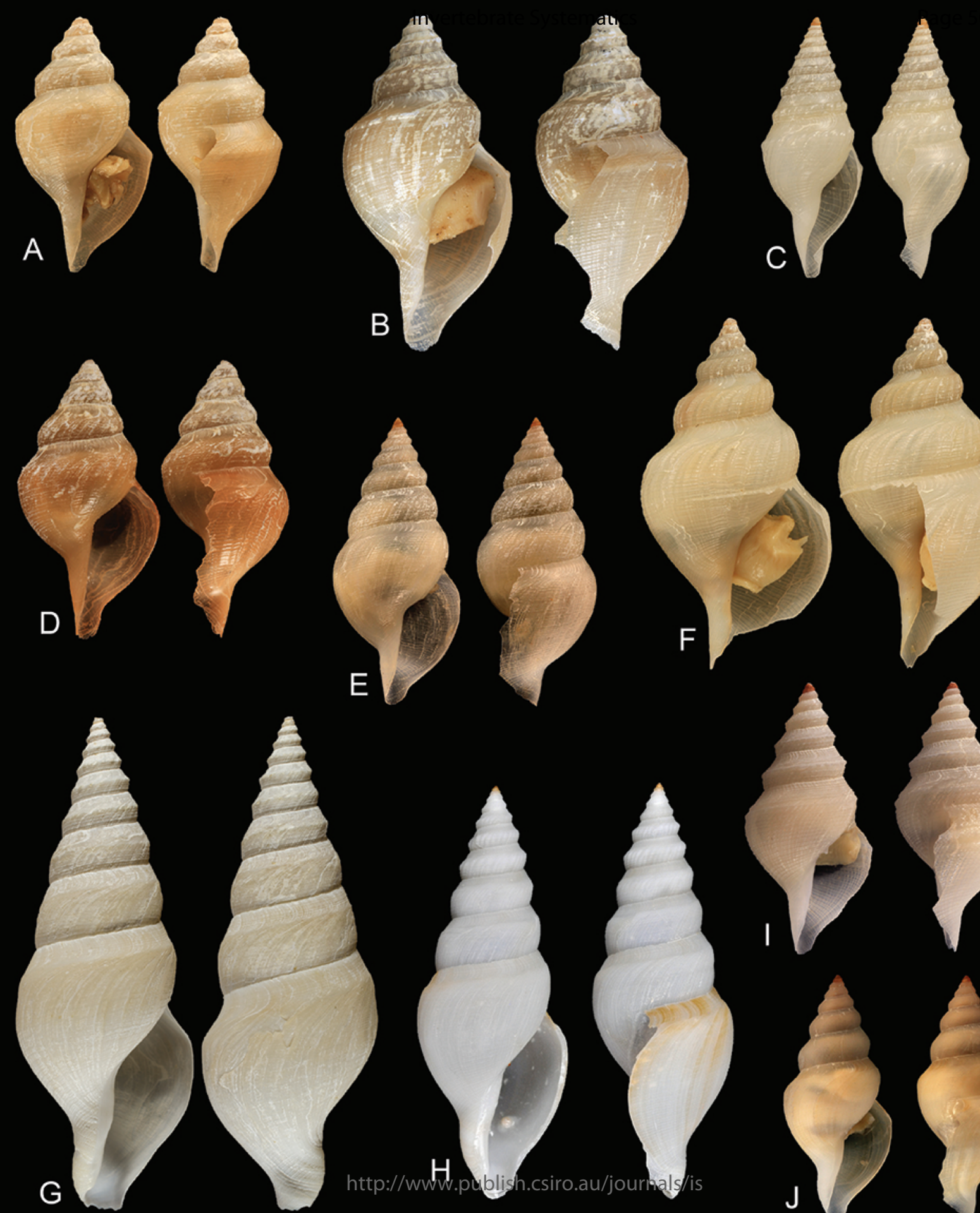

$\mathrm{H}$
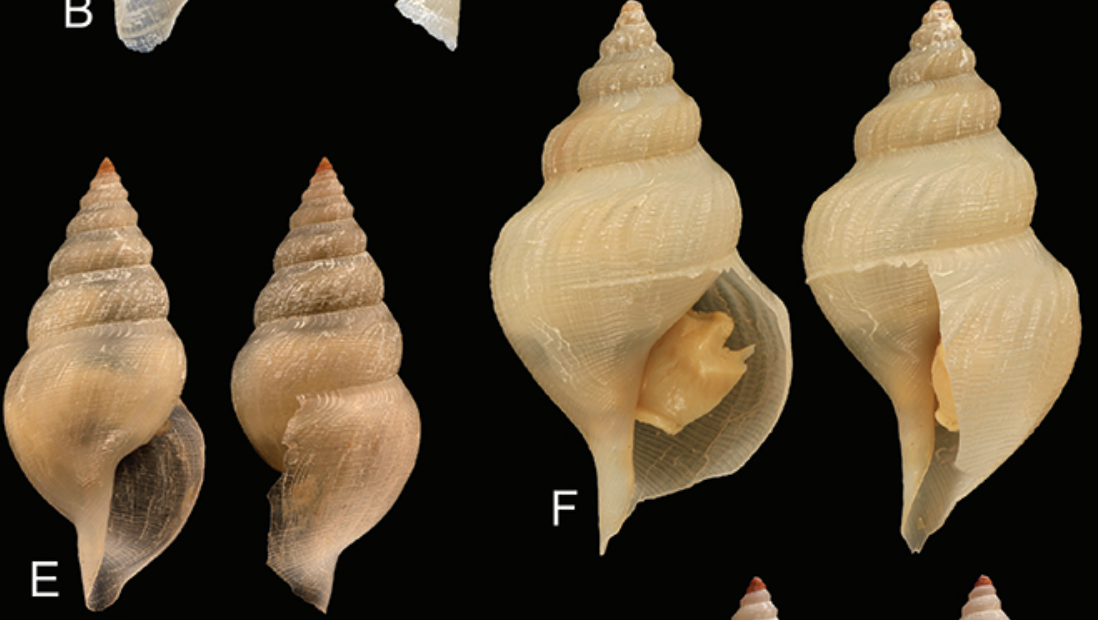
Page 51 of 111 Invertebrate Systematics

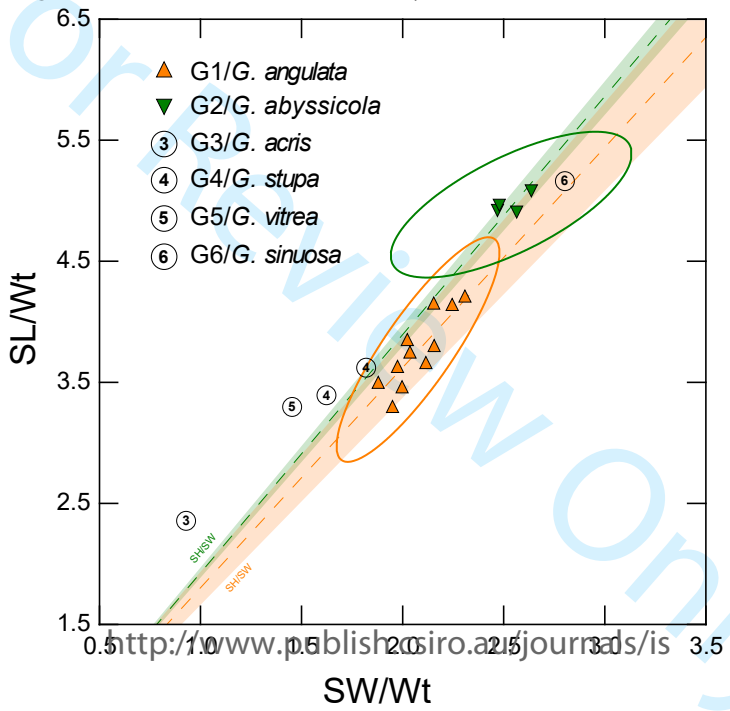




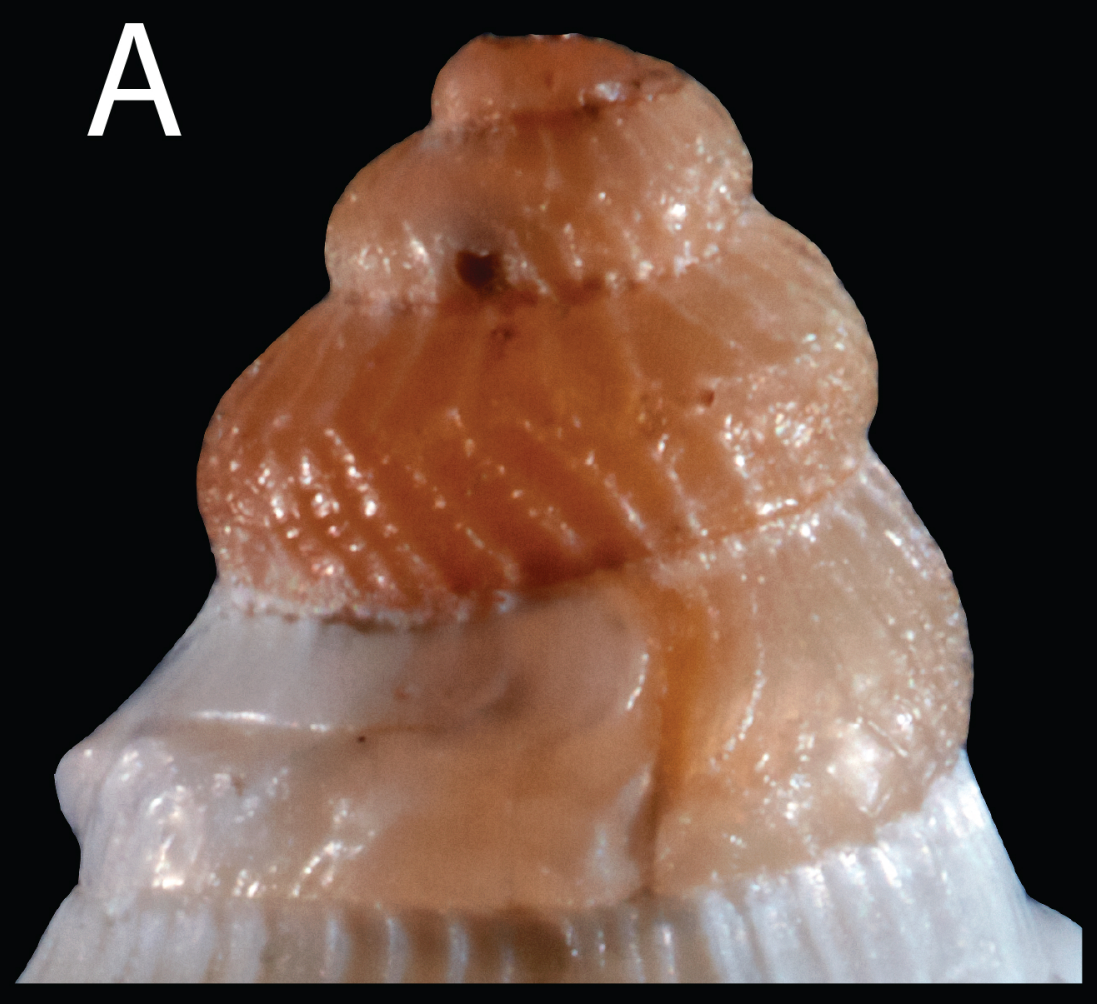

B

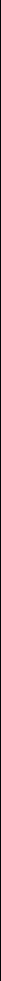





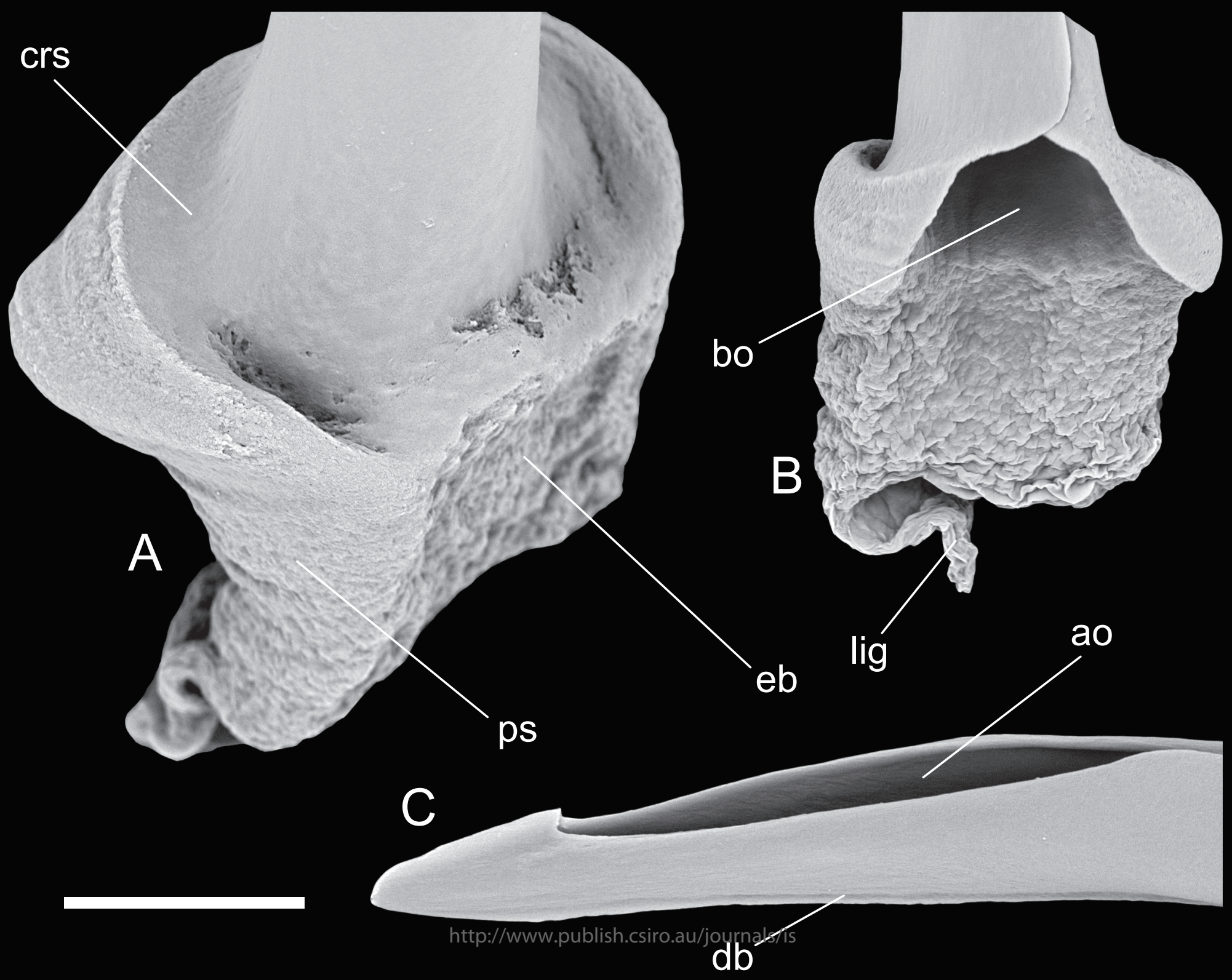




\section{Page 55 of 111 Invertebrate Systematics}

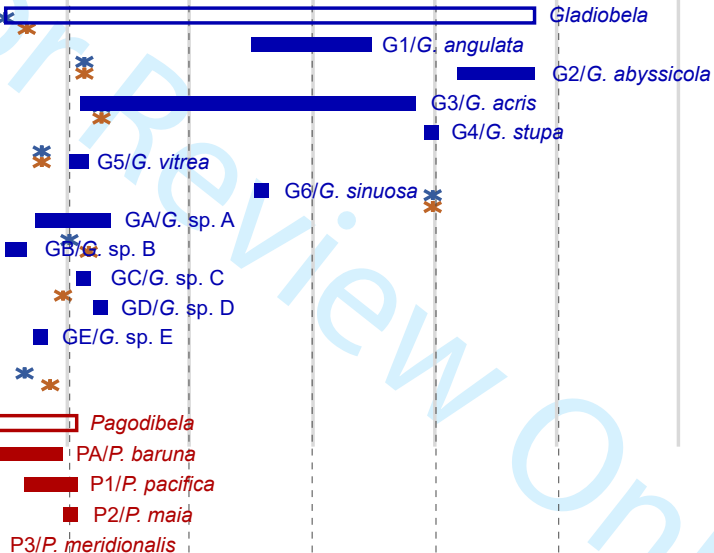

- $\mathrm{P} 3 / P$. meridionalis

http://www.publish.csiro.au/journals/is

$\vec{\circ}$

ัั

$\stackrel{\leftrightarrow}{\circ}$

형

잉

용 


\begin{tabular}{lcccccccccc}
\hline & G1/ang & G3/acr & G2/aby & G4/stu & G5/vit & GA & GB & GC & GD & GE \\
\hline G1/ang & 0.006 & & & & & & & & min & max \\
G3/acr & 0.105 & 0.011 & & & & & within & 0.000 & 0.011 & 0.005 \\
G2/aby & 0.054 & 0.101 & 0.005 & & & & between & 0.040 & 0.117 & 0.082 \\
G4/stu & 0.098 & 0.088 & 0.090 & 0.005 & & & & & \\
G5/vit & 0.101 & 0.106 & 0.106 & 0.087 & 0.000 & & & & \\
GA & 0.098 & 0.076 & 0.090 & 0.058 & 0.099 & 0.006 & & & \\
GB & 0.101 & 0.049 & 0.099 & 0.080 & 0.104 & 0.069 & 0.005 & & \\
GC & 0.097 & 0.057 & 0.093 & 0.071 & 0.079 & 0.062 & 0.060 & - & \\
GD & 0.110 & 0.040 & 0.108 & 0.084 & 0.103 & 0.071 & 0.043 & 0.067 & - \\
GE & 0.114 & 0.040 & 0.117 & 0.094 & 0.109 & 0.076 & 0.052 & 0.061 & 0.040 \\
\hline
\end{tabular}




\begin{tabular}{|c|c|c|c|c|c|c|c|c|}
\hline & $\mathrm{PA} / \mathrm{bar}$ & P1/pac & $\mathrm{P} 2 / \mathrm{mai}$ & P3/mer & & & & \\
\hline PA/bar & 0.019 & & & & & $\min$ & $\max$ & mean \\
\hline P1/pac & 0.047 & 0.018 & & & within & 0.018 & 0.019 & 0.018 \\
\hline P2/mai & 0.044 & 0.048 & - & & between & 0.044 & 0.071 & 0.056 \\
\hline P3/mer & 0.063 & 0.071 & 0.065 & - & & & & \\
\hline
\end{tabular}




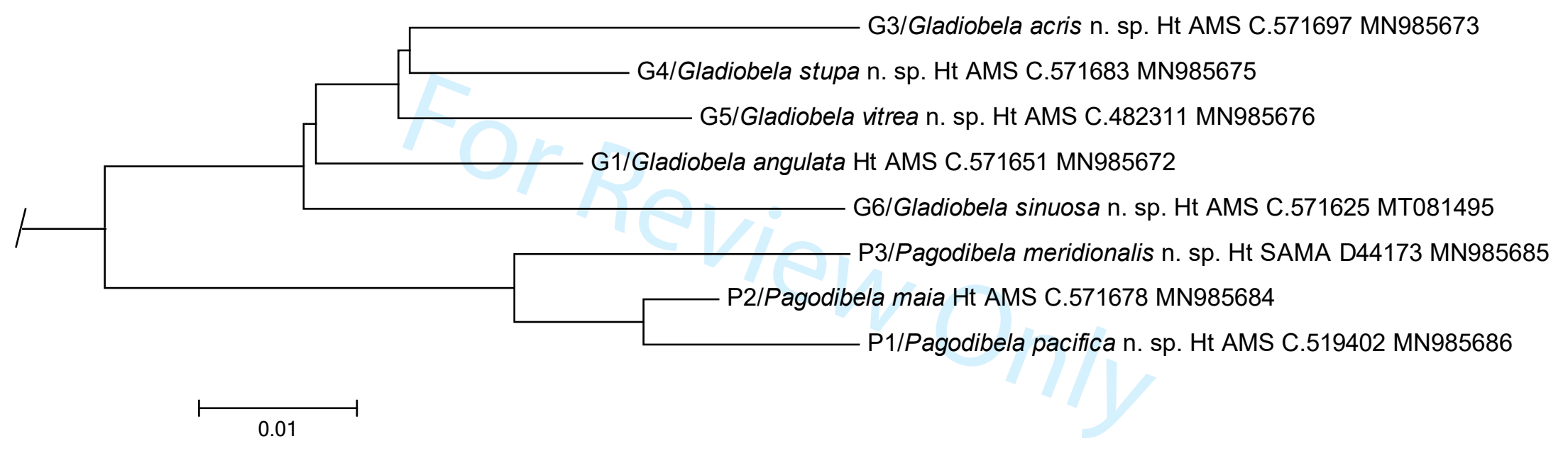

Figure S1 - Detail of the optimal Neighbor-Joining tree based on 179 12S sequences of species of Raphitomidae. The tree is drawn to scale, with branch lengths in the same units as those of the evolutionary p-distances used to infer the phylogenetic tree.

GenBank accession numbers (MN-) are indicated on brantchvlabeiss.blish.csiro.au/journals/is 


\begin{tabular}{|c|c|c|c|c|c|c|c|}
\hline Taxon & Museum & Registration no. & $\begin{array}{l}\text { vouc } \\
\text { her }\end{array}$ & Locality/Expedition & BOLD id & col & $12 S$ \\
\hline \multicolumn{8}{|l|}{ Ingroup } \\
\hline \multirow[t]{4}{*}{ Gladiobela abyssicola $\mathrm{n} . \mathrm{sp}$. } & AMS & C.571656 & $\mathrm{Ht}$ & Australia, NSW, off Bermagui, (-36.351, 150.914), IN2017_V03_043, 4750-4763 m. & & MT081415 & \\
\hline & AMS & C.571717 & $\mathrm{Pt}$ & Australia, NSW, off Bermagui, (-36.351, 150.914), IN2017_V03_043, 4750-4763 m. & & MN983182 & \\
\hline & AMS & C.519329 & $\mathrm{Pt}$ & Australia, TAS, Bass Strait, (-39.552, 149.553), IN2017_V03_030, 4133-4197 m. & & MT081413 & \\
\hline & AMS & C.519389 & $\mathrm{Pt}$ & Australia, NSW, off Bermagui, (-36.351, 150.914), IN2017_V03_043, 4750-4763 m. & & MT081414 & \\
\hline \multirow[t]{2}{*}{ Gladiobela acris $\mathrm{n} . \mathrm{sp}$. } & AMS & C.571697 & $\mathrm{Ht}$ & Australia, VIC, East Gippsland CMR, (-38.479, 150.185), IN2017_V03_032, 3850-3853 m. & & MN983181 & MN985673 \\
\hline & MNHN & IM-2009-19029 & $\mathrm{Pt}$ & Solomon Islands, (-6.417, 156.35), SOLOMON_2, CP2231, 1083-1100 m. & CONO3079-20 & MT256948 & \\
\hline \multirow[t]{11}{*}{ Gladiobela angulata Criscione et al., 2020} & AMS & C.571651 & $\mathrm{Ht}$ & Australia, NSW, Hunter CMR, $(-32.575,153.162)$, IN2017_V03_070, 2474-2595 m. & & MN983180 & MN985672 \\
\hline & AMS & C.571735 & $\mathrm{Pt}$ & Australia, GAB, (-34.452, 129.492), IN2017_C01_197, 3235-3350 m. & & МT081403 & \\
\hline & AMS & C.572166 & $\mathrm{Pt}$ & Australia, GAB, (-34.452, 129.492), IN2017_C01_197, 3235-3350 m. & & MT081404 & \\
\hline & AMS & C.572167 & $\mathrm{Pt}$ & Australia, GAB, (-34.452, 129.492), IN2017_C01_197, 3235-3350 m. & & MT081405 & \\
\hline & AMS & C.571737 & $\mathrm{Pt}$ & Australia, GAB, (-34.452, 129.492), IN2017_C01_197, 3235-3350 m. & & МT081406 & \\
\hline & AMS & C.571738 & $\mathrm{Pt}$ & Australia, GAB, (-34.452, 129.492), IN2017_C01_197, 3235-3350 m. & & MT081407 & \\
\hline & AMS & C.572168 & $\mathrm{Pt}$ & Australia, GAB, (-34.452, 129.492), IN2017_C01_197, 3235-3350 m. & & MT081408 & \\
\hline & SAMA & D49341 & $\mathrm{Pt}$ & Australia, GAB, (-34.574, 129.572), IN2017_C01_198, 3389-3540 m. & & МT081409 & \\
\hline & SAMA & D67750 & $\mathrm{Pt}$ & Australia, GAB, (-34.574, 129.572), IN2017_C01_198, 3389-3540 m. & & MT081410 & \\
\hline & SAMA & D67751 & $\mathrm{Pt}$ & Australia, GAB, (-34.574, 129.572), IN2017_C01_198, 2474-2595 m. & & Мт081411 & \\
\hline & SAMA & D49343 & $\mathrm{Pt}$ & Australia, GAB, (-34.452, 129.492), IN2017_C01_197, 3235-3350 m. & & МT081412 & \\
\hline Gladiobela sinuosa n. sp. & AMS & C.571625 & $\mathrm{Ht}$ & Australia, NSW, Hunter CMR, (-32.575, 153.162), IN2017_V03_070, 2474-2595 m. & & - & MT081495 \\
\hline Gladiobela stupa n. sp. & AMS & C.571683 & $\mathrm{Ht}$ & Australia, NSW, Hunter CMR, (-32.138, 153.527), IN2017_V03_078, 3980-4029 m. & & MN983183 & MN985675 \\
\hline Gladiobela stupa $\mathrm{n} . \mathrm{sp}$. & AMS & C.519345 & $\mathrm{Pt}$ & Australia, NSW, Hunter CMR, $(-32.138,153.527)$, IN2017_V03_078, 3980-4029 m. & & МT081416 & \\
\hline \multirow[t]{2}{*}{ Gladiobela vitrea $\mathrm{n} . \mathrm{sp}}$. & AMS & C.482311 & $\mathrm{Ht}$ & Australia, NSW, Hunter CMR, (-32.479, 152.994), IN2017_V03_069, 1006-1036 m. & & MN983184 & MN985676 \\
\hline & MNHN & IM-2013-52094 & $\mathrm{Pt}$ & New Caledonia, (-22.267, 167.383), EXBODI, CP3793, 951-1180 m. & CONO3087-20 & MT256973 & \\
\hline Gladiobela sp. A & MNHN & IM-2013-52055 & & Papua New Guinea, (-6.933, 147.133), BIOPAPUA, CP3632, 700-740 m. & CONO3085-20 & MT256949 & \\
\hline Gladiobela sp. A & MNHN & IM-2013-59402 & & Taiwan, (19.8, 116.483), ZhongSha_2015, CP4157, 1205-1389 m. & CONO3091-20 & MT256959 & \\
\hline Gladiobela sp. B & MNHN & IM-2013-52059 & & Papua New Guinea, (-5.067, 154.483), BIOPAPUA, CP3755, $662 \mathrm{~m}$. & CONO3086-20 & MT256969 & \\
\hline Gladiobela sp. B & MNHN & IM-2013-61802 & & Taiwan, (19.217, 113.933), ZhongSha_2015, DW4138, 470-494 m. & CONO3090-20 & MT256961 & \\
\hline Gladiobela sp. C & MNHN & IM-2007-39375 & & Tuamotu Archipelago, (-17.45, -149.833), TARASOC, DW3462, 1000-1145 m. & CONO3074-20 & MT256957 & \\
\hline Gladiobela sp. D & MNHN & IM-2013-61660 & & Taiwan, (19.833, 116.45), ZhongSha_2015, CP4134, 1128-1278 m. & CONO3092-20 & MT256951 & \\
\hline Gladiobela sp. E & MNHN & IM-2007-39254 & & Tuamotu Archipelago, (-16.7, -151.517), TARASOC, CP3449, $780 \mathrm{~m}$. & CONO3073-20 & MT256972 & \\
\hline \multirow[t]{4}{*}{ Pagodibela baruna (Sysoev, 1997) } & MNHN & IM-2009-29111 & & New Caledonia, (-21.683, 166.617), EXBODI, CP3809, 685-880 m. & CONO3080-20 & MT256963 & \\
\hline & MNHN & IM-2007-42312 & & New Caledonia, Chesterfield Islands, (-21.483, 162.6), EBISCO, CP2651, 883-957 m. & CONO578-08 & MT256968 & \\
\hline & MNHN & IM-2013-19691 & & Papua New Guinea, $(-4.733,146.183)$, PAPUA_NIUGINI, CP3979, 540-580 m. & CONO3084-20 & MT256955 & \\
\hline & MNHN & IM-2009-17156 & & Papua New Guinea, (-4.967, 145.833), BIOPAPUA, CP3708, 502-529 m. & CONO3076-20 & MT256954 & \\
\hline
\end{tabular}


Pagodibela maia Criscione et al., 2020

Pagodibela pacifica n. sp.

Pagodibela meridionalis n. sp.

Outgroups

Aplotoma brevitentaculata Criscione et al., 2020

Austrobela micraulax (Sysoev, 1997)

Austrobela n. sp. 2

Austrobela n. sp. 3

Austrobela n. sp. 4

Austrobela rufa Criscione et al., 2020

Biconitoma cretosa $\mathrm{n}$. sp.

Mioawateria n. sp. 1

Nodothauma magnifica Criscione et al., 2020

Pueridaphne cirrisulcata Criscione et al., 2020 Spergo fusiformis (Habe, 1962)

Spergo n. sp. 1

Spergo n. sp. 2

Spergo n. sp. 3

Spergo n. sp. 4

Spergo sp.

Taranis sp.
IM-2009-17197

IM-2013-19729

IM-2013-9836

IM-2009-17116

MNHN IM-2007-42518

MNHN IM-2007-42519

MNHN IM-2007-42528

MNHN IM-2013-62987

MNHN IM-2009-14887

MNHN IM-2013-59316

MNHN IM-2013-59352

MNHN IM-2007-17695

AMS C.571678

MNHN IM-2007-17844

AMS C.519402

MNHN IM-2009-29189

MNHN IM-2013-69658

MNHN IM-2007-38860

SAMA D44173

AMS

AMS

AMS

AMS

AMS

AMS

AMS

AMS

AMS

AMS

AMS

AMS

AMS

AMS

AMS

MNHN

MNHN

C. 482239

C. 532707

C.572165

C. 482154

C.519290

C.519331

C.519392

C. 571638

IM-2007-17841

IM-2007-42296
Papua New Guinea, (-4.967, 145.833), BIOPAPUA, CP3708, 502-529 m.

Papua New Guinea, $(-5.183,147.05)$, PAPUA_NIUGINI, CP3981, $688 \mathrm{~m}$.

Papua New Guinea, (-5.367, 145.85), PAPUA_NIUGINI, CP4026, 620-677 m.

Papua New Guinea, $(-9.15,152.25)$, BIOPAPUA, CP3739, 503-546 m.

Solomon Islands, (-7.717, 156.417), SOLOMON_2, CP2246, 664-682 m.

Solomon Islands, (-7.75, 156.933), SOLOMON_2, CP2269, 768-890 m.

Solomon Islands, (-9.15, 158.983), SOLOMON_2, CP2176, 600-875 m.

Glorioso Islands, (-12.5, 44.933), BIOMAGLO, DW4863, 606-610 m.

South Madagascar, (-25.617, 46.367), ATIMO_VATAE, CP3566/DW3565, 618-624 m.

Taiwan, (16.233, 114.5), ZhongSha_2015, CP4153, $318 \mathrm{~m}$.

Taiwan, (16.25, 114.567), ZhongSha_2015, CP4154, 321-326 m.

Vanuatu, $(-16.717,167.983)$, BOA1, CP2465, $770 \mathrm{~m}$

Australia, QLD, Coral Sea CMR, (-23.587, 154.194), IN2017_V03_121, 1013-1093 m.

New Caledonia, Chesterfield Islands, (-20.967, 160.967), EBISCO, CP2645, 641-652 m.

Australia, QLD, Coral Sea CMR, (-23.587, 154.194), IN2017_V03_121, 1013-1093 m.

New Caledonia, (-22.283, 171.3), EXBODI, DW3876, 518-833 m.

New Caledonia, (-23.283, 167.933), KANACONO, CP4750, 750-850 m.

Tuamotu Archipelago, (-17.783, -149.383), TARASOC, DW3489, 450-720 m.

Australia, SA, GAB, (-35.043, 134.079), IN2015_C02_126, 367-409 m.

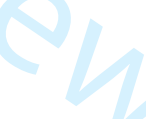

Ht Australia, VIC, East Gippsland CMR, (-37.792, 150.382), IN2017_V03_035, 2338-2581 m. Australia, QLD, Coral Sea CMR, (-23.587, 154.194), IN2017_V03_121, 1013-1093 m. Australia, SA, GAB, (-34.074, 129.182), IN2015_C01_064, 2649-2803 m. Australia, SA, GAB, (-34.823, 132.692), IN2015_C02_167, 998-1015 m. Australia, NSW, Hunter CMR, (-32.575, 153.162), IN2017_V03_070, 2474-2595 m.

Pt Australia, SA, GAB, (-35.345, 134.045), IN2015_C02_134, 1509-1544 m.

Ht Australia, NSW, off Byron Bay, (-28.677, 154.203), IN2017_V03_090, 2562-2587 m. Australia, VIC, East Gippsland CMR, (-37.815, 150.373), IN2017_V03_040, 2600-2746 m.
Ht Australia, SA, GAB, (-35.558, 134.083), IN2015_C02_137, 1927-1995 m.

Ht Australia, SA, GAB, (-34.452, 129.492), IN2017_C01_197, 3235-3350 m.

Australia, QLD, Coral Sea CMR, (-23.587, 154.194), IN2017_V03_121, 1013-1093 m. Australia, TAS, Freycinet CMR, (-41.731, 149.12), IN2017_V03_004, 2751-2820 m. Australia, Bass Strait, (-39.552, 149.553), IN2017_V03_030, 4133-4197 m.

Australia, TAS, Flinders CMR, $(-40.473$, 149.397), IN2017_V03_015, 4114-4139 m. Australia, NSW, Hunter CMR, (-32.575, 153.162), IN2017_V03_070, 2474-2595 m.

New Caledonia, (-21.533, 162.5), EBISCO, CP2648, 458-750 m.

Philippines, Aurora, off Dipaculao, (15.95, 121.833), AURORA 2007, CP2749, $473 \mathrm{~m}$.
CONO3077-20

CONO3082-20

MT256950

MT256962

CONO3083-20 MT256974

CONO3075-20 MT256960

CONO793-08 MT256966

CONO794-08 MT256953

CONO804-08 MT256967

CONO3093-20 MT256965

CONO3078-20 MT256958

CONO3088-20 MT256964

CONO3089-20 MT256970

CONO143-08 MT256956

MN983188

CONO186-08 EU015652

MN983190

CONO3081-20 MT256971

CONO3094-20 MT256947

CONO3072-20 MT256952

MN983189

MN983163

MN983164

MN983165

MN983166

MN983167

MN983168

MN983169

MN983186

MN983187

MN983198

MN983201

MN983202

MN983203

MN983204

MN983205

CONO184-08 EU015650

CONO561-08 HQ401584
MN985685

MN985684

MN985686 
Teretiopsis sp.

Thatcheria mirabilis Angas, 1877

Theta lyronuclea (A. H. Clarke, 1959)

Theta n. sp. 2

Theta n. sp. 3

Trochodaphne cuprosa Criscione et al., 2020

Typhlosyrinx sp.
AMS $\quad$ C.571622

MNHN IM-2007-17924

AMS $\quad$ C.482290

AMS C.532711

AMS C.571657

AMS C.571611

AMS C.519335
Australia, QLD, Coral Sea CMR, (-23.587, 154.194), IN2017 V03_121, 1013-1093 m.

Solomon Islands, $(-8.283,160)$, SOLOMON 2, CP2184, 464-523 m

CONO349-08

Australia, NSW, Jervis CMR, (-35.114, 151.469), IN2017_V03_053, 3952-4011 m.

Australia, SA, GAB, (-35.818, 134.109), IN2015_C02_141, 2800-2852 m.

Australia, NSW, Hunter CMR, (-32.575, 153.162), IN2017_V03_070, 2474-2595 m.

Australia, NSW, Jervis CMR, (-35.333, 151.258), IN2017_V03_056, 2650-2636 m.

Australia, NSW, off Byron Bay, (-28.054, 154.083), IN2017_V03_100, 999-1013 m.
MN983206

EU015736

MN983207

MN983209

MN983210

MN983211

MN983212 
Table S2. Inter-PSHs/specific genetic differentiation of 12S sequences in Gladiobela by means of p-distances. Reciprocal distances of G6/G. sinuosa shaded. Species codes: acr, $G$. acris n. sp.; ang, G. angulata.; sin, G. sinuosa n. sp.; stu, G. stupa n. sp.; vit, G. vitrea n. sp. Codes of species described herein in bold.

\begin{tabular}{lcccc}
\hline & G3/acr & G1/ang & G6/sin & G4/stu \\
\hline G1/ang & 0.051 & & & \\
G6/sin & 0.066 & 0.051 & & \\
G4/stu & 0.042 & 0.035 & 0.053 & \\
G5/vit & 0.046 & 0.040 & 0.061 & 0.033 \\
\hline
\end{tabular}


Figure captions

Figure 1. Distribution of taxa studied herein. (A) Records of sequenced specimens of Gladiobela in Australian waters (numbered circles). Inset: section of the Hunter region coast where four different records occur in close vicinity. (B) Records of sequenced specimens of Pagodibela with distribution in Australian waters (numbered squares). Inset: record of $P$. pacifica in the Tuamotu Archipelago. (C) Records of sequenced specimens of Gladiobela outside Australian waters (lettered and numbered circles). (D) Records of sequenced specimens of PA/Pagodibela baruna (Sysoev, 1997) (black squares). Numbers in circles indicate PSHs/species of Gladiobela (1-G1/G. angulata, 2-G2/G. abyssicola, 3-G3/G. acris, $4-G 4 / G$. stupa, 5-G5/G. vitrea, 6-G. sinuosa). Letters in circles indicate PSHs of Gladiobela with distribution outside Australia (A - GA, B - GB, C-GC, D - GD, E-GE). Numbers in squares indicate PSHs/species of Pagodibela (1 - P1/P. pacifica, 2- P2/P. maia, $3-\mathrm{P} 3 /$ P. meridionalis). Records of micro-sympatry (see text) are indicated by numbers connected by ' + '. Thin lines mark limits among marine realms (numbered as in Costello et al., 2017). Main scalebars $=1000 \mathrm{~km}$, insets scalebars $=50 \mathrm{Km}$.

Figure 2. Bayesian consensus phylogram ( $\mathrm{BI}$, left) and Maximum-Likelihood tree (ML, right) based on analyses of the COI sequences dataset. Clades containing congeneric species in the outgroup are collapsed. Numbers above branches indicate nodal support (\%) by Bayesian posterior probabilities (BPP) and ML bootstrap (BS). For both BPP and BS values of $100 \%$ are represented by asterisks. Support values for clades below the species level are omitted. Names of species described herein, and sequences of Australian samples are in bold. Vertical bars mark distinct primary species hypotheses (PSHs) as delimited by the ABGD method. Samples whose shells are figured (scale bar $=10 \mathrm{~mm}$ ) are underlined.

Figure 3. Shells of PSHS/species studied herein. (A) G1/Gladiobela angulata Criscione et al., 2020 holotype AMS C.571561; (B) G2/Gladiobela abyssicola n. sp., holotype AMS C.571656; (C) G3/Gladiobela acris n. sp., holotype AMS C.571697; (D) G4/Gladiobela stupa n. sp., holotype AMS C.571683; (E) G5/Gladiobela vitrea n. sp., holotype AMS C.482311; (F) Gladiobela sinuosa n. sp., holotype AMS C. 571625; (G) PA/Pagodibela baruna (Sysoev, 1997) n. comb., holotype MNHN IM-2000-2772; (H) P1/Pagodibela pacifica n. sp., holotype 
MNHN IM-2007-17844; (I) P2/Pagodibela maia Criscione, 2020, holotype AMS C.571678; (J) P3/Pagodibela meridionalis n. sp., holotype SAMA D44173. Scale bar $=10 \mathrm{~mm}$.

Figure 4. Scatter plot of SW and SH ratios with Wt for all measured shells of Gladiobela. 95\% confidence ellipses are drawn for species represented by more than 4 shells. Shaded areas correspond to portion of morpho-space delimited by minimum and maximum values of $\mathrm{SH} / \mathrm{SW}$ for species represented by more than 4 shells. Dashed lines represent mean SH/SW values.

Figure 5. Larval shells of PSHS/species studied herein. (A) G3/Gladiobela acris n. sp., holotype AMS C.571697; (B) G4/Gladiobela stupa n. sp., holotype AMS C.571683; (C) G5/Gladiobela vitrea n. sp., holotype AMS C.482311; (D) P2/Pagodibela maia Criscione, 2020, holotype AMS C.571678; (E) P3/Pagodibela meridionalis n. sp., holotype SAMA D44173. Scale bar $=500 \mu \mathrm{m}$.

Figure 6. Hypodermic teeth of PSHs/species studied herein. (A) G1/Gladiobela angulata Criscione et al., 2020, holotype AMS C.571561; (B) G5/Gladiobela vitrea n. sp., holotype AMS C.482311; (C) G3/Gladiobela acris n. sp., holotype AMS C.571697; (D) Gladiobela sinuosa n. sp., holotype AMS C. 571625; (E) G2/Gladiobela abyssicola n. sp., paratype AMS C.519389; (F) G4/Gladiobela stupa n. sp., paratype AMS C.519345; (G) P2/Pagodibela maia Criscione, 2020, holotype AMS C.571678; (H) P3/Pagodibela meridionalis n. sp., holotype SAMA D44173; (J) P2/Pagodibela pacifica n. sp., holotype MNHN IM-2007-17844. Scale bar $=100 \mu \mathrm{m} . \mathrm{Db}=$ dorsal blade.

Figure 7. Radular details of Gladiobela PSHs/species (A) G1/Gladiobela angulata Criscione et al., 2020, holotype AMS C.571561, showing dorso-lateral view of tooth base, with crescentshaped indentation (crs), posterior shelf (ps) and sculpture of external base (eb); (B) G1/G. angulata paratype AMS C.571737, showing basal opening (bo) and short ligament (lig); (C) G2/G. abyssicola n. sp., paratype AMS C.519389, showing adapical opening (ao) and dorsal blade $(\mathrm{db})$. Scale bar $=20 \mathrm{um}$. 
Figure 8. Bathymetric ranges of taxa studied herein as inferred from records of sequenced specimens. Species represented by a single record are indicated by a square.

Table 1. Intra- and inter-PSHs/specific genetic differentiation of COI sequences in Gladiobela by means of p-distances. Intra-PSH/specific distances shaded. Inset: minimum, maximum and average intra- and inter-PSHs/specific p-distances within Gladiobela. Species codes: aby, G. abyssicola n. sp; acr, G. acris n. sp.; ang, G. angulata.; stu, G. stupa n. sp.; vit, G. vitrea n. sp. Codes of species described herein in bold.

Table 2. Intra- and inter-PSHs/specific genetic differentiation of COI sequences in Pagodibela by means of p-distances. Intra-PSH/specific distances shaded. Inset: minimum, maximum and average intra- and inter-PSHs/specific p-distances within Pagodibela. Species codes: bar, P. baruna; P.; mai, P. maia; pac, P. pacifica n. sp.; P.; pho, P. meridionalis n. sp. Codes of species described herein in bold. 
Tables captions

Table 1. Intra- and inter-PSHs/specific genetic differentiation of COI sequences among Gladiobela PSHs/species by means of p-distances. Intra-PSHs/specific distances shaded. Inset: minimum, maximum and average intra- and inter-PSHS/specific $p$-distances within Gladiobela. Species codes: acr, G. acris n. sp.; ang, G. angulata; car, G. abyssicola n. sp.; stu, G. stupa n. sp.; vit, G. vitrea n. sp. Codes of species described herein in bold.

Table 2. Table 1. Intra- and inter-PSHs/specific genetic differentiation of COI sequences among Pagodibela PSHs/species by means of p-distances. Intra-PSHs/specific distances shaded. Inset: minimum, maximum and average intra- and inter-PSHS/specific $p$-distances within Pagodibela. Species codes: bar, P. baruna; P.; mai, P. maia; pac, P. pacifica n. sp.; P.; pho, $P$. meridionalis n. sp. Codes of species described herein in bold. 
1 Few and far apart: integrative taxonomy of Australian species of Gladiobela and Pagodibela

2 (Conoidea: Raphitomidae) reveals patterns of wide distributions and low abundance

3

4 Anders Hallan A, Francesco Criscione ${ }^{A *}$, Alexander Fedosov ${ }^{B}$, Nicolas Puillandre ${ }^{C}$ 5

6

7

8

9 A - Australian Museum, 1 William Street, Sydney NSW 2010, Australia

10 B - A.N. Severtsov Institute of Ecology and Evolution of Russian Academy of Sciences,

11 Leninski Prospect 33, Moscow 119071, Russia

12 C - Institut Systématique Evolution Biodiversité (ISYEB), Muséum National d'Histoire

13 Naturelle, CNRS, Sorbonne Université, EPHE, Université des Antilles. 57 rue Cuvier, CP 26,

1475005 Paris, France

$15 *$ Corresponding author: francesco.criscione@austmus.gov.au

19 Running title: Molecular systematics of Gladiobela and Pagodibela 
Abstract

The deep-sea malacofauna of temperate Australia remains comparatively poorly known. However, a recent influx of DNA-suitable material obtained from a series of deep-sea cruises facilitated integrative taxonomic study on the Conoidea (Caenogastropoda: Neogastropoda). Building on a recent molecular phylogeny of the conoidean family Raphitomidae, this study focussed on the genera Gladiobela and Pagodibela (both Criscione et al., 2020). We subjected a comprehensive mtDNA COI dataset of deep-sea raphitomids to ABGD barcode gap detection, which recognised 14 primary species hypotheses (PSHs), nine of which were converted to secondary species hypotheses (SSHs). Following the additional examination of the shell and hypodermic radula features, as well as consideration of bathymetric and geographic data, seven of these PSHs were recognised as new to science and given full species rank. Subsequently, full systematic descriptions were provided herein. Of these, five were attributed to Gladiobela (three of which are endemic to Australia and with two more widely distributed) and two were placed in Pagodibela (one endemic to southern Australia and one widespread in the Pacific). The rarity of many 'turrids' reported in previous studies was confirmed herein, as particularly indicated by highly disjunct geographic records for two taxa. Additionally, several of the studied taxa exhibited wide Indo-Pacific distributions, suggesting that wide geographic ranges in deep-sea 'turrids' may be more common than previously assumed. Finally, impediments to deep-sea 'turrid' taxonomy in the light of such comparative rarity and unexpectedly wide distributions were discussed. 
Introduction

It is a well-known notion among malacologists that 'turrids' - members of the hyper-diverse superfamily Conoidea (Caenogastropoda: Neogastropoda) not including Conidae and Terebridae and historically treated as Turridae (herein referred to as 'turrids' to clearly distinguish from Turridae sensu stricto) - are a particularly challenging group taxonomically. Hedley (1922: p. 213) stated that the marine gasteropods [sic] embraced in the family Turridae (formerly Pleurotomidae) are considered by those who meddle with them to be more perplexing than any other molluscan family'. The literature provides numerous examples in support of that statement, such as 'turrid pairs', where separate species (not necessarily sister taxa) have virtually indistinguishable teleoconch morphologies but differing protoconchs (Powell 1942) or where even species from different families cannot be readily differentiated based on shell characters (Hallan et al. 2020; Kantor et al. 2018; Sysoev and Kantor 1990). Other impediments to 'turrid' taxonomic study include low abundances in many taxa and relative difficulty in collecting due to their largely subtidal habitats (Bouchet and Waren 1980; Todd and Rawlings 2014). Challenges with 'turrid' taxonomy are further exacerbated in the deep sea, where protoconchs are commonly eroded or missing entirely (Criscione et al. 2020), and sculptural elements of the teleoconch may be significantly worn owing to the dissolution of $\mathrm{CaCO}_{3}$ (Burton 1998). Furthermore, some deep-sea taxa exhibit an overall lack of indicators of terminal shell growth [such as apertural thickening, formation of a varix, or similar (Bouchet and Waren 1980)]. In these cases, inferences about the stage of maturity (and therefore about representative adult size) are difficult, particularly where material is scarce. Paraphrasing the sentiment by Marshall (1983) that material of Triphoridae ought not to be described in the absence of an intact protoconch, Puillandre et al. (2017) emphasised that no new 'turrids' should be described without molecular data, preferably designating a molecular voucher as a type. This is particularly true for deep-sea material, given the issues raised above. When conducting 'turrid' systematics research, notably on deep-sea taxa, there is also the need to consult with taxonomic work on species that may occur far beyond conventionally expected geographic limits of conspecific taxa. A study by Zaharias et al. (2020) demonstrated that several deep-sea species of the genus Cryptogemma Dall, 1918 (Turridae) exhibit notably wide distributions. Corroborated by mitochondrial DNA evidence, one species, C. phymatias (R. B. Watson, 1886) was shown to have a trans-oceanic 
distribution, arguably providing the first molecularly confirmed such case in a benthic gastropod. Such unexpectedly wide geographic ranges may routinely escape the attention of taxonomists, notably where morphologically heterogeneous taxa are concerned; Zaharias et al. (2020) synonymised several species names attributable to Cryptogemma, suggesting that while analyses of molecular data commonly reveal unnamed taxa in the Conoidea (e.g., Fedosov and Puillandre 2012; Puillandre et al. 2010a), taxonomic over-splitting may also occur, arguably in part as a consequence of underestimated distribution ranges. While trans-oceanic ranges, such as that documented for $C$. phymatias, appear to be exceptionally rare based on existing evidence, wide distributions in the deep sea, particularly in the Conoidea, may not be so uncommon. Bouchet and Waren (1980) noted that among their deep-sea study material from the Western and Eastern Atlantic, there was a 34\% species overlap between the two regions, suggesting that a significant portion of deep-sea 'turrids' may have ocean-wide distributions. Furthermore, they predicted that percentage would increase with additional study.

The deep-sea Australian malacofauna has, until recently, remained among the most poorly known in the Indo-Pacific region owing to a lack of study material, particularly that suitable for molecular analysis (Criscione et al. 2020). However, recent deep-sea expeditions in southern and eastern Australia, notably aboard the research vessel Investigator, have delivered a wealth of material from several major groups of the Mollusca (see Maclntosh et al. 2018; O'Hara 2019). The extremely diverse superfamily Conoidea is prevalent in these samples, and now subject to ongoing collaborative study between the Australian Museum, Sydney (AM) and the Muséum National d'Histoire Naturelle, Paris (MNHN) (Criscione et al. 2020; Hallan et al. 2020; Zaharias et al. 2020). The 'turrid' family Raphitomidae is particularly well-represented among this conoidean material (O'Hara 2019). A recent molecular phylogeny by Criscione et al. (2020) revealed a considerable diversity of previously unknown deep-sea raphitomid lineages and included the description of twelve new genera. Building on the classification framework set out by this latter study, two of the genera described therein are further treated here: Gladiobela Criscione et al., 2020 and Pagodibela Criscione et al., 2020. Gladiobela angulata Criscione et al., 2020, type species of its genus, is known from bathyal depths (3350-3807 m) of the Great Australian Bight (henceforth GAB), and from a single locality off the NSW Central Coast ( $2600 \mathrm{~m}$ ). This study describes five additional species of Gladiobela, three of which are possibly endemic to 
109 temperate Australia, and two potentially widespread in the eastern Indo-Pacific, with all 110 members of the genus occurring from bathyal to abyssal depths ( $500-4850 \mathrm{~m}$ ). Pagodibela 111 maia Criscione, 2020, type species of its genus, is known only from a single record from the 112 Coral Sea ( $\sim 1000 \mathrm{~m}$ ). Two additional species of Pagodibela, one from the GAB and the other 113 from north Queensland to the Society Islands, are also described herein. Generic diagnoses 114 are provided for both genera, as well as details of the shell and venom apparatus.

115 Furthermore, morphological characters, as well as patterns of bathymetry and biogeography 116 are presented. Finally, impediments to future 'turrid' systematics given their comparative 117 scarcity (in terms of number of individuals) and unusually wide distributions at the species118 level are discussed. 
Materials and methods Taxon sampling

The samples studied herein were selected from among all deep-sea Raphitomidae ethanolpreserved material from the malacological collections of the Australian Museum, Sydney (AMS), the South Australian Museum, Adelaide (SAMA) and the Muséum national d'Histoire naturelle, Paris (MNHN). As a result of ongoing systematic research on the Conoidea at the AMS and MNHN, several hundreds sequences of the mitochondrial gene cytochrome $c$ oxidase subunit 1 (COI) were obtained from a few hundreds largely undescribed representative raphitomid taxa. In order to assist with the selection of the study material, a pilot analysis was performed on a dataset including all raphitomid COI sequences, using the neighbour-joining method (NJ) (Saitou and Nei 1987) implemented in MEGA 7 (Kumar et al. 2016). The dataset encompassed sequences of the type species of many deep-sea raphitomid genera, including the holotypes of G. angulata (MN983180) and P. maia (MN983188). A subset of sequences was generated which included all COI sequences that in the resulting tree (not shown) were more closely related to the sequences of either of the two holotypes than to any type species of any other raphitomid genus in the dataset. The dataset thus obtained (henceforth referred to as 'ingroup') forms the basis for the molecular analysis described below. Additional material relevant to this study, but for which attempts of amplifying COI failed, was selected based on the results of a NJ analysis (see below) of a dataset comprising all $12 \mathrm{~S}$ sequences available for raphitomids. This dataset, albeit much smaller than the COI one (about 200 sequences), included sequences of the holotypes of type species of Gladiobela (MN985672) and Pagodibela (MN985684). A subset of $12 \mathrm{~S}$ sequences was formed with these and other sequences that in the resulting tree (not shown) were to them-more closely related to them than to any type species of any other raphitomid genus in the dataset. Among the ingroup specimens, morphological examination was only conducted on those collected in Australian waters and some of those collected outside Australia (see Results). Geographic and bathymetric data were available for all ingroup specimens. Geographic distributions were assessed with reference to marine biogeographic realms as delimited in Costello et al. (2017). According to Bouchet et al. (2008), when inferring species distributions from sampling depth intervals, only shallower depth values were considered, as there is no evidence that the species collected occurs beyond that value. 
Molecular methods

Molecular work was performed in laboratories at two different Institutions (AMS and

MNHN). Unless otherwise stated, the same methodology was followed by both laboratories.

DNA extraction was performed on at least one specimen per morphospecies per collecting

site. DNA was extracted from small pieces of foot muscle by use of a Bioline Isolate II

Genomic DNA extraction kit for animal tissue, following the standard procedure of the manual (AM) or using the Epmotion 5075 robot (Eppendorf), following the recommendations by the manufacturer (MNHN). Fragments of the two mitochondrial genes COI and $12 S$ were amplified using the primer pairs LCO1490/HCO2198 (Folmer et al. 1994) and 12S-I/12S-III for 12S (Simon et al. 1991). PCR reactions were performed in volumes of 25 $\mu \mathrm{l}$, containing 3 ng DNA, 1X Qiagen CoralLoad PCR Buffer, 2.5mM MgCl $2,0.25 \mathrm{mM}$ dNTP, $0.5 \mathrm{mM}$ of each primer, $0.5 \mu \mathrm{g} / \mu \mathrm{l}$ of BSA and $0.2 \mu \mathrm{l}$ of Bioline MyTaq DNA polymerase. Amplification consisted of an initial denaturation step at $94^{\circ} \mathrm{C}$ for $4 \mathrm{~min}$, followed by 37 cycles of denaturation at $94^{\circ} \mathrm{C}$ for $30 \mathrm{~s}$, annealing at $50^{\circ} \mathrm{C}(\mathrm{COI})$ or $57^{\circ} \mathrm{C}(12 \mathrm{~S})$ for $30 \mathrm{~s}$, followed by extension at $72^{\circ} \mathrm{C}$ for $1 \mathrm{~min}$. The final extension was conducted at $72^{\circ} \mathrm{C}$ for 5 $\min$.

PCR products were purified and sequenced by the Macrogen (AMS) and Eurofins (MNHN) sequencing facilities. When necessary, chromatograms were manually corrected for misreads and forward and reverse strands were merged into one sequence file using CodonCode Aligner v. 9.0.1 (CodonCode Corporation, Dedham, MA). COI sequences did not require alignment as these had identical lengths of $658 \mathrm{bp}$ after trimming of the primer sites. Alignments of $12 S$ sequences were generated using MUSCLE as implemented in MEGA7 (Kumar et al. 2016). Phylogenetic analyses were conducted on the COI dataset, using Maximum Likelihood (ML) and Bayesian inference (BI) methods. All sequences used deposited in GenBank (Table S1). Sequences of thirteen deep-sea raphitomid genera were added to serve as outgroups (Table S1). Their selection was based on a multi-gene (mitochondrial and nuclear) phylogeny containing many southern and south-eastern Australian Raphitomidae (Criscione et al. 2020). ML was performed using the program MEGA7 with Nearest-Neighbour-Interchange (NNI) as heuristic method and automatic generation of the initial tree. One thousand bootstrap replicates (BS) were performed to assess the topology support. The BI analysis 
was performed in MrBayes 3.2.6 (Ronquist and Huelsenbeck 2003) and included 2 runs of $10^{7}$ generations, with 4 chains each and a sampling frequency of one tree per 1,000 generations. Other parameters were set to default. A consensus tree was then calculated after checking for chain convergence and discarding the first $25 \%$ trees as burn-in. Prior to the model-based ML phylogenetic analyses, $T N 93+G+I$ was identified as best-fit model of nucleotide substitution by means of the Bayesian Information Criterion as implemented in MEGA 7 (Kumar et al. 2016). According to MrBayes manual (p. 94), a priori model testing was not performed, and the $\mathrm{GTR}+\mathrm{G}+\mathrm{I}$ model was applied to the $\mathrm{BI}$ analysis. Nodal support was assessed by values of Bayesian posterior clade probabilities (BPP).

Due to the smaller number of sequences selected to form the $12 \mathrm{~S}$ dataset, a NJ analysis only was deemed sufficient to represent the phylogenetic relationships based on this gene. This analysis was performed in MEGA 7 (Kumar et al. 2016). Uncorrected pairwise genetic distances were calculated using MEGA7 with the option 'pair-wise deletion of gaps'.

\section{Morphological examinations}

All studied samples consisted of soft parts and shells, which had been separated following the methodology (drilling or microwaving) mentioned in Criscione et al. (2020). We studied shell morphology and (when possible) internal anatomy, including radular morphology. Shells were affixed to plasticine and positioned with their vertical axis parallel to the observation plane. Each shell was then photographed from above using a Canon EOS 6D digital SLR camera. Maximum shell length (SL) and width (SW) were measured on digitised images using the calibrated ruler tool in Adobe Photoshop CC v.20.0.6 and measurements rounded to the nearest $0.1 \mathrm{~mm}$. The number of shell whorls was counted under a Leica MZ8 stereomicroscope, according to Bouchet and Kantor (2004). While it was possible to obtain the number of teleoconch whorls $(\mathrm{Wt})$ for all studied specimens, protoconch whorls could only be counted occasionally due to widespread erosion of the apex. In order to capture the shell proportions regardless of their size, the ratios SL/SW, SL/Wt and SW/Wt were generated. Ideally, to prevent the effects of allometry, only shells at terminal growth could be used in the morphometric analysis of this study. However, terminal growth could not be assessed for the samples of this study (see above). As an approximation, shells of a given PSHs were assumed to have reached terminal growth when their Wt was-were within one 
unit of the maximum Wt value observed for that given PSHs. Based on the data obtained, descriptive statistics and plots were produced in SYSTAT v.13.1 (Systat Software, Inc., 2009). Anatomical studies were conducted on animals removed from ethanol and briefly rehydrated in distilled water. Using standard dissection tools, the venom apparatus was excised and the radular sac isolated and placed on a glass slide; during this dissection process, head-foot, mantle, genital and (non-radula) foregut characters were examined where possible. After dissolution in diluted commercial bleach, clusters of hypodermic teeth where rinsed repeatedly in distilled water, then separated into individuals and ligamentconnected pairs/smaller clusters. Subsequently, the glass stub was affixed to a carbon adhesive placed on a $12 \mathrm{~mm}$ diameter aluminium mount. All samples were imaged at Macquarie University, Sydney, using a Phenom XL Scanning Electron Microscope.

Species delimitation

The Automatic Barcode Gap Discovery (ABGD) (Puillandre et al. 2012b) was applied for primary species delimitation to the dataset containing all COI ingroup sequences. The webbased version of ABGD (https://bioinfo.mnhn.fr/abi/public/abgd/abgdweb.html) was used with a $\mathrm{p}$-distance model. The relative gap width $(X)$ was set to 1 and other parameters left to default. Resulting ABGD groups were considered primary species hypotheses, henceforth referred to as PSHs. Following Puillandre et al. (2012c), conversion of PSHs to secondary species hypotheses (SSHs) was conducted through comparative examination of morphological characters as well as through evaluation of geographic and bathymetric data. In particular, for each PSH examined, the co-occurrence of the following conditions was considered evidence supporting such conversion: (i) the PSH is a highly supported clade (BPP $>98 \%$ and $B S>90 \%$ ), (ii) the PSH shows lower values of intra-PSH genetic $p$-distance in $\mathrm{COI}$ when compared with values of inter-PSH distances measured with the most closely related PSH, (iii) all its constituent specimens share at least one distinctive morphological feature deemed not to be polymorphic or ecophenotypic, and without exhibiting intermediate forms. When the above criteria were met, the presence of genetic or morphological divergence and/or bathymetrical partitioning in sympatry was considered additional evidence supporting species delimitation. Clearly, when PSHs are represented by one sequence only, criteria (i) and (ii) cannot be assessed. In those cases, the decision was guided by presence of additional bathymetrical and morphological evidence fsuch as that 
described above)-as well as comparisons with intra-generic patterns of genetic distance. When available, species names were assigned to SSHs based on the current taxonomy. New species names were introduced when no names were available, and formal descriptions for these taxa are given in the systematic section below.

\section{Abbreviations}

$\mathrm{CMR}=$ Commonwealth Marine Reserve; Ht=holotype; NSW=New South Wales; PNG= Papua New Guinea; Pt=paratype; QLD=Queensland, SA=South Australia, TAS=Tasmania; VIC=Victoria; wet=number of ethanol-preserved (wet) specimens.

\section{Results}

Molecular studies

Molecular analyses were based on a total of $75 \mathrm{COI}$ sequences (42 newly produced and 33 GenBank-sourced) generated from specimens collected off Australia during the expeditions IN2015_C01, IN2015_C02 (GAB) and IN2017_V03 (Tasman and Coral Seas) and other localities of the tropical and temperate Indian and Pacific Oceans, during a number of voyages that formed part of the Tropical Deep-sea Benthos programme of MNHN (Fig. 1, Table S1). The dataset analysed included 51 ingroup sequences and 24 sequences representing 24 deep-water raphitomid species of 13 different genera that were used as outgroups

Except for extremely low and high prior values, the ABGD analysis of the COI ingroup dataset consistently returned a partition with 14 groups of sequences (PSHs). Among all PSHs (Fig. 2), five (G1, G2, G4, P2 and P3) contain exclusively Australian samples, three (G3, G5 and P1) include samples from Australian seas and beyond, while the remaining six (GAGE and PA) encompass sequences from outside Australian waters.

The $\mathrm{BI}$ and $\mathrm{ML}$ analyses generated trees with nearly identical topologies, showing only minor differences in the relative position of individual sequences within some of the PSH clades (Fig. 2). Clades representing PSH-level relationships and above were generally wellsupported, with very few exceptions. In both analyses, two major genus-level clades were retrieved, namely Gladiobela ( $\mathrm{BPP}=100 \%, \mathrm{BS}=93 \%$ ) and Pagodibela (BPP and $\mathrm{BS}=100 \%$ ). These two clades included ten and four PSHs respectively, all forming well-supported (in 
terms of nodal support: BPP>98\%; BS $>90 \%$ ) and well-differentiated (in terms of branch lengths) PSH clades. Within the two genus-level clades, there was no overlap between intra- and inter-PSH distances. In the Gladiobela clade, the intra-PSH pairwise distances in COI ranged from 0 to $1.1 \%$ (average=0.5 \%) with inter-PSH distances ranging from 4.0 to $11.7 \%$ (average=8.2 \%) (Table 1). The lowest inter-PSH distances were observed between GD and GE and the highest intra-PSH distances were found within G3. In the Pagodibela clade, the intra-PSH pairwise distances were between 1.8 and 1.9\%, whereas inter-PSH distances ranged from 4.4 to $7.1 \%$ (average=5.6\%) (Table 2). The lowest inter-PSH distances were observed between P2 and PA and the highest intra-PSH distances were found within P1. The NJ tree obtained analysing the $12 \mathrm{~S}$ dataset contained four sequences in a cluster, each obtained from samples of four distinct Gladiobela PSHs (G1, G3, G4, G5 - as delimited above). One additional sequence (MT081495), from sample AMS C.571625, was the sister group of this former cluster and exhibited values of $p$-distances (5.1-6.6\%; Table S2) with its members that were within the range of those measured for COI between Gladiobela PSHs. Additionally, its genetic similarity (in terms of $p$-distance values) with G1, G3, G4, G5 was greater than that measured with sequences of samples of Pagodibela or of any other genus in the analysis (data not shown), suggesting its attribution to Gladiobela. Given that $12 \mathrm{~S}$ largely shares patterns of inheritance with $\mathrm{COI}$, this sample is-was considered an additional Gladiobela PSH (G6) to undergo further testing for conversion to SSH.

Morphological studies

Shell morphology was examined for all sequenced material and internal anatomy, including radular morphology was studied-(when possible) for at least two sequenced specimens per PSH. The Gladiobela clade contains three PSHs (G1, G2 and G4) exhibiting a gross shell morphology, whorl profile and sculptural elements that are comparatively similar (Fig. 3A, B, D), whereas the remaining taxa possess heterogeneous shell morphologies, including highspired and broad fusiform shells with varying sculpture (Fig. 3). Due to the limited amount of material available (and specifically of shells at a stage equivalent terminal growth), the sample size was too small to permit inclusion of all PSHs in a statistically rigorous morphometric analysis at this time. A scatterplot of SW/Wt and 
(with the latter exhibiting larger values of both length and width) and proportions (with the latter showing a larger SH/SW ratio). The plot shows that G3 has the smallest and most slender shell of all congeners, while G6 has the largest and broadest shell. As protoconchs were largely eroded (an intact protoconch could not be observed for all species), this character will not be given much emphasis herein. However, all larval shells that could be examined were multispiral and exhibited the typical raphitomid diagonally cancellate sculpture (Fig. 5).

All members of Gladiobela shared hypodermic, somewhat tightly rolled teeth with a very long dorsal blade (Fig. 6A), elongate adapical opening and moderately broad to very broad base (Fig. 6). The sister taxa G1, G2 and G3 can be characterised by teeth with extremely long dorsal blades and a very broad, angular base with a crescent-shaped indentation around the perimeter of the lower shaft and an elongate posterior extension (Fig. 7); G4 is a notable outlier with an extremely long tooth compared to its congeners (Fig. 6F), whereas G5 and G6 possess teeth with a narrower, less angular base (Fig. 6B, D). All members exhibit moderate to long, tapering to cylindrical cephalic tentacles with very small eyespots at their lower outer bases.

Pagodibela PSHs vary notably in shell morphology, from strongly pagodiform with prominent sculpture, to subconical and comparatively smooth (Fig. 3G-J). Their radulae consist of hypodermic morphologically uniform teeth: awl-shaped, with a long dorsal barb, an elongate adapical opening and a swollen base with coarse external texture (Fig. 6G-I). All PSHs possess small eyes at the outer lower bases of cylindrical cephalic tentacles.

Geographical and bathymetrical distributions The genus-level clade Gladiobela is recorded from three marine realms (sensu Costello et al. 2017) (Fig. 1A, C) and Pagodibela clade from at least seven marine realms (Fig. 1B, D). Gladiobela exhibits a wide bathymetric range, from 470 to 4750 metres, and Pagodibela from 318 to 1013 metres (Fig. 8). The sister clades G1 and G2, G4 and G6 are known only from off Australia, where they are restricted to bathyal and abyssal depths of the temperate south (Fig. 1A). The three former PSHs are not recorded micro-sympatrically (e.g. in the same trawl haul): G1 exhibits a disjunct distribution with the majority of records in the GAB and a single record in the Hunter CMR (depth range 2474-3389 m); G2 occurs between (off) 
341 G4 is known from a single locality in the Hunter CMR (3980 m). G6, known only from a sole

342 individual, was collected at the same site as G1 in the Hunter CMR. G3 is known from two widely separated localities, both geographically and bathymetrically, namely in the East Gippsland CMR, at 3850 metres and NW Choiseul, Solomon Islands, between 1083 and 1100 metres. G5 is recorded from the Hunter CMR and Canal de l'Havannah, New Caledonia, with depth records occurring between 951 and 1006 metres.

For Pagodibela, P2 and P3 are only known as single specimens from the Coral Sea and GAB respectively, of which the former is known from approximately 1000 metres and the latter approximately 370 metres. Conversely, P1 is widely distributed between (off) North Queensland, via the Coral Sea, New Caledonia and eastward to the Society Islands at a depth range of 450-1013 metres. PA has the most widespread known distribution of all Pagodibela PSHs, occurring in at least four marine realms between the South Pacific and off the east African coast (Fig. 1D).

\section{PSH to SSH conversion}

Comparative examination of the morphological, geographic and bathymetric data available was employed to attempt the conversion of PSHs to SSHs. As generating morphological data for most species with distribution outside Australian waters was beyond the scope of this study, testing of five PSHs (i.e. GA-GE), out of the total of fourteen retrieved by ABGD, was not attempted and these are pending further sampling and taxonomic investigation. As detailed below, all remaining nine PSHs retrieved by ABGD, namely G1-G5, PA and P1-P3 satisfied the three conditions described in the methodological section. G1 and G2 corresponded to highly supported clades (BPP and BS=100\%; Fig. 2) in a sister relationship. Both exhibited low intra-PSH genetic distance (average $0.06 \%$ and $0.05 \%$ respectively; Table 1) and comparatively high reciprocal genetic distance (average 5.4\%; Table 1). Both G1 and G2 could be distinguished from all other PSHs by their distinctly carinated shells (Fig. 3A-B). G1 could be differentiated from G2 by their smaller, broader shells (Fig. 4) with a carina that is comparatively less pronounced. In addition, their bathymetrical range did not overlap (Fig. 8). The genetic, morphological and bathymetrical distinction between $G 1$ and $G 2$ was maintained in spite of their apparent high dispersal potential (as inferred by the multispiral protoconch) and their sympatry in the South Australia realm (Fig. 1A). 
Clade G3 was highly supported (BPP and BS=100\%), exhibiting values of intra-PSH genetic distances (average 1\%; Table 1) well below values of reciprocal between-PSH genetic distance with its most closely related PSHs (4\% with both GE and GD; Table 1). Its shell was the smallest and most elongate of all other PSHs (Fig. 4) and could readily be distinguished by its raised peripheral cord (Fig. 3C).

G4 corresponded to a highly supported clade (BPP and BS=100\%), exhibiting values of intraPSH genetic distances (average $0.5 \%$; Table 1) and comparatively high genetic distance with its most closely related PSH, GA (5.8\%; Table 1). It could be clearly differentiated from all other PSHs by its shell exhibiting a long, clearly demarcated siphonal canal (Fig. 3D) and by its uniquely long hypodermic teeth (Fig. 6F).

Clade G5 was highly supported (BPP and BS=100\%) and included a single haplotype that exhibited a large genetic distance from its most closely related PSH, GC (average 7.9\%; Table 1). All shells of this PSH shared distinctively rounded lower teleoconch whorls (Fig. 3E) that allowed their differentiation from shells of all other PSH in the Gladiobela clade. Along with the aforementioned comparatively high values of inter-PSHs genetic $\mathrm{p}$-distance in $12 \mathrm{~S}$ (Table S2), the shell of G6 could be differentiated from that of all other PSHs by its broad whorls with opisthocline axial ribs, and by its comparatively rounded shoulder (Fig 3F). Such genetic and morphological differentiation was maintained in spite of its sympatry with $\mathrm{G} 1$ at the boundary between the two marine realms encompassing the Australian seas (Fig. 1A).

PA and P1 both corresponded to highly supported clades (BPP $=98 \%$ and $B S=93 \%, B P P$ and $\mathrm{BS}=99 \%$ respectively; Table 2 ) showing comparatively high values of reciprocal genetic differentiation (average 4.7\%; Table 2). These two PSHs exhibited similar shells that could be differentiated from other Pagodibela PSHs by their comparatively thicker and more elongate shells. However, PA and P1 could be differentiated from each other based on shell sculpture - while shells of P1 possess juvenile whorls with weakly opisthocline axial riblets extending across the periphery (although weakening towards suture), in shells of PA the axial elements were significantly weaker, and there was a prominent, slightly gemmate subsutural cord in the early- to median teleoconch whorls (Fig. $3 \mathrm{H}$ and $3 \mathrm{G}$ respectively). In both PA and P1, the overall shell shape was rather conserved across its constituent samples. The minor differences observed among PA shells in their peripheral sculpture (smooth, 
403

404

405

406

407

408

409

410

411

412

413

414

415

416

417

418

419

420

421

422

423

424

425

426

427

428

429

carinate or tuberculate), were consistent with distributional patterns and thus interpreted as intraspecific geographical variation.

The only sample included in P2 was separated from the sister pair PA and P1 by high values of genetic distance ( 4.4 and $4.8 \%$ respectively; Table 1 ). The pagodiform shell of $P 2$ exhibited a gemmate carina that was unique among PSHs of Pagodibela. This distinctiveness was maintained in spite of geographic and bathymetric overlap with P1 in the Coral Sea. Clade P3 was the sister group of all other Pagodibela PSHs, revealing comparatively high values of reciprocal genetic distance with all congeneric PSHs (>6.3\%; Table 2). It included only one sample with a uniquely thin, fragile shell with comparatively rounded whorls (Fig. 3J), which differentiated it from any other PSH within the Pagodibela clade.

\section{Assigning names to $\mathrm{SSHs}$}

A search was conducted for all names available and potentially applicable to the nine SSHs resulting from the conversion process described above. By consulting the relevant literature on Raphitomidae (e.g. Bouchet and Sysoev 2001; Bouchet and Waren 1980; Sysoev and Bouchet 2001) and by comparison of molecular and morphological data available on type specimens with the data generated on sequenced specimens, we found three names applicable to three SSHs. Two SSHs, G1 and P2, included the type material of two species, $G$. angulata and $P$. maia respectively, and could therefore be readily respectively associated with these species. As its constituent specimens shared shells that closely resembled the holotype of Gymnobela baruna Sysoev, 1997 (Fig. 3G), clade PA was attributed to this taxon, thus requiring a formal transfer of this species to Pagodibela as hereby proposed (Pagodibela baruna n. comb.). As no available names could be found for the remaining six SSHs, new taxon names were assigned, namely G. abyssicola n. sp. (G2), G. acris n. sp. (G3), G. stupa n. sp. (G4), G. vitrea n. sp. (G5), G. sinuosa n. sp. (G6), P. pacifica n. sp. (P1) and P. meridionalis n. sp. (P3). Formal taxonomic descriptions of these newly recognised species are provided below. 
Discussion

Phylogenetic relationships and generic taxonomy

Building on the five-gene phylogeny of Criscione et al. (2020), that established the phylogenetic framework upon which Gladiobela and Pagodibela were recognised and described, it is shown herein that there is strong support in both $\mathrm{BI}$ and $\mathrm{ML}$ analyses for their monophyly (Fig. 2).

The integrity of these genera is corroborated by radular features diagnostic for each genus. The radula of Gladiobela is characterised by hypodermic awl-shaped teeth with an elongate adapical opening, a very long dorsal blade about half the length of the shaft, a (mostly) broad, angular base and a broad, medium long ligament (Fig. 6A-F). Members of Pagodibela exhibit evenly tapering awl-shaped hypodermic teeth with a comparatively narrow, sloping base with coarse external texture, and a comparatively small, short ligament (Fig. 6G-I). The wide, strongly perpendicular base and the long posterior extension, particularly noticeable in G. angulata, G. abyssicola and, G. acris (Fig. 6A, C, E; Fig. 7) are particularly prominent features, notably the crescent-shaped indentation around the base of the shaft (Fig. 7A). While nothing is known of any potential corresponding features in the proboscis interior of these taxa, such as the presence and nature of an epithelial pad seen in several 'turrid' lineages (Kantor and Taylor 2002; Medinskaya 1999), the following speculations can nevertheless be made: the long posterior extension (Fig. 7A) facilitates physical contact with the internal proboscis (thus the area which can be attached), while the crescentic indentation possibly facilitates the proboscis sphincter in holding the tooth securely. A firm, secure grip can hypothetically perform a number of functions, such as aiding in speed and precision during attacks and in securing tooth recovery after- or between attacks (thus assisting in both performing successive stabs and conserving teeth).

While the general configuration of the radula of $G$. stupa conforms with that of its congeners, this species is a notable outlier, due to its very long hypodermic tooth (Fig. 6F). Bouchet and Waren (1980; p. 5) stated that 'it must be remembered that the radula is an organ for capture of food'; the fact that G. stupa possesses extremely long teeth compared to its congeners (Fig. 6F) does suggest that the radular morphology of the group may not purely be ascribed to phylogenetic signal, but that feeding mechanism exerts some selective pressure on their morphology. A similar anomalous enlargement of the radula while retaining the overall tooth configuration (i.e., size and configuration of barbs, length of 
adapical opening, base morphology, etc.) of its congeners is also seen in a hitherto unnamed species of Austrobela Criscione, Hallan, Fedosov \& Puillandre 2020 (unpublished data). The morphology of the radula reflects feeding mechanism to a larger extent than the phylogenetic signal in cone snails (Olivera et al. 2015; Puillandre et al. 2014). However, dietary habits are not sufficiently known for the Raphitomidae and little inference can be made with regards to the respective influences by phylogenetic signal and feeding in shaping their radular morphology. The radulae of Pagodibela species examined here are highly similar (Fig. 6G-J), and therefore present a solid diagnostic generic-level character. In both genera, shells are heterogeneous, but in gross morphology the overall pagodiform shell of Pagodibela is a recognisable character in its composite taxa (Fig. 3G-J). While some species are similar in shell morphology (notably G. angulata and G. abyssicola), Gladiobela cannot readily be circumscribed based on its shell at the genus-level (Fig. 3A-F).

At the species-level, genetic distinctiveness as shown by ABGD and sequence divergence (Tables 1, 2), demonstrable differences in shell morphology and dimensions (Figs 3, 4) and to a lesser extent radular morphology (particularly for Pagodibela, see Fig. 6G-J), translate into robust hypotheses for all the new species described herein. The genetic distinctiveness reported at the intra- and interspecific levels for the two genera (Tables 1, 2) is comparable, but overall lower than those reported for the raphitomid genera Kermia W. R. B. Oliver, 1915 and Pseudodaphnella Boettger, 1895 (Fedosov and Puillandre 2012), and significantly lower than those reported for Hemilienardia Boettger, 1895 (Fedosov et al. 2017). This could be explained by differences e.g. in population effective size, with the-mutations being fixed more rapidly in smaller populations due to genetic $\mathrm{drift}_{.,- \text {or }}$ in evolutionary rates, the compared taxa living in different environments that could have different impact on rates of molecular evolution.

Biogeographical and bathymetrical patterns Most species of Gladiobela named herein occur within an area corresponding approximately to the South Australia marine realm of Costello et al. (2017). Unsurprisingly, the records are concentrated in the areas of sampling: a relatively restricted portion of the GAB and on a section of the temperate E Australian coast between NE Tasmania and the Hunter CMR (Fig. 1A). As neighbouring regions with comparable environmental conditions remain virtually unexplored, it is plausible that disjunct distributions, like that observed for G. angulata (Fig. 
$1 \mathrm{~A})$, are the result of sampling bias, rather than a reflection of any underlying biological process. In G. angulata, the mean genetic p-distance between the Hunter CMR COI haplotype and the GAB haplotypes is low $(0.4 \%)$, when compared with the range of $p$ distances calculated within the GAB sequences (0.2-2.0\%), indicating very recent or ongoing gene flow between the two areas. It remains unclear whether genetic connectivity in $G$. angulata is realised through a stepping-stone process, involving additional geographically intervening populations, or through long range dispersal of the planktotrophic larva (or both).

In a scenario of a continuous distribution of $G$. angulata, there would be potential range overlap with its sister taxon, G. abyssicola, off the southeast Australian coast. However, the two taxa are not recorded in micro-sympatry. Additionally, there is no recorded overlap in their bathymetric ranges, with an approximately 650-metre gap between their lower and upper bathymetric extremes (Fig. 8), despite some sampling coverage within this gap at corresponding areas. It is conceivable that the two taxa have partitioned into separate bathymetric niches, although the present knowledge of their ecological requirements is insufficient to explain the mechanism involved. Separate bathymetric distributions of sister species have been previously reported for at least three conoidean genera, namely Bathytoma Harris \& Burrows, 1891, Lophiotoma T. L. Casey, 1904 and Cryptogemma Dall, 1918 (Turridae) (Puillandre et al. 2017; Puillandre et al. 2010b; Zaharias et al. 2020) and presented as examples of speciation where bathymetric niche partitioning is the driver of genetic isolation in absence of topographic barriers.

The two records of $G$. acris are separated by an entire marine realm (Fig. 1A, C) in which there are no records despite moderately comprehensive sampling in recent times and in the relevant depth range (O'Hara 2019), and within which other congeners (Fig. 1A) as well as several other raphitomids have been recorded (Criscione et al. (2020). Similarly, G. vitrea is recorded from widely separated localities (Hunter CMR and New Caledonia), although both in the same marine realm (Fig. 1A) and both within a relatively narrow depth range when compared to G. acris (Fig. 8). Assuming that all species of Gladiobela have similar dispersal capabilities, it is plausible that the difference in intraspecific p-distance between G. acris (average 1.1\%; Table 1) and G. vitrea (one haplotype only) is the result of their difference in geographical and bathymetrical distribution. 
The comparatively wide geographic distributions of P. pacifica, P. baruna, G. acris and G. vitrea are not entirely unexpected given the mounting evidence of wide distributions in deep-sea 'turrids' (Bouchet and Waren 1980; Zaharias et al. 2020; Criscione et al., subm.). Our results suggest that Gladiobela may comprise species that are comparatively common (e.g., G. angulata/G. abyssicola) and some of which may be either rare in terms of their abundance or exhibit fragmented distributions (or both). The bathymetric range of G. acris (about $2770 \mathrm{~m}$ ) (Fig. 8) possibly constitutes the widest ever reported for a conoidean species. While similarly wide depth ranges have been documented for a number of deep-sea 'turrids' [including some raphitomids (Bouchet and Waren 1980)], the wide range of the trans-oceanic turrid C. phymatias (about $2000 \mathrm{~m}$ ) is so far the only one reported with support from genetic evidence (Zaharias et al. 2020). Due to the scarcity of material for most other species studied here, little inference can be made with regards to their bathymetric zonation.

Challenges to deep-sea 'turrid' taxonomy

While extremely diverse, most 'turrids' are commonly found in low to very low abundance, frequently even as single individuals (Bouchet et al. 2009; Todd and Rawlings 2014). The findings of this study largely conform to that observation, with P. maia, P. meridionalis and G. sinuosa known from only single specimens and G. acris n. sp. and G. vitrea n. sp. known from two individuals each. Such scarcity of material makes meaningful comparison between taxa with regards to a range of characters difficult. Limited inference can be made about relative size and maturity, as the lack of terminal shell growth makes it is difficult to ascertain if a specimen has attained maturity, particularly in the absence of comparative material. While the number of teleoconch whorls may be an indicator of maturity, Bouchet and Waren (1980) suggested that this may not be a reliable character for some taxa, as terminal shell growth has been observed in taxa with very few teleoconch whorls. While the challenge of assessing maturity persists also where sample populations are larger, a growth series can at least provide some insights into any developmental changes that may occur with increasing size. Studies on the genus Cryptogemma of the Turridae sensu stricto

554 (Kantor and Sysoev 1991; Zaharias et al. 2020), suggest that the characteristic apertural notch and a large penial appendage in Cryptogemma praesignis (Smith, 1895) are both 
(2020) reported developmental changes in the eye morphology of Nodothauma magnifica

558 Criscione, Hallan, Fedosov \& Puillandre, 2020, in which juvenile and young adults may possess large eyes which with maturity become obscured by epidermis. With species known only from single or very few specimens, such characters may be readily missed. So, what should then be considered an appropriate threshold in terms of available material for describing a new deep-sea 'turrid'? The absolute minimum ought to be a molecular voucher linked to a type (Puillandre et al. 2017) and providing details of radular- and other non-shell characters where available. Satisfying these criteria, meaningful species descriptions can be conducted even where limited material is known. Any effort towards inventorying the diversity of 'turrids' is vital to the understanding of their evolution and to the characterization of turritoxins (e.g. Gonzales and Saloma 2014; Lopez-Vera et al. 2004; Puillandre et al. 2012a), far lesser known than the pharmacologically relevant conotoxins (Conidae; e.g. Prashanth et al. 2014) and teretoxins (Terebridae; e.g. Gorson et al. 2015). A molecular type voucher also allows for a cumulative taxonomic process, where any future conspecific material suitable for DNA analysis can then be readily identified, and systematic descriptions revised accordingly where new anatomical and/or morphological data are obtained. However, where scarce material (even single individuals) cannot be analysed molecularly, particularly where only the shell is available for study, new species descriptions of deep-sea 'turrids' are virtually meaningless; in fact, such descriptions may complicate integrative taxonomic efforts on this group by the proliferation of taxon names that can never reliably serve as references to any future anatomical and molecular study. With tendencies in several taxa toward shell plasticity, geographically and bathymetrically widespread distributions, and low abundance (Bouchet et al. 2009; Bouchet and Waren 1980; Criscione et al. 2020; Kantor et al. 2008; Zaharias et al. 2020), taxonomic endeavours on 'turrids' pose logistical as well as theoretical challenges best met by integrative, and preferably collaborative efforts to enable optimal sharing of data, material, and expertise. The numerous synonyms in Cryptogemma (Zaharias et al. 2020) are a salient recent example of how integrative taxonomy is critical to constraining and understanding morphological heterogeneity and elucidating biogeographical patterns at the species level. Todd and Rawlings (2014) give examples of how taxonomic efforts on Polystira (Turridae) have resulted in greatly underestimated distribution ranges due to a lack of examination of museum holdings, and where taxonomic decisions have been made with 'relatively few 
589 comparisons with other taxa' (p. 470). The results herein further illustrate the need for the 590 integrative approach, associated with a high sampling effort, without which inadequate or 591 redundant taxonomic decisions can too readily be made due to lacking consultation with the 592 broader taxonomic, biogeographical and molecular contexts. 
Systematics

General remarks

If not stated otherwise, holotypes are dissected ethanol-preserved specimens and all systematic descriptions are based on the holotype. Shell whorls counts (approximated to one decimal unit) are reported with reference to intact whorls only. When applicable, the expression 'at least' is used in combination with the whorl count to indicate potential additional missing whorls that could not be counted. Shell and head-foot colouration reported in the descriptions are based on observations performed prior to fixation, and thus may not be fully reflected in the illustrations provided (Figs 3,5 ).

Measurements of radular features, mainly the length of the adapical opening and the dorsal blade, are given as ratios of the length of the shaft. The 'shaft' is here defined as the entire length of the tooth minus the base, where there is a notable swelling and angulation that clearly differentiates it from the comparatively thin-walled hypodermic, rolled structure. This is done to ensure consistency with the terminology used in Criscione et al. (2020).

\section{Superfamily Conoidea Fleming, 1822}

Family Raphitomidae Bellardi, 1875

Genus Gladiobela Criscione, Hallan, Puillandre and Fedosov, 2020

Diagnosis

Shell (SH=13.5-27.3, SW=7.5-14.0) fusiform-biconical, broadly- to elongate- biconical, thinwalled, semi-translucent to opaque. Protoconch multispiral, orange, cyrthoconoid, with up to four whorls with diagonally cancellate sculpture. Teleoconch of four to eight whitish, cream to orange whorls, suture impressed. Whorl profile medium- to very broad, with wide, rather lightly concave to straight subsutural ramp, indistinctly to clearly demarcated from whorl periphery; distinctly angulated shoulder sometimes bearing clearly defined carina situated at mid-height to abapical third. Lower portion of whorl sub-cylindrical or slightly narrowed toward suture. Teleoconch sculpture of spirals only (striae) or spiral cords and axial riblets/ribs. Subsutural ramp sculpture of axial growth lines to slightly raised riblets, spirals absent to very faint. Last adult whorl evenly convex or with slight concavity below carina, evenly convex below carina (in latter) or below subsutural ramp, clearly demarcated from rather straight, subcylindrical to tapering siphonal canal. Aperture elongate, about $40 \%$ to half total shell length; outer lip thin, unsculptured. Inner lip whitish, gently recurved, with 
or without spiral cords extending onto columella. No distinct callus. Anal sinus wide to very wide, (moderately) deep, u-shaped.

Animal uniform whitish to cream. Cephalic tentacles short to rather long. Eyes very small. Radula of straight to slightly curved, medium to very long hypodermic teeth (150-460 $\mu \mathrm{m}$ in length); no ventral barb; dorsal blade extremely long, from about $1 / 3$ to half of length of shaft; adapical opening very elongate to subtriangular, rather narrow, ranging from about $1 / 10$ to $1 / 3$ of length of shaft. Base broad to very broad, with or without distinctly indented 'shelf' perpendicular to shaft; large dorsal wall extending posteriorly, with numerous internal pits or folds; exterior of base with fine texture; basal opening large, subcircular. Ligament broad.

Remarks

Gladiobela can be differentiated from other raphitomid genera by the following combined characters: a (generally) broadly to elongate fusiform shell with a large aperture extending about half of total shell length; a weakly to distinctly carinate shoulder (notably in juvenile teleoconch whorls); rather dense, evenly set spiral cords throughout periphery of teleoconch whorls (include base of last adult whorl); straight to slightly curved hypodermic teeth with a very long dorsal blade, elongate adapical opening, a (generally) very broad, distinctly angular base and a broad, medium long ligament. In terms of shell morphology, Gladiobela bears some superficial resemblance to a number of other Australian deep-sea raphitomid genera including Biconitoma, Aplotoma, Pueridaphne and Fusobela (all Criscione et al., 2020), all of which exhibit comparatively broadly fusiform shells where the length of the aperture is approximately half of total shell length. However, Biconitoma and Aplotoma differ from Gladiobela in their opaque, chalky shells, which also exhibit prominent spiral cords. Pueridaphne is characterised by a finely cancellate sculpture and a deep, wide anal sinus (Criscione et al. 2020), whereas Fusobela bears distinctly rounded whorls with a very weakly defined subsutural ramp. Additionally, these genera differ from Gladiobela with respect to a number of anatomical characters (see Criscione et al. 2020) The ranges for this genus are here expanded from those provided in Criscione et al. (2020), with a reported bathymetric range of $470-4750$ metres (Fig. 8) and occurring in the GAB, Tasman Sea, Coral Sea, New Caledonia and the Solomon Islands (Fig. 1A, C). 
Gladiobela abyssicola n. sp.

(Figs 3B, 6E)

Material examined

Holotype: Australia, NSW, off Bermagui, (-36.351, 150.914), IN2017_V03_043, 4750-4763 m, (AMS C.571656). COI: MT081415.

Paratype material: As for holotype, 1 wet (AMS C.571717), 1 wet (AMS C.519389), Australia, Bass Strait, (-39.552, 149.553), IN2017_V03_030, 4133-4197 m, 1 wet (AMS C.519329).

\section{Etymology}

In reference to its presence in the abyssal zone, derived from 'abyssus' (Latin=abyss) and colus (New Latin=inhabitant). Adjective of feminine gender.

\section{Distribution}

Known from abyssal waters off the southern coast of NSW and Bass Strait, Australia.

Shell $(\mathrm{SH}=25.6 \mathrm{~mm}, \mathrm{SW}=12.8 \mathrm{~mm}$ ) broadly fusiform-biconical, rather thin-walled, semitranslucent. Protoconch eroded. Teleoconch of at least 5.2 rather uniformly cream whorls, suture impressed. Whorls broad, with very wide, lightly concave to straight subsutural ramp; well-defined carina situated at approximately mid-height of whorl, periphery subcylindrical. Axial sculpture of growth lines only, on early whorls forming slightly raised, densely set riblets. Spiral sculpture of evenly paced, densely set subperipheral cords (about 6 on median whorl, 8 on penultimate whorl, $40+$ on last whorl), few weaker supra-peripheral cords present immediately above carina. Last adult whorl with slight concavity immediately below carina, later - evenly convex, rather clearly demarcated from slightly tapering, moderately long siphonal canal. Aperture elongate, approximately equal to spire length; outer lip thin, unsculptured. Inner lip whitish, gently recurved, spiral cords extending uninterrupted onto columella. No distinct callus. Anatomy (based on AMS C.571656 [female] and AMS C.519329 [male]). Animal uniform whitish. Cephalic tentacles broad, muscular, short to medium length, somewhat tapering toward blunt tip; miniscule eyespots situated at their outer lower bases. Short, muscular 
689

690

691

692

693

694

695

696

697

698

699

700

701

702

703

704

705

706

707

708

709

710

711

712

713

714

715

716

717

718

719

720

introvert. Proboscis long; venom gland very long, white, convoluted; muscle bulb large, elongate, lustrous; large radular sac. Oviduct large. Penis narrow, simple, no obvious glands or swellings.

Radula (based on AMS C.519389 and AMS C.571717) of straight to slightly curved hypodermic teeth attaining $215 \mu \mathrm{m}$ in length; no ventral barb; dorsal blade sharp, extremely long, approximately half of length of shaft; adapical opening very elongate, rather narrow, about $1 / 3-1 / 4$ of length of shaft. Base broad, with distinct crescentic, slightly excavated shelf more or less perpendicular to orientation of tooth; large dorsal platform extending posteriorly, with numerous, densely arranged folds on inner surface; exterior of base with comparatively fine texture; basal opening large, subcircular. Ligament broad.

\section{Remarks}

G. abyssicola n. sp. is the sister taxon to G. angulata, with which it shares notable similarities in shell- and radular morphology. In terms of shell morphology, G. abyssicola possesses a more acute carina, which forms an elevated spiral cord at the whorl periphery and a slightly shorter, less attenuated siphonal canal (Fig. 3B). Compared to its sister taxon, G. abyssicola has larger and more slender shells (Fig. 4). It can readily be differentiated from the remaining Gladiobela spp. by its distinctly carinate shell. Of all Gladiobela and Pagodibela species, G. abyssicola n. sp. and G. angulata are the only to appear in comparative abundance. The two latter species occupy different bathymetric ranges, in which G. abyssicola is recorded only from abyssal depths ( $\sim 100-4800 \mathrm{~m}$ ) (Fig. 8). Gladiobela abyssicola constitutes the deepest-living conoidean gastropod to be described from Australian waters.

Gladiobela acris n. sp.

(Figs 3C, 5A, 6C)

Material examined:

Holotype: Australia, VIC, East Gippsland CMR, (-38.479, 150.185), IN2017_V03_032, 38503853 m, 1 wet (AMS C.571697). COI: MN983181.

Paratype: Solomon Islands, (-6.417, 156.35), SOLOMON_2, CP2231, 1083-1100 m, 1 wet

(MNHN-IM-2009-19029). 
Etymology

723 In reference to the pointed shape of its shell, derived from 'acer' (Latin=pointed). Adjective of feminine gender.

Distribution

Distribution: Known only from the Hunter Commonwealth Reserve, NSW, Australia and NW Choiseul, Solomon Islands. Potentially widespread.

Shell ( $\mathrm{SH}=19.0 \mathrm{~mm}, \mathrm{SW}=7.5 \mathrm{~mm}$ ) fusiform-biconical, thin, semi-translucent, with tall, orthoconoid spire. Protoconch multispiral, orange, with at least four whorls. PI largely eroded; PII with indistinctly shouldered median whorl, sculpture of axial riblets on shoulder slope changing to diagonally cancellate on whorl periphery. Protoconch-teleoconch transition well-defined, broadly sinuate. Teleoconch of eight uniformly white whorls, suture deeply impressed. Whorls medium-broad, with wide, steep, flat subsutural ramp followed by cylindrical low periphery limited to abapical third in early whorls and subsequently occupying about half of whorl height. Periphery notably raised on early whorls, having appearance of strongly widened cord, in later whorls transition from subsutural ramp to whorl periphery with clear angulation forming distinct shoulder at abapical third of whorl. Axial sculpture of regularly arranged, rounded opisthocline ribs on whorl periphery $(20+$ on penultimate and last whorls), rapidly weakening and becoming obsolete toward base of last whorl. Spiral sculpture of evenly spaced, gently undulating spiral cords, also confined to whorl periphery (3-4 on mature whorls, $15+$ on last whorl). Microsculpture of growth lines, forming arcuate riblets on subsutural ramp, reflecting outline of anal sinus. Last adult whorl evenly convex below subsutural ramp, clearly demarcated from long, tapering siphonal canal. Aperture very elongate, narrow, approximately half of shell length; outer lip thin, unsculptured. Inner lip whitish, distinctly recurved, no distinct callus. Anal sinus wide, moderately deep, u-shaped.

Cephalic tentacles long, cylindrical; eyes very small. Muscular bulb elongate. Radula (Fig. 6C) of straight to slightly curved hypodermic teeth attaining $175 \mu \mathrm{m}$ in length; no ventral barb; dorsal blade sharp, extremely long, approximately half of length of shaft; adapical opening very elongate, rather narrow, about $1 / 3$ of length of shaft. Base broad, 
753

754

755

756

757

758

759

760

761

762

763

764

765

766

767

768

769

770

771

772

773

774

775

776

777

778

779

780

781

782

783

784

with distinct crescentic, slightly excavated shelf more or less perpendicular to orientation of tooth; large dorsal platform extending posteriorly, with numerous, densely arranged folds on inner surface; exterior of base with comparatively fine texture; basal opening large. Ligament broad.

Remarks

This species exhibits the smallest and most slender shell of all congeners (Fig. 4) and it is characterised by its distinctly raised whorl periphery. While differing significantly from the sister taxa G. angulata/abyssicola in its shell morphology, it possesses a similar radula with a broad, angular base with a crescentic indentation around the lower shaft (Fig. 6C). Its only two records (Fig. 1A) suggest a wide bathymetric range of at least 2760 metres (Fig. 8).

Gladiobela sinuosa n. sp.

(Figs 3F, 6D)

Material examined:

Holotype: Australia, NSW, Hunter CMR, (-32.575, 153.162), IN2017_V03_070, 2474-2595 m, (AMS C.571625).

In reference to the undulating pattern of its shells axial sculpture, derived from 'sinuosus' (Latin=sinuous, flexuous). Adjective of feminine gender.

Distribution

Known from a single locality in the Hunter CMR, NSW.

Shell (SL=25.6 mm, SW=14.1 mm) broadly fusiform, rather thin, opaque. Protoconch at least two heavily eroded, orange whorls with diagonally cancellate sculpture. Teleoconch of at least five uniformly whitish whorls, suture deeply impressed. Whorls very broad, tumid, with very wide subsutural ramp, straight in early whorls then weakly concave in later whorls; distinctly angulated shoulder at mid-height of whorl, relatively consistent throughout. Axial 
sculpture of raised, sharp, evenly interspaced opisthocline ribs below subsutural ramp (25+ on penultimate whorl, 30+ on last whorl), becoming subobsolete toward base of last whorl. Spiral sculpture of densely set, evenly spaced, straight to somewhat undulating cords below subsutural ramp (12+ on penultimate whorl, $50+$ on last whorl), weakening towards base of last whorl. Microsculpture of growth lines only, forming semi-regularly spaced arcuate riblets on subsutural ramp. Anal sinus broad, moderately deep, u-shaped. Aperture elongate-pyriform.

Cephalic tentacles muscular, long, cylindrical. Extremely reduced eye spots on outer lower base of tentacles. Mantle roof with large oviduct; ctenidium large, covering much of length of mantle roof; osphradium large. Proboscis long, conical; radular sac of medium size; venom gland long; muscular bulb large.

Radula of straight to slightly curved hypodermic teeth attaining $180 \mu \mathrm{m}$ in length; no ventral barb; dorsal blade sharp, very long, ranging between $1 / 3$ and half of length of shaft; adapical opening elongate-triangular, about $1 / 4$ of length of shaft. Base rather broad, with distinct crescentic, steep shelf more or less perpendicular to orientation of tooth; large dorsal platform, extending posteriorly, with numerous, densely arranged folds and pits on inner surface; exterior of base with comparatively fine texture; basal opening large, subcircular. Ligament broad.

\section{Remarks:}

This new taxon exhibits the largest and least slender shell of all congeners (Fig. 4), which can readily be differentiated by its broad whorls with opisthocline axial ribs and comparatively rounded shoulder, the latter usually more prominent in most other taxa (see below for comparison with $G$. vitrea). The siphonal canal is broken in the only specimen available, thus the length of both the aperture and the siphonal canal could not be ascertained. The intestine contained ample polychaete fragments.

Gladiobela stupa n. sp.

(Figs 3D, 5F, 6F)

\section{Material examined:}


817 Holotype: Australia, NSW, Hunter CMR, (-32.138, 153.527), IN2017_V03_078, 3980-4029 m, 8181 wet (AMS C.571683). COI: MN983183.

819 Paratype: As for holotype (AMS C.519345).

820

821 Etymology

822 In reference to the shape of its shell, somewhat recalling some sacred Buddhist buildings, derived from the Latinised term 'stupa'. Noun of feminine gender in apposition.

Shell ( $\mathrm{SH}=20.9 \mathrm{~mm}, \mathrm{SW}=10.6 \mathrm{~mm}$ ) broadly fusiform, rather thin, semi-translucent.

Protoconch eroded. Teleoconch of at least 5 uniformly orange whorls, suture impressed. Whorls broad, with wide, straight, poorly defined subsutural ramp. Lower portion of whorl convex, with shell periphery situated at lower third of whorl, producing slightly pagodiform spire outline. Axial sculpture of growth lines only, most noticeable as slightly raised, rather evenly spaced arcuate riblets on subsutural ramp. Spiral sculpture of densely set, low, spiral cords (8+ on penultimate whorl, 30+ on last whorl), somewhat undulating, at irregular intervals distorted by growth lines. Last adult whorl evenly convex below subsutural ramp, very clearly demarcated from straight, long siphonal canal. Aperture elongate, approximately equal to spire length; outer lip thin, unsculptured, convex at its mid-height, its anterior part extended towards end of siphonal canal. Inner lip orange, rather straight, no distinct callus. Anal sinus wide, deep, u-shaped.

837 Penis large, thick, muscular, club-shaped, with near-distal swelling and distal seminal papilla; dense latitudinal folds. Cephalic tentacles long, muscular, cylindrical, with distinct longitudinal groove. Minuscule eyespots on outer lower base of tentacles. Radula (based on AMS C.571683 and AMS C.519345) of very long, narrow, straight hypodermic teeth attaining $460 \mu \mathrm{m}$ in length; no ventral barb; dorsal blade sharp, extremely long, approximately $40 \%$ of shaft length; adapical opening elongate, rather narrow, about $1 / 10$ of length of shaft. Base rather broad, with large dorsal platform extending posteriorly, with numerous, densely arranged pits on inner surface; exterior of base with comparatively fine texture; basal opening rather large. Ligament broad. 
In terms of shell morphology, G. stupa is most similar to G. angulata and G. abyssicola, from which it can readily be differentiated by its distinctly less shouldered whorl profile (Fig. 3D), and the comparatively sharper concavity, where the outer lip meets the siphonal canal, the latter of which is also markedly longer in the observed material. Its radula is considerably longer than that of any of its congeners (Fig. 6F).

A longitudinal groove in the cephalic tentacles is also observed for Pueridaphne cirrisulcata Criscione, Hallan, Fedosov \& Puillandre, 2020 (Criscione et al. 2020; Fig. S4). Gladiobela stupa $\mathrm{n}$. sp. is differentiated from the former in its orange shell with a rather long, clearly delineated siphonal canal, its very long radular teeth, and in the former having a reddishbrown animal and cancellate sculpture of the teleoconch.

\section{Gladiobela vitrea n. sp.}

(Figs 3E, 5C, 6B)

Material examined:

Holotype: Australia, NSW, Hunter CMR, (-32.479, 152.994), IN2017_V03_069, 1006-1036 m, (AMS C.482311). COI: MN983184.

Paratype: New Caledonia, Canal de l'Havannah, (-22.267, 167.383), EXBODI, CP3793, 9511180 m, 1 wet (MNHN-IM-2013-52094).

\section{Etymology}

In reference to its transparent, somewhat glass-like shell, derived from 'vitreus' (Latin=made of glass). Adjective of feminine gender.

Distribution: Known only from the Hunter CMR, NSW, Australia and Canal de l'Havannah, New Caledonia. Potentially widespread.

Shell $(\mathrm{SH}=21.4, \mathrm{SW}=9.5)$ elongate-fusiform, rather thin-walled, semi-translucent. Protoconch orange, cyrtoconoid, multispiral, of at least 4 evenly convex whorls. Sculpture diagonally cancellate. Protoconch teleoconch transition, wide, narrowly sinuated. Teleoconch of 6.5 uniformly whitish whorls, suture impressed. Whorls medium broad, with wide subsutural ramp, moderately straight, rather poorly demarcated; early to median whorls with distinct 
880

881

882

883

884

885

886

887

888

889

890

891

892

893

894

895

896

897

898

899

900

901

902

903

904

905

906

907

908

909

910

carina at lower third mark, with rounded shoulder on median whorl, penultimate and last whorl rather evenly convex. Axial sculpture of growth lines only, on early whorls forming slightly raised, semi-regular riblets. Spiral sculpture of regularly set, distinct, straight to somewhat undulating spiral cords (about 13 on penultimate whorl, 40+ on last whorl), commencing below subsutural ramp, evenly pronounced except for last whorl where they weaken towards base. Last adult whorl evenly convex below subsutural ramp, clearly demarcated from medium long, subcylindrical siphonal canal. Aperture elongate, about $40 \%$ of total shell length; outer lip thin, unsculptured. Inner lip whitish, very gently curved. No distinct callus. Anal sinus wide, moderately deep, u-shaped.

Eyes very small. Anal gland rather long. Radular sac small, bearing few teeth; muscular bulb large.

Radula of straight to gently curved, tapering hypodermic teeth attaining $140 \mu \mathrm{m}$ in length; no ventral barb; dorsal blade long, approximately $1 / 3$ of length of shaft; adapical opening elongate, rather narrow, about 1/4 of length of shaft. Base rather broad; large dorsal platform, extending posteriorly, bearing numerous internal pits; exterior of base with comparatively fine texture; basal opening large. Ligament broad.

\section{Remarks}

This new species is readily differentiated from its congeners in its comparatively elongate shell with a comparatively taller spire (with the height of the aperture is about $40 \%$ of total shell length) and its relatively short siphonal canal. With the exception of $G$. sinuosa, all other Gladiobela species treated herein (G. angulata, G. abyssicola, G. acris and G. stupa) possess an angulate whorl profile, which is more or less evenly convex in G. vitrea. It can be differentiated from $G$. sinuosa by its far narrower shell and its absence of axial ribs.

Type species Pagodibela maia Criscione, 2020 by monotypy and original designation.

Pagodibela Criscione, Hallan, Puillandre and Fedosov, 2020

Diagnosis 
Shell (SL=16-36 mm, SW=6-12 mm), fusiform-biconical, thin-walled, semi-translucent. Protoconch multispiral (2.5-3.5 whorls), orange, broadly conical, cyrtoconoid, sculpture diagonally cancellate. Teleoconch of 5.7-8.5 whorls, whitish to pale cream, suture impressed, whorl profile indistinctly angulated to pagodiform. Subsutural ramp wide, straight, indistinctly to clearly demarcated from whorl periphery. Lower portion of whorl sub-cylindrical or narrowing toward suture. Teleoconch sculpture of spirals only (striae) or spiral cords and axial riblets. Subsutural ramp sculpture of axials only (growth lines or riblets) or of spiral cords and axial riblets. Last adult whorl evenly convex below subsutural ramp, clearly demarcated from stout, tapering siphonal canal. Aperture elongate, approximately $40 \%$ to half of shell length; outer lip thin; inner lip whitish, with thin callus, straight. Anal sinus narrow to broad, shallow to moderately deep, u-shaped.

Head wide, cephalic tentacles of median size, cylindrical; small black eyes situated at their bases. Penis small, simple. Proboscis elongate, conical; venom gland short with large muscular bulb. Osphradium large, approximately $2 / 3$ of ctenidium length, and of equal width. Rhyncocoel not capacious; proboscis small, shifted leftward; venom gland long, on right; muscular bulb very large.

Radular teeth of hypodermic type, slender, straight to slightly curved, $\sim 140-200 \mu \mathrm{m}$ in length; barbs absent; dorsal blade nearly half of length of shaft; adapical opening very narrow to narrow and elongate, $1 / 4$ to $1 / 3$ of length of shaft; base comparatively narrow, steep, with coarse external texture; lateral process very weak; basal opening subcircular; ligament small, short.

\section{Remarks}

Pagodibela can be differentiated from other raphitomid genera by the following combined characters: a (generally) distinctly pagodiform shell (notably in juvenile and subadult juvenile whorls), a medium- to tall spire, and awl-shaped, evenly tapering hypodermic teeth with a comparatively narrow, steep base with coarse external texture. It can be differentiated from the similarly named raphitomid genus Pagodidaphne Shuto, 1983 (comparison made with type species $P$. colmani Shuto, 1983) by the very prominent spiral sculpture, tall cylindrical periphery and tall aperture of the latter. Pagodibela, particularly 
the tall-spired $P$. baruna and $P$. pacifica, bears superficial resemblance to tall-spired members of Typhlosyrinx Thiele, 1925 and Leiosyrinx Bouchet \& Sysoev, 2001, but can be differentiated from both of the latter in the (generally) distinctly pagodiform early teleoconch whorls in Pagodibela, and also in details of the radula, with the type species $T$. vepallida (Martens, 1902) and T. supracostata (Schepman, 1913) shown to have two distinct barbs, and the L. immedicata Bouchet \& Sysoev, 2001 (genus type species) and $L$. matsukumai Bouchet \& Sysoev, 2001 both exhibiting comparatively short (both $<100 \mu \mathrm{m}$ ) teeth with short blades and very large, broad bases (Bouchet and Sysoev 2001). Furthermore, the molecular phylogeny by Criscione et al. (2020) recovered Typhlosyrinx and Pagodibela in separate, non-sister clades.

The ranges for this genus are here expanded from those provided in Criscione et al. (2020), with a bathymetric range of 318-1013 metres (Fig. 8) and occurring in the GAB, temperate to tropical eastern Australia, and large swathe of the Indo-Pacific, from the central South Pacific, PNG, Indonesia and north toward Taiwan, and to the far western Indian Ocean off the East African coast (Fig. 1B, D).

\section{Pagodibela baruna (Sysoev, 1997)}

(Fig. 3G)

Gymnobela baruna Sysoev, 1997: 339, figs 6, 49-50.

Material examined

Holotype: Indonesia, Kai Islands, N of channel between small and Big Kai Island (-5.230, 133.000), KARUBAR, CC21, 688-694 m.

Paratype: As for holotype.

Other material: Glorioso Islands, (-12.5, 44.933), BIOMAGLO, DW4863, 606-610 m, 1 wet (MNHN-IM-2013-62987); New Caledonia, Chesterfield Islands, (-21.483, 162.600), EBISCO, CP2651, 883-957 m, 1 wet (MNHN-IM-2007-42312); (-21.683, 166.617), EXBODI, CP3809, 685-880 m, 1 wet (MNHN-IM-2009-29111); PNG, (-4.967, 145.833), BIOPAPUA, CP3708, 502-529 m, 1 wet (MNHN-IM-2009-17156), 1 wet (MNHN-IM-2009-17197); (-9.150, 152.250), BIOPAPUA, CP3739, 503-546 m, 1 wet (MNHN-IM-2009-17116); (-4.733, 146.183), PAPUA_NIUGINI, CP3979, 540-580 m, 1 wet (MNHN-IM-2013-19691); (-5.183, 147.050), PAPUA_NIUGINI, CP3981, 688 m, 1 wet (MNHN-IM-2013-19729); (-5.367, 145.85), 
PAPUA_NIUGINI, CP4026, 620-677 m, 1 wet (MNHN-IM-2013-9836). Solomon Islands, (7.717, 156.417), SALOMON_2, CP2246, 664-682 m, 1 wet (MNHN-IM-2007-42518); (-7.750, 156.933), SALOMON_2, CP2269, 768-890 m, 1 wet (MNHN-IM-2007-42519); (-9.150, 158.983), SALOMON_2, CP2176, 600-875 m, 1 wet (MNHN-IM-2007-42528). South Madagascar, (-25.617, 46.367), ATIMO_VATAE, CP3566/DW3565, 618-624 m, 1 wet (MNHNIM-2009-14887); Taiwan, (16.233, 114.500), ZhongSha_2015, CP4153, 318 m, 1 wet (MNHNIM-2013-59316); (16.250, 114.567), ZhongSha_2015, CP4154, 321-326 m, 1 wet (MNHN-IM2013-59352). Vanuatu, (-16.717, 167.983), BOA1, CP2465, 770-799 m, 1 wet (MNHN-IM2007-17695).

Distribution: W Pacific: Indonesia, PNG, New Caledonia and Vanuatu in the south; Taiwan in the north. SW Indian Ocean: Madagascar and Glorioso Islands.

\section{Remarks}

G. baruna was previously known exclusively for its live-collected holotype (Fig. 3D) and the shell of its paratype (Sysoev 1997, fig. 50), both collected off the Kai Islands (Indonesia). As already noted by Sysoev (1997, p. 339), the two specimens differ mainly in the prominence of their shell sculpture, specifically with the paratype exhibiting a distinctively more pronounced shoulder. The examination of shells of $P$. baruna conducted in this study, reveals that, while the first 4-5 teleoconch whorls are distinctively more shouldered in all studied shells, only some specimens have shells exhibiting this feature on subsequent (5+) whorls.

The degree of prominence of the whorl angulation, as well as of other sculptural elements, varies across the sample along a morphological continuum, suggesting that such differences are likely to be the expression of intraspecific variability.

In our molecular analysis (Fig. 2), sequences of this species form a strongly supported clade, exhibiting significant genetic structure, which is largely consistent with geographical patterns. The comparatively low average intraspecific pairwise distance in COI (less than $2 \%$ ), along with the relative homogeneity in shell morphology, suggest that no further taxonomic splitting is required. 
1005 The inclusion of additional material into P. baruna, results in an expansion of the

1006

1007

1008

1009

1010

1011

1012

1013

1014

1015

1016

1017

1018

1019

1020

1021

1022

1023

1024

1025

1026

1027

1028

1029

1030

1031

1032

1033

1034

1035

1036

\section{Pagodibela meridionalis $\mathrm{n} . \mathrm{sp}$.}

(Figs 3J, 5E, 6H)

\section{Material examined}

Holotype: Australia, SA, GAB, (-35.043, 134.079), IN2015_C02_126, 367-409 m, (SAMA D44173). COI: MN983189.

\section{Etymology}

For its presence in the southernmost part of the genus range, derived from 'meridionalis' (Latin=from the south). Adjective of feminine gender.

Shell

Shell (SL=19 mm, SW=8 mm), fusiform-biconical, thin-walled, semi-translucent. Protoconch orange, broadly conical, of at least three gently convex, diagonally cancellate whorls.

Teleoconch of 6.5 pale cream whorls, suture impressed, whorl profile convex, with moderate, non-carinate angulation at periphery. Subsutural ramp wide, straight, indistinctly demarcated from rounded whorl periphery located at whorl mid-height. Lower portion of whorl sub-cylindrical, narrowing towards lower suture. Subsutural ramp sculpture of dense arcuate growth lines, reflecting shape of anal sinus. Sculpture of regularly spaced, fine, shallow striae, uniformly pronounced over entire shell surface, and dense collabral growth lines. Last adult whorl evenly convex below subsutural ramp, clearly demarcated from stout, tapering whitish siphonal canal with wide opening. Aperture elongate, approximately half of 
1037

1038

1039

1040

1041

1042

1043

1044

1045

1046

1047

1048

1049

1050

1051

1052

1053

1054

1055

1056

1057

1058

1059

1060

1061

1062

1063

1064

1065

1066

1067

shell length; outer lip thin; inner lip whitish, with thin callus, straight. Anal sinus moderately deep, u-shaped.

Head wide, cephalic tentacles of median size, cylindrical; small black eyes situated at their bases. Osphradium large, approximately $2 / 3$ of ctenidium length, and of equal width.

Rhyncocoel not capacious; proboscis small, shifted leftward; venom gland long, on right; muscular bulb very large.

Radular teeth of hypodermic type, attaining about $200 \mu \mathrm{m}$ in length, straight to slightly curved, somewhat loosely rolled; barbs absent; dorsal blade nearly half of length of shaft; adapical opening wide and elongate, approximately $1 / 4$ of length of shaft; base comparatively narrow, steep with coarse external texture; lateral process very weak; basal opening large, subcircular. Ligament short, small.

\section{Remarks}

This new taxon can be differentiated from the Pagodibela spp. studied herein based on its thin, semi-translucent, smooth shell with no distinct carina. Pagodibela baruna (Sysoev, 1997 ) is superficially similar in also having a comparatively smooth (in adults), tall-spired shell, but the latter is opaque and chalky in texture, possesses a significantly taller spire, and more marked angulations at the shoulder in early teleoconch whorls and a comparatively prominent, gemmate supra-sutural cord in early teleoconch whorls (Fig. 3G). None of the Pagodibela spp. can readily be differentiated on the basis of radular morphology only (Fig. 6G-I).

This is the only Pagodibela taxon from temperate Australia, where it is known only from upper bathyal depths in the GAB.

Pagodibela pacifica n. sp.

(Figs 3H, 6J)

\section{Material examined}

Holotype: New Caledonia, Chesterfield Islands, (-20.967, 160.967), EBISCO, CP2645, 641-652

m, (MNHN-IM-2007-17844). COI: EU015652. 
1068

1069

1070

1071

1072

1073

1074

1075

1076

1077

1078

1079

1080

1081

1082

1083

1084

1085

1086

1087

1088

1089

1090

1091

1092

1093

1094

1095

1096

1097

1098

Paratypes: Tuamotu Archipelago, (-17.783, -149.383), TARASOC, DW3489, 450-720 m, 1 wet

(MNHN-IM-2007-38860); New Caledonia, (-22.283, 171.3), EXBODI, DW3876, 518-833 m, (MNHN-IM-2009-29189); New Caledonia, (-23.283, 167.933), KANACONO, CP4750, 750-850

m, 1 wet (MNHN-IM-2013-69658); Australia, QLD, Coral Sea CMR, (-23.587, 154.194),

IN2017_V03_121, 1013-1093 m, 1 wet (AMS C.519402).

\section{Etymology}

For its wide distribution across the Pacific Ocean, derived from 'pacificus' (New Latin=from the Pacific Ocean). Adjective of feminine gender.

\section{Distribution}

Widespread; recorded from off north Queensland, Coral Sea, New Caledonia and to the Society Islands.

Shell (SL=30 mm, SW=11 mm) elongate, fusiform-biconical, moderately thin-walled, rather opaque. Protoconch of 3.5 whorls, broadly cyrthoconoid, light orange. Protoconch 2 with distinct diagonally cancellate sculpture throughout whorl height. Protoconch-teleoconch transition somewhat weakly defined, only detectable by change in sculpture pattern. Teleoconch of 8.5 whorls, pale cream; suture deeply impressed. Whorl profile distinctly angulated, with peripheral carina in early to median teleoconch whorls and rounded angulation in mature whorls. Subsutural ramp wide, straight, concluded by peripheral carina at about mid-height of whorl in early to median teleoconch whorls. Lower portion of whorl subcylindrical or slightly narrowed towards lower suture. Subsutural ramp sculpture of arcuate riblets, reflecting shape of anal sinus, intersected by narrow raised spiral cords, forming somewhat reticulate pattern in juvenile whorls; arcuate riblets continuous across periphery of early to median teleoconch whorls, strongly opisthocline, sub-obsolete to absent in subsequent whorls. Spiral sculpture of supra-peripheral cords in early to median teleoconch whorls, forming weak nodules at intersections with arcuate riblets, with cords less prominent and more densely set in subsequent whorls. Last adult whorl evenly convex below subsutural ramp, clearly demarcated from broad, stout siphonal canal with distinct concavity on left side (when seen in apertural view, Fig. 3H). Aperture elongate, 
approximately $40 \%$ of total shell length; outer lip thin, unsculptured; inner lip whitish, with thin callus, slightly recurved. Anal sinus moderately wide and deep, u-shaped.

Radula (based on paratype AMS C.519402) of hypodermic type, approximately $140 \mu \mathrm{m}$ long, straight to slightly curved; barbs absent; dorsal blade sharp, nearly half of length of shaft; adapical opening narrow and elongate, $1 / 3$ of length of shaft; base comparatively narrow, steep, with coarse external texture; lateral process very weak; basal opening large, subcircular. Ligament short, small.

\section{Remarks}

This species can be recognised by its elongate, slender shell with strongly carinated early teleoconch whorls. It is rather similar to the sister taxon P. baruna in its shell morphology, with both species exhibiting comparatively large, elongate shells with distinctly pagodiform early to median teleoconch whorls (Fig. 3G, H). However, when compared to the holotype of the latter (Fig. 3G), P. pacifica is comparatively smaller, less opaque, and possessing more prominent axial ribs and carina on early teleoconch whorls, and does not possess a distinct, gemmate supra-sutural cord in early teleoconch whorls (Fig. 3G, H).

This new species, along with the sister species G. baruna, appear to be the most geographically and bathymetrically widespread members of the genus. However, unlike the sister species G. angulata/abyssicola (Fig. 3A, B) they are not allopatric, with largely overlapping bathymetric ranges and with both taxa occurring in the New Caledonian region (Figs 1, 8). 
1121 The authors declare no conflicts of interest.

\section{Acknowledgments}

This work has been made possible through financial support from the Australian Government (ABRS grant RF217-57, principal investigator FC). The participation of AF was also supported by the Russian Science Foundation (grant 16-14-10118 to Yuri Kantor). Voyages in the GAB were part of: (a) the GAB Research Program [GABRP - a collaboration between BP, CSIRO, the South Australian Research and Development Institute (SARDI), the University of Adelaide, and Flinders University] and (b) the GAB Deepwater Marine Program (GABDMP - a CSIRO led research program sponsored by Chevron Australia]. Funding for the 'Eastern Abyss' voyage (IN2017_V03) was provided by the Marine Biodiversity Hub (MBH), supported through the Australian Government's National Environmental Science Program (NESP). The authors wish to thank the CSIRO MNF for its support in the form of sea time aboard, support personnel, scientific equipment and data management. We also thank all the scientific staff and crew who participated in all voyages generating the samples studied herein.

The MNHN samples used in this study originates from shore-based expeditions (ATIMO VATAE, PAPUA NIUGINI; PI Philippe Bouchet) and deep-sea cruises (BIOMAGLO, BIOPAPUA, BOA1, EBISCO, EXBODI, KANACONO, TARASOC, SALOMON 2, ZHONGSHA 2015; PIs Philippe Bouchet, Tin-Yam Chan, Laure Corbari, Nicolas Puillandre, Sarah Samadi, Wei-Jen Chen) conducted by MNHN, Pro-Natura International (PNI) and Institut de Recherche pour le Développement as part of the Our Planet Reviewed and the Tropical Deep-Sea Benthos programs. Funders and sponsors included the CONOTAX project funded by the French National Research Agency [grant number ANR-13-JSV7-0013-01], a bilateral cooperation research funding from the Taiwan Ministry of Science and Technology (MOST 102-2923-B002-001-MY3, PI Wei-Jen Chen) and the French National Research Agency (ANR 12-ISV70005-01, PI Sarah Samadi), the Total Foundation, Prince Albert II of Monaco Foundation, Stavros Niarchos Foundation, and Richard Lounsbery Foundation. All expeditions operated under the regulations then in force in the countries in question and satisfy the conditions set by the Nagoya Protocol for access to genetic resources (expeditions.mnhn.fr). We would like to express our gratitude to Mandy Reid, Alison Miller and Jennifer Caiza (AM) for 
1152 assistance with registration and databasing of material, to Barbara Buge and Virginie Héros

1153 (MNHN) for the sample preparation, and to Andrea Crowther (SAMA, Adelaide) for

1154 smoothly and promptly handling our loan requests. Special thanks are due to Sue Lindsay

1155 and Chao Shen (Macquarie University, Sydney) for assisting with SEM work. The holotype of

1156 Gymnobela baruna was taken by Manuel Caballer (MNHN) (project E-RECOLNAT: ANR-11-

1157 INBS-0004). Finally, the reviewers are thanked for their helpful suggestions which served to improve the manuscript. 
References

Bouchet, P., Heros, V., Lozouet, P., and Maestrati, P. (2008) 'A quarter - century of deep-sea malacological exploration in the South and West Pacific: where do we stand? How far to go?' $9-40$

Bouchet, P., Kantor, Y.I., Sysoev, A., and Puillandre, N. (2011) A new operational classification of the Conoidea (Gastropoda). Journal of Molluscan Studies 77(3), 273308.

Bouchet, P., Lozouet, P., and Sysoev, A. (2009) An inordinate fondness for turrids. Deep-Sea Research Part II Topical Studies in Oceanography 56(19-20), 1724-1731.

Bouchet, P., and Sysoev, A. (2001) Typhlosyrinx-like tropical deep-water turriform gastropods (Mollusca, Gastropoda, Conoidea). Journal of Natural History 35(11), 1693-1715. [In English]

Bouchet, P., and Waren, A. (1980) Revision of the north east Atlantic bathyal and abyssal Turridae (Mollusca, Gastropoda). Journal of Molluscan Studies Supplement 8, 1-119.

Burton, E.A. (1998) Carbonate compensation depth. In 'Geochemistry.' pp. 73-73. (Springer Netherlands: Dordrecht)

Costello, M.J., Tsai, P., Wong, P.S., Cheung, A.K.L., Basher, Z., and Chaudhary, C. (2017) Marine biogeographic realms and species endemicity. Nature Communications 8(1), 1057.

Criscione, F., Hallan, A., Puillandre, N., and Fedosov, A.E. (2020) Where the snails have no name: A molecular phylogeny of Raphitomidae (Neogastropoda: Conoidea) uncovers vast unexplored diversity in the deep seas of temperate southern and eastern Australia. Zoological Journal of the Linnean Society, In press.

Fedosov, A.E., and Puillandre, N. (2012) Phylogeny and taxonomy of the KermiaPseudodaphnella (Mollusca: Gastropoda: Raphitomidae) genus complex: a remarkable radiation via diversification of larval development. Systematics and Biodiversity 10(4), 447-477. [In English]

Fedosov, A.E., Stahlschmidt, P., Puillandre, N., Aznar-Cormano, L., and Bouchet, P. (2017) Not all spotted cats are leopards: evidence for a Hemilienardia ocellata species complex (Gastropoda: Conoidea: Raphitomidae). European Journal of Taxonomy 268, 1-20. [In English] 
Folmer, O., Black, M., Hoeh, W., Lutz, R., and Vrijenhoek, R. (1994) DNA primers for amplification of mitochondrial cytochrome c oxidase subunit I from diverse metazoan invertebrates. Molecular Marine Biology and Biotechnology 3(5), 294-299.

Gonzales, D.T.T., and Saloma, C.P. (2014) A bioinformatics survey for conotoxin-like sequences in three turrid snail venom duct transcriptomes. Toxicon 92, 66-74. [In English]

Gorson, J., Ramrattan, G., Verdes, A., Wright, M.E., Kantor, Y., Rajaram Srinivasan, R., Musunuri, R., Packer, D., Albano, G., Qiu, W.G., and Holford, M. (2015) Molecular Diversity and Gene Evolution of the Venom Arsenal of Terebridae Predatory Marine Snails. Genome biology and evolution 7.

Hallan, A., Criscione, F., Fedosov, A.E., and Puillandre, N. (2020) Bouchetispira ponderi n. sp. (Conoidea: Bouchetispiridae), a new deep-sea gastropod from temperate Australia. Molluscan Research 40(1), 86-92.

Hedley, C. (1922) A revision of the Australian Turridae. Records of the Australian Museum 13, pp. 213-359. [In English]

Kantor, Y.I., Fedosov, A.E., and Puillandre, N. (2018) New and unusual deep-water Conoidea revised with shell, radula and DNA characters. Ruthenica $\mathbf{2 8}$, 47-82.

Kantor, Y.I., Puillandre, N., Olivera, B.M., and Bouchet, P. (2008) Morphological proxies for taxonomic decision in turrids (Mollusca, Neogastropoda): a test of the value of shell and radula characters using molecular data. Zoological Science (Tokyo) 25(11), 11561170.

Kantor, Y.I., and Sysoev, A.V. (1991) Sexual dimorphism in the apertural notch of a new species of Gemmula (Gastropoda: Turridae). Journal of Molluscan Studies 57, 205209. [In English]

Kantor, Y.I., and Taylor, J.D. (2002) Foregut anatomy and relationships of raphitomine gastropods (Gastropoda: Conoidea: Raphitominae). Bollettino Malacologico 38, 83110. [In English]

Kumar, S., Stecher, G., and Tamura, K. (2016) MEGA7: Molecular Evolutionary Genetics Analysis version 7.0 for bigger datasets. Molecular Biology and Evolution 33, 1870 1874.

Lopez-Vera, E., de la Cortera, E.P.H., Maillo, M., Riesgo-Escovar, J.R., Olivera, B.M., and Aguilar, M.B. (2004) A novel structural class of toxins: the methionine-rich peptides 
from the venoms of turrid marine snails (Mollusca, Conoidea). Toxicon 43(4), 365374. [In English]

Maclntosh, H., Althaus, F., Williams, A., Tanner, J.E., Alderslade, P., Ahyong, S.T., Bax, N., Criscione, F., Crowther, A.L., Farrelly, C.A., Finn, J.K., Goudie, L., Gowlett-Holmes, K., Hosie, A.M., Kupriyanova, E., Mah, C., McCallum, A.W., Merrin, K.L., Miskelly, A., Mitchell, M.L., Molodtsova, T., Murray, A., O’Hara, T.D., O'Loughlin, P.M., Paxton, H., Reid, A.L., Sorokin, S.J., Staples, D., Walker-Smith, G., Whitfield, E., and Wilson, R.S. (2018) Invertebrate diversity in the deep Great Australian Bight (200-5000 m). Marine Biodiversity Records 11(1), 23.

Marshall, B.A. (1983) A revision of the Recent Triphoridae of southern Australia (Mollusca: Gastropoda). Records of the Australian Museum 35, 1-119. [In English]

Medinskaya, A. (1999) Foregut anatomy of Cochlespirinae (Gastropoda, Conoidea, Turridae). Zoosystema 21(2), 171-198.

O'Hara, T.D. (2019) The eastern Australian Marine Parks: biodiversity, assemblage structure, diversity and origin.

Olivera, B.M., Seger, J., Horvath, M.P., and Fedosov, A.E. (2015) Prey-Capture Strategies of Fish-Hunting Cone Snails: Behavior, Neurobiology and Evolution. Brain Behav Evol 86(1), 58-74. [In eng]

Powell, A.W.B. (1942) The New Zealand recent and fossil Mollusca of the-the Family Turridae with general notes on turrid nomenelature and systematics. Bulletin Auckland Institute and Museum 2, pp. 1-188. [In English]

Prashanth, J.R., Brust, A., Jin, A.-H., Alewood, P., Dutertre, S., and Lewis, R. (2014) Cone snail venomics: From novel biology to novel therapeutics. Future medicinal chemistry 6 , 1659-75.

Puillandre, N., Bouchet, P., Duda, T.F., Kauferstein, S., Kohn, M., Olivera, B., Watkins, M., and Meyer, C. (2014) Molecular phylogeny and evolution of the cone snails (Gastropoda, Conoidea). Molecular Phylogenetics and Evolution 78.

Puillandre, N., Cruaud, C., and Kantor, Y.I. (2010a) Cryptic species in Gemmuloborsonia (Gastropoda: Conoidea). Journal of Molluscan Studies 76, 11-23.

Puillandre, N., Fedosov, A.E., Zaharias, P., Aznar-Cormano, L., and Kantor, Y.I. (2017) A quest for the lost types of Lophiotoma (Gastropoda: Conoidea: Turridae): integrative 
taxonomy in a nomenclatural mess. Zoological Journal of the Linnean Society 181(2), 243-271.

Puillandre, N., Koua, D., Favreau, P., Olivera, B.M., and Stoecklin, R. (2012a) Molecular Phylogeny, Classification and Evolution of Conopeptides. Journal of Molecular Evolution 74, 297-309.

Puillandre, N., Lambert, A., Brouillet, S., and Achaz, G. (2012b) ABGD, Automatic Barcode Gap Discovery for primary species delimitation. Molecular Ecology 21, 1864-1877.

Puillandre, N., Modica, M.V., Zhang, Y., Sirovich, L., Boisselier, M.C., Cruaud, C., Holford, M., and Samadi, S. (2012c) Large-scale species delimitation method for hyperdiverse groups. Molecular Ecology 21(11), 2671-2691.

Puillandre, N., Sysoev, A.V., Olivera, B.M., Couloux, A., and Bouchet, P. (2010b) Loss of planktotrophy and speciation: geographical fragmentation in the deep-water gastropod genus Bathytoma (Gastropoda, Conoidea) in the western Pacific. Systematics and Biodiversity 8(3), 371-394. [In English]

Ronquist, F., and Huelsenbeck, J.P. (2003) MrBayes 3: Bayesian phylogenetic inference under mixed models. Bioinformatics 19(12), 1572-1574.

Saitou, N., and Nei, M. (1987) The neighbor-joining method: a new method for reconstructing phylogenetic trees. Molecular Biology and Evolution 4(4), 406-425. [In English]

Simon, C., Franke, A., and Martin, A. (1991) The polymerase chain reaction: DNA extraction and amplification. NATO ASI Series Series H Cell Biology 57, 329-355.

Sysoev, A. (1997) Mollusca Gastropoda: new deep-water turrid gastropods (Conoidea) from eastern Indonesia. Memoires du Museum National d'Histoire Naturelle 172, 325-355. [In English]

Sysoev, A., and Bouchet, P. (2001) New and uncommon turriform gastropods (Gastropoda: Conoidea) from the South-West Pacific. Memoires du Museum National d'Histoire Naturelle 185, 271-320. [In English]

Sysoev, A.V., and Kantor, Y.I. (1990) A new genus and species of 'Cochlespira-like' turrids (Gastropoda, Toxoglossa, Turridae). Apex (Brussels) 5, 1-6.

Todd, J.A., and Rawlings, T.A. (2014) A review of the Polystira clade-the Neotropic's largest marine gastropod radiation (Neogastropoda: Conoidea: Turridae sensu stricto). Zootaxa 3884(5), 445-491. [In English] 
1285 Zaharias, P., Kantor, Y.I., Fedosov, A.E., Criscione, F., Hallan, A., Kano, Y., Bardin, J., and 1286 Puillandre, N. (2020) Just the once will not hurt: DNA suggests species lumping over two oceans in deep-sea snails (Cryptogemma). Zoological Journal of the Linnean Society. 